Reasoned versus reactive prediction of behaviour: A meta-analysis of the prototype willingness model

Health Psychology Review

Jemma Todd $^{a *}$, Emily Kothe ${ }^{\mathrm{b}}$, Barbara Mullan ${ }^{\mathrm{c}}$ \& Lauren Monds ${ }^{\mathrm{c}}$

a School of Psychology, The University of Sydney, 2006, Sydney, NSW, Australia

b School of Psychology, Deakin University, 3125, Melbourne, VIC, Australia

c School of Psychology and Speech Pathology, Curtin University, 6102, Perth, WA, Australia

For the definitive version

http://www.tandfonline.com/doi/suppl/10.1080/17437199.2014.922895 
REASONED VERSUS REACTIVE PREDICTION

\begin{abstract}
The prototype willingness model (PWM) was designed to extend expectancy-value models of health behaviour by also including a heuristic, or social reactive pathway, to better explain health-risk behaviours in adolescents and young adults. The pathway includes prototype; i.e., images of a typical person who engages in a behaviour; and willingness to engage in behaviour. The current study describes a meta-analysis of predictive research using the PWM, and explores the role of the heuristic pathway and intentions in predicting behaviour. Eighty-one studies met inclusion criteria. Overall, the PWM was supported and explained $20.5 \%$ of the variance in behaviour. Willingness explained $4.9 \%$ of the variance in behaviour over and above intention, although intention tended to be more strongly related to behaviour than was willingness. The strength of the PWM relationships tended to vary according to the behaviour being tested, with alcohol consumption being the behaviour best explained. Age was also an important moderator, and, as expected, PWM behaviour was best accounted for within adolescent samples. Results were heterogeneous even after moderators were taken into consideration. This meta-analysis provides support for the PWM and may be used to inform future interventions that can be tailored for at-risk populations.
\end{abstract}

Key Words: prototype willingness model; meta-analysis; health behaviour; health models 
REASONED VERSUS REACTIVE PREDICTION

\section{Reasoned versus reactive prediction of behaviour: A meta-analysis of the prototype willingness model}

\section{Rationale}

Many illnesses and diseases are at least partly attributable to the performance or nonperformance of health-risk or health-enhancing behaviours (World Health Organization: WHO, 2009). Investigating reasons for engaging or not engaging in these behaviours is a major area of interest for health psychologists, and many theoretical models have been proposed to explain such behaviours. Models often concentrate on social-cognitive aspects of behaviour, as these aspects tend to be malleable (Conner \& Norman, 1996), and indeed such expectancy-value models dominate the literature (Gerrard, Gibbons, Houlihan, Stock, \& Pomery, 2008). These models assume that health-related behaviour is planned, by a process of weighing up the costs and benefits of behavioural outcomes.

Expectancy-value models such as the Theory of Planned Behaviour (TPB), and its precursor the Theory of Reasoned Action (TRA) place intention as the most proximal determinant of volitional behaviour (Ajzen, 1991). The TPB and TRA have been used to predict a range of behaviours; however, these models tend to predict intention better than behaviour (Armitage \& Conner, 2001), and the relatively weak relationship between intention and behaviour indicates that individuals do not always act as they intend (Sheeran, 2002).

A number of dual-process models have also received attention in the literature; for example, Fuzzy Trace Theory (Rivers, Reyna, \& Mills, 2008), Cognitive Experiential Self Theory (Epstein, 1985), and within health psychology, the Prototype-Willingness Model (PWM; Gerrard et al., 2008). These models accept the importance of planned determinants of behaviour 


\section{REASONED VERSUS REACTIVE PREDICTION}

such as intentions, but also include unplanned, intuitive or heuristic elements to account for variations in behaviour that extend beyond the focus on rational factors encompassed by most social-cognitive models.

The PWM was developed by Gibbons, Gerrard and colleagues (Gibbons, Gerrard, Blanton, \& Russell, 1998; Gibbons, Gerrard, \& McCoy, 1995) to explain risk elements of behavioural decisions in adolescents. The PWM includes both a reasoned pathway, determined by intentions, and a social reactive pathway, determined by willingness to engage in the behaviour (Gibbons, Gerrard, \& Lane, 2003; see Supplementary File 1). The reasoned pathway of the PWM is very similar to the TRA: attitudes and subjective norms predict intention to engage in that behaviour, and intention subsequently predicts actual behaviour. The social reactive pathway includes prototypes and willingness. Prototypes are images of the type of person who engages in the target behaviour, and are shaped by perceptions of favourability and similarity of the prototype to the individual. Gibbons, Gerrard, Lando, and McGovern (1991) found that individuals who were trying to quit smoking would consider the image of a typical smoker more negatively, and would also consider themselves less similar to this image than smokers who were not trying to quit. According to the model, these prototype images then influence how willing the individual is to engage in that particular behaviour when the opportunity arises. Gibbons et al. (1998) argued that willingness differs from intentions, as individuals may not intend to engage in a risky behaviour, but may still do so if the opportunity is available. Willingness therefore represents a reactive determinant of behaviour, unlike intentions, which tend to be planned.

The PWM has been used to predict a range of health-risk behaviours in adolescents, such as smoking and alcohol use (Andrews, Hampson, \& Barckley, 2008), and unsafe sex (Gibbons et 


\section{REASONED VERSUS REACTIVE PREDICTION}

al., 1998), as well as health-promoting behaviours such as exercising and breakfast eating (Rivis, Sheeran, \& Armitage, 2006). Two reviews have been conducted by Gibbons, Gerrard and their colleagues. Firstly, Gerrard et al. (2008) reviewed dual-process theories within psychology (including the PWM) and concluded that these models could help to better explain the decisionmaking of adolescents compared to single-process motivational models. This review was, however, primarily an explanation of dual-process models, and did not provide a systematic review or meta-analytic analysis of the literature.

Gibbons, Houlihan, and Gerrard (2009) subsequently provided an overview of both expectancy-value theories of health behaviour and the PWM. It was found that including both dual-process and expectancy-value elements in health behaviour models was a more effective way of predicting health behaviour than considering these elements alone. Again, however, the review of PWM studies was not systematic, included only studies published up to 2008, and focussed more on the predictive utility of willingness and intention, rather than prototypes. A systematic examination of PWM research is therefore needed in order to clarify the relative contributions of the reasoned and heuristic pathways to determining health behaviour engagement.

\section{Objectives}

The current meta-analysis has two main aims:

1. To meta-analytically evaluate the associations between key PWM constructs. It was expected that prototypes would be positively associated with willingness to engage in behaviour, and that willingness would be associated with actual behavioural engagement. Given that no relationship between prototypes and intention was specified in the PWM, it 


\section{REASONED VERSUS REACTIVE PREDICTION}

was also expected that prototypes would not be directly associated with intention or behaviour.

2. To explore whether the strength of PWM construct relationships is moderated by context factors (type of behaviour), sample factors (age and gender of the sample) and study factors (length of follow-up, presence of an intervention, or reporting data that overlaps with the data of other studies).

While the PWM overlaps somewhat with the TRA/TPB, the constructs of attitudes and subjective norm were not investigated in the current meta-analysis for a number of reasons. Firstly, there are a number of TPB meta-analyses that have investigated the relationship between these constructs and their ability to predict intentions (McEachan, Conner, Taylor, \& Lawton, 2011), and therefore this was deemed to be redundant. Secondly, many of the studies reviewed did not report on these variables, and instead focused on the heuristic pathway. Finally, the main question of interest was to determine what the PWM model added to reasoned models such as the TRA/TPB, and therefore this review focused on the heuristic pathway, and its role in the prediction of behaviour.

\section{Method}

\section{Information Sources and Search Strategy}

Studies were identified by searching electronic databases. The search was applied to Medline, PubMed, PsycINFO, Web of Science, Cinahl, Scopus, and Science Direct databases. The search period was from 1990 up to and including January 2014. The search terms used were Prototype* AND Willing*. Key authors in the field were contacted for any recent publications that may have been missed. A total of 4813 articles were identified.

\section{Inclusion and Exclusion Criteria}




\section{REASONED VERSUS REACTIVE PREDICTION}

The following inclusion and exclusion criteria were used:

1. Studies needed to explicitly test the PWM (including making reference to the PWM and/or Gerrard and Gibbons);

2. While papers did not need to provide a full test of the model (i.e., measure all components), in order to compute the relevant correlations, it was necessary that at least two of the following constructs were measured: prototype, willingness, intention, and behaviour. Whilst prototype measures could include prototype similarity, prototype favourability and/or overall prototype (usually a combination of prototype similarity and prototype favourability), where more than one prototype measure was included, at least one other non-prototype construct needed to be included. Studies were required to report bivariate correlations between these constructs; i.e., at least one of the prototypewillingness, willingness-behaviour, willingness-intention, prototype-intention or prototype-behaviour correlations;

3. Studies needed to employ a cross-sectional or prospective design; where interventions were reported, the study needed to include a cross-sectional measure of key variables so that relationships between these variables were not influenced by the intervention;

4. Studies needed to focus on health behaviour (health-risk and/or health-promoting), even when a measure of actual behaviour was not present;

5. Studies needed to be reported in the English language;

6. Studies needed to be published between 1990 and January 2014, inclusive.

Studies were included regardless of the nature of behaviour measurement (i.e., self-report or objective behaviour), type of sample (i.e., all ages and clinical and non-clinical samples were included) and publication status (i.e., unpublished dissertation theses were included). 


\section{REASONED VERSUS REACTIVE PREDICTION}

Studies that reported on identical or overlapping datasets were included; for example, when data from a sub-sample of participants was used, when data was used from different timepoints in a longitudinal study, or where the sample was identical but either the studies had a different focus or used different measures. The rationale for including studies that may report identical datasets was that it was often difficult to identify whether the sample was identical or overlapping, and thus these decisions would be arbitrarily based on clarity of reporting rather than reflecting the actual data. The exception to this was when the results of a thesis were clearly reported in a publication, utilising identical data. In this case, the thesis was excluded and the article was included. Dissertation theses were otherwise included to reduce the chance of publication bias (i.e., that published studies may be more likely to include significant results than unpublished studies), as has been recommended in the literature (McAuley, Pham, Tugwell, \& Moher, 2000). Conference presentations and secondary sources such as reviews were also excluded.

\section{Information Extracted}

Pearson's correlations for prototype-willingness (including prototype favourabilitywillingness and prototype similarity-willingness), willingness-behaviour, prototype-behaviour, intention-behaviour, intention-willingness, and prototype-intention relationships, as well as number of participants reported for these relationships were extracted from the relevant studies. For each study that reported some form of prototype, these were used to compute an overall prototype construct, either by combining prototype similarity and favourability, or directly from the results. In addition, where possible, separate prototype favourability and prototype similarity indexes were extracted for further analysis. Although health-protective behaviour studies may not include a measure of willingness, and therefore may not include relationships between all the 


\section{REASONED VERSUS REACTIVE PREDICTION}

constructs as specified in the PWM, such studies frequently included prototype-behaviour or prototype-intention relationships, and thus were included based on this information. These relationships were also included to determine whether they added to the relationship theoretically specified in the PWM.

Where studies reported results for more than one behaviour, these were analysed separately. Further, where more than one measure of a key variable was used (e.g., prototype similarity, prototype favourability), these were also pooled to create a weighted average correlation for that variable. In addition where behaviour was measured at more than one time point, correlations at these time points were pooled to create a weighted average behaviour correlation. For studies reporting interventions, only cross-sectional data was used.

The following moderators were extracted:

Behaviour type: Based on consensus between the authors, behaviours were grouped into the following categories: sexual behaviour, sun protection, vaccination, alcohol use, smoking cigarettes, substance use, performance-enhancing substance use, risky driving, and unhealthy eating.

The sexual behaviour category included contraception use, unprotected sex, and casual sex behaviours, as these were frequently confounded in the measurement of PWM constructs and behaviour. For example, frequency of casual sex and frequency of contraception use (reverse coded) were often combined into a single risky sex measure. In addition, there was variation in measures of target behaviours across constructs. For example, willingness was often framed in terms of risk, such as willingness to engage in unsafe sex; whilst intention was often framed in terms of health-promoting behaviour, such as intention to use contraception. Likewise, behaviour and prototype measures were framed both in terms of health-risk behaviour and health- 


\section{REASONED VERSUS REACTIVE PREDICTION}

promoting behaviour. A combined sexual behaviour moderator was therefore used. Where target behaviours were not consistent, absolute values of the correlations were used to ensure that the relationship was coded in the correct direction. For example, negative correlations between willingness to engage in unsafe sex and intention to use contraception were re-coded as positive.

Studies were assigned to the alcohol use (encompassing general alcohol use, bingedrinking, and excessive alcohol use) and cigarette smoking categories when this was the only behaviour under investigation. Because many studies measured substance use without providing data for each included substance separately (e.g., alcohol, cigarettes, and marijuana combined), a substance use category was also included and reflected studies that measured a combination of substances, as well as studies that measured illicit drugs only. Performance enhancing substances included athletic enhancing substances and non-prescription stimulants for enhancing cognitive capacity. Risky driving included studies that measured driving under the influence of alcohol and other drugs, as well as speeding. Unhealthy eating included unhealthy snacking and composite unhealthy diet measures.

Age of sample: Average age was used as a continuous moderator. Although this is not an accurate indicator of sample age range, it can provide some indication of whether variation in sample age was influential in PWM relationships. In addition, samples were classified according to whether they were pre-adolescent (under 13 years), adolescent (13-18 years) or adult (18+ years). Where the sample contained both pre-adolescent and adolescent categories, the sample was classified as adolescent, as many of these samples used longitudinal follow-ups and sample age was taken at the first assessment. Whilst both age measures have limitations, inclusion of both may help to overcome some of the limitations of each whilst still obtaining meaningful results. 


\section{REASONED VERSUS REACTIVE PREDICTION}

Gender: Proportions of females in the sample was used to determine whether gender was influential in PWM relationships. In addition, where studies reported separate correlations for males and females, these were also included in a categorical variable that classified samples as female, male, or of mixed gender.

Length of follow-up: Whether the study was cross-sectional or included prospective measures was used as a dichotomous moderator variable. A continuous variable was also created based on the length of time between data collection for measures of willingness and measures of behaviour. If studies reported correlations for more than one follow-up time, these correlations were pooled, and the length of follow-up was also averaged. As only single time point data was used from intervention studies even if they had longer follow-ups, these studies were classified as cross-sectional.

Presence of an intervention: Although only cross-sectional data was used from intervention studies, whether or not a study reported an intervention was used as a moderator, as there may have been differences in how intervention studies are conducted that led to differences in the PWM relationships.

Overlapping datasets: As many of the studies reported samples and data that overlapped with at least one other study included in the meta-analysis, these studies were coded according to whether or not they contained overlapping data.

\section{Risk of Bias}

In order to reduce the risk of bias, the following measures were taken. An effort was made to include unpublished studies, as including only published studies risks inflation of effects due to significant results potentially being more likely to be published (Fanelli, 2010). Furthermore, when required statistics were not reported in published papers, the authors were 


\section{REASONED VERSUS REACTIVE PREDICTION}

contacted in order to avoid potential inflation ${ }^{1}$. In addition, by focusing on Pearson's product correlations rather than other analytic forms (such as regression), it is likely that these results were not the primary focus of the paper, and therefore may have been included regardless of whether they were significant or not. Fail-safe $\mathrm{N}$ was used to assess the likelihood that, had studies had been missed, that a null result would have been obtained, to further assess the risk of bias (Rosenthal, 1979).

\section{Summary Measures and Synthesis of Results}

Meta-analytical correlation statistics were obtained using the Metafor meta-analysis package for R (Viechtbauer, 2010), using a random effects model. Within these calculations, Fisher's $Z$ transformed correlations were used to minimise bias (Silver \& Dunlap, 1987). Forest plots were used to illustrate the relative strength of the effect for each study included in the analyses, and funnel plots were generated in order to provide further information about the likelihood of publication bias. Categorical and continuous moderator analyses were also conducted using the Metafor package for R. Where a significant categorical moderator was identified for three or more model relationships, the studies were split according to the moderator and correlations were meta-analysed separately for these groups.

Meta-analytic path analysis conducted in AMOS 19.0 was performed using the pooled correlation matrix in order to provide an overall estimate of the variance in behaviour accounted for by PWM variables. Three models were created; 1) only the reasoned pathway (i.e., intentionbehaviour), 2) including the social reactive pathway (i.e., addition of prototype-willingness, willingness-intention, and willingness-behaviour), and 3) including additional relationships (i.e., prototype-intention and prototype-behaviour). This stepped modelling enabled investigation of the relative contribution of the socially reactive pathway, as well as testing relationships that 


\section{REASONED VERSUS REACTIVE PREDICTION}

were reported in the literature but are not explicitly part of the PWM. See Figure 1 for a pictorial representation of these models. For the purposes of the analyses, the harmonic mean $\mathrm{N}$ was used to specify sample size. The percentage variance explained was reported $\left(R^{2}\right)$ and the relative contribution of each variable to the final equation was reported by way of beta weights $(\beta)$. The $95 \%$ confidence interval for each beta weight was also reported. Significance levels have not been reported, as they are not meaningful due to the high numbers of participants included in the analyses.

\section{FIGURE 1 NEAR HERE}

\section{Results}

\section{Study Selection}

Following removal of duplicate articles, 4244 manuscripts were identified. A title search and abstract search were used to eliminate studies that were clearly not related to health behaviour and health models. A full text search was then conducted on 223 manuscripts, removing studies that did not meet the selection criteria. Additional reasons for excluding studies at the full text search level included investigating non-health behaviours such as recycling (Ohtomo \& Hirose, 2007), organ donation (Hyde \& White, 2009; Hyde \& White, 2010), or helpseeking decisions (Hammer \& Vogel, 2013); investigating the outcome of behaviour (e.g., BMI) rather than the behaviour itself (Hampson, Andrews, Peterson, \& Duncan, 2007); or dissertation theses where the findings had since been published in an article (Lane, 2005; Litt, 2011). Studies that measured PWM constructs were excluded if the necessary information was not reported in the paper and the primary author/s no longer had access to the data (Blanton, Gibbons, Gerrard, Conger, \& Smith, 1997; Blanton et al., 2001), were not able to provide the information in the required timeframe (Spijkerman, van den Eijnden, Vitale, \& Engels, 2004), were not able to be 


\section{REASONED VERSUS REACTIVE PREDICTION}

contacted (Pomery, Gibbons, Reis-Bergan, \& Gerrard, 2009; Wills et al., 2007), or were deceased (Ge et al., 2006). In addition, intervention studies that did not report cross-sectional PWM data were also excluded (e.g. Brody et al., 2004).

Eighty-one articles were retained (see Supplementary File 2 for a flow diagram of study selection, and Supplementary File 3 for a full list of references included). A selection of approximately ten percent of titles and ten percent of abstracts was screened by a second author for the purposes of ensuring reliability. Inter-rater reliability using Cohen's (1960) kappa was good for titles $(k=0.59)$ and excellent for abstracts $(k=0.86)$. Furthermore, $93 \%$ and 94\% of disagreements on titles and abstracts respectively were due to conservative inclusions on the part of the primary researcher. Abstract discrepancies were resolved with discussion between authors. Full text articles retrieved were included based on consensus between authors.

\section{Study Characteristics}

A total of 81 articles reporting 90 studies were included, although 36 of these studies reported data that overlapped with at least one other study. Sample sizes ranged from 50 to 6522, with the average age at baseline ranging from 9 to 46.3 years. Twenty-one interventions were included. Of the rest, the majority of studies were prospective $(k=46)$, with follow-up ranging from 5 days to 11 years, and the remainder of studies were cross-sectional $(k=24)$. Six dissertation theses were included. For further details of the study characteristics, see the Supplementary File 4. Behaviours included alcohol $(k=29)$, smoking $(k=15)$, substance use $(k=14)$, performance enhancing substance use $(k=3)$, sexual behaviour $(k=22)$, sun protection $(k=4)$, exercise $(k=2)$, risky driving $(k=5)$, flu vaccination $(k=1)$, unhealthy eating $(k=3)$, and multiple health behaviours $(k=1)$, with some studies reporting separate data for more than one behaviour. 


\section{REASONED VERSUS REACTIVE PREDICTION}

\section{Overall Model Results}

The mean correlations as a general test of the model are presented in Table 1, which includes the meta-analysed Fisher corrected $(Z)$ correlations. In accordance with the PWM, prototype was a stronger predictor of willingness $(r=0.34)$ than intention $(r=0.25)$. When prototype was separated into prototype similarity and prototype favourability, prototype favourability was a stronger predictor of willingness $(r=0.31)$ than intention $(r=0.23)$; however, prototype similarity was the stronger predictor of intention $(r=0.47)$ than willingness $(r=0.41)$.

\section{INSERT TABLE 1 HERE}

In addition, a series of path analytic models were computed. In the first model, paths were drawn from intention to behaviour (see Figure 1, Panel 1). The hypothesised paths from overall prototype to willingness, from willingness to intention, and from willingness to behaviour were added in the second model (see Figure 1, Panel 2). In the third model, pathways from prototype to intention and from prototype to behaviour were added.

Results from these path analyses for the overall model are reported in Table 2. Intention accounted for $15.6 \%$ of variance in behaviour; the addition of willingness in Model 2 accounted for a further $4.9 \%$ of the variance in behaviour; and the addition of prototype in Model 3 accounted for a further $1.2 \%$ of the variance in behaviour (Final $R^{2}=.217$ ). In the final model, intention and willingness were the main predictors of behaviour $(\beta=.263$ and $\beta=.235$ respectively). Prototype was not a strong direct predictor of behaviour $(\beta=.096)$, after accounting for intention and willingness. Willingness was the main predictor of intention, and accounted for $21.6 \%$ of the variance $(\beta=.465)$. Prototype was not a strong predictor of intention, accounting for $0.5 \%$ of the variance $(\beta=.100)$, but accounted for $10.5 \%$ of the variance in willingness $(\beta=.325)$.

\section{INSERT TABLE 2 HERE}




\section{REASONED VERSUS REACTIVE PREDICTION}

It is important to note that there was significant heterogeneity across all correlations $\left(I^{2}=\right.$ 83.77-97.60\%; $\left.H^{2}=6.16-41.68\right)$. Therefore, exploring potential study and methodological covariates was warranted, and a series of moderator analyses were conducted for this purpose.

\section{Behaviour Type as a Moderator}

Type of behaviour was a significant moderator for the prototype-intention $\left(Q M_{(\mathrm{df}=7)}=18.94, p=.01\right)$, prototype similarity-intention $\left(Q M_{(\mathrm{df}=5)}=65.43, p<.001\right)$, prototype favourability-intention $\left(Q M_{(\mathrm{df}=5)}=16.59, p=.01\right)$, prototype similarity-willingness $\left(Q M_{(\mathrm{df}=5)}=16.22, p=.01\right)$, prototype-behaviour $\left(Q M_{(\mathrm{df}=8)}=19.44, p=.01\right)$, and willingness-intention $\left(Q M_{(\mathrm{df}=7)}=30.40, p<.001\right)$ relationships. Other relationships were not significantly moderated by behaviour $\left(Q M_{(\mathrm{df}=4-9)}=0.69-11.76, p=.08-.95\right)$. Separate analyses were conducted by behaviour type to further explore these differences, as displayed in Table 3. Significant differences between groups were determined using confidence intervals. Only behaviour types that were measured with more than five studies were included in these analyses; i.e., alcohol use, cigarette use, substance use and sexual behaviours. Prototype similarity and prototype favourability measures were not used in these analyses due to a smaller number of studies reporting these constructs separately.

\section{INSERT TABLE 3 HERE}

A series of path analytic models were also conducted separately for each behaviour type, as with the overall data. These results are displayed in Table 4. For alcohol use, intention accounted for $41.3 \%$ of variance in behaviour. The addition of willingness accounted for a further $1.4 \%$ of the variance in behaviour, and the addition of prototype accounted for a further $1.1 \%$ of the variance in behaviour (Final $R^{2}=.436$ ). In the final model, intention was the main predictor of behaviour $(\beta=.537)$. Willingness $(\beta=.069)$ and prototype $(\beta=.145)$ were not strong 


\section{REASONED VERSUS REACTIVE PREDICTION}

direct predictors of behaviour, after accounting for intention. Willingness alone was a strong predictor of intention, accounting for $56.4 \%$ of the variance, and the addition of prototype did not improve the variance explained $(\beta=.054)$. Prototype accounted for $19.3 \%$ of the variance in willingness $(\beta=.325)$ in the final model.

For cigarette use, intention accounted for $24.1 \%$ of variance in behaviour. The addition of willingness accounted for a further $3.1 \%$ of the variance in behaviour, and the addition of prototype accounted for a further $0.1 \%$ of the variance in behaviour (Final $R^{2}=.273$ ). In the final model, intention and willingness were the main predictors of behaviour $(\beta=.323, \beta=.227$ respectively). Prototype was not a strong predictor of behaviour $(\beta=.050)$ after accounting for intention and willingness. Willingness was initially a strong predictor of intention, explaining $48.3 \%$ of the variance $(\beta=.695)$, which was not improved by the addition of prototype to predict intention $(\beta=.002)$. Prototype accounted for $6.9 \%$ of the variance in willingness $(\beta=.262)$ in the final model.

For substance use, intention accounted for $8.3 \%$ of variance in behaviour. The addition of willingness accounted for a further $20.2 \%$ of the variance in behaviour; and the addition of prototype accounted for a further $0.5 \%$ of the variance in behaviour (Final $R^{2}=.207$ ). In the final model, intention and willingness were the main predictors of behaviour $(\beta=.225, \beta=.360$ respectively). Prototype was not a strong predictor of behaviour $(\beta=-.008)$ after accounting for intention and willingness. Willingness initially explained $3.9 \%$ of the variance in intention, and the addition of prototype accounted for a further $6.9 \%$ of the variance. In the final model, prototype was the main predictor of intention $(\beta=.289)$, and willingness was not a strong predictor of intention $(\beta=.087)$. Prototype accounted for $11.2 \%$ of the variance in willingness in the final model $(\beta=.335)$. 


\section{REASONED VERSUS REACTIVE PREDICTION}

For sexual behaviour, intention accounted for $16.9 \%$ of variance in behaviour. The addition of willingness accounted for a further $5.2 \%$ of the variance in behaviour, and the addition of prototype accounted for a further $0.5 \%$ of the variance in behaviour (Final $R^{2}=.226$ ). In the final model, intention and willingness were the main predictors of behaviour $(\beta=.343, \beta$ $=.226$ respectively). Prototype was not a strong predictor of behaviour $(\beta=.058)$ after accounting for intention and willingness. Willingness initially explained $7.1 \%$ of the variance in intention, and the addition of prototype accounted for a further $0.3 \%$ of the variance. In the final model, willingness was the main predictor of intention $(\beta=.249)$, and prototype was not a strong predictor $(\beta=.061)$. Prototype accounted for $7.9 \%$ of the variance in willingness in the final $\operatorname{model}(\beta=.281)$.

\section{INSERT TABLE 4 HERE}

\section{Age of Sample as a Moderator}

Average age as a continuous variable significantly moderated the prototype-behaviour $\left(Q M_{(\mathrm{df}=1)}=6.15, p=.01\right)$ and intention-behaviour relationships, $\left(Q M_{(\mathrm{df}=1)}=6.30, p=.01\right)$ such that the relationships were stronger amongst older samples. Average age did not moderate other relationships $\left(Q M_{(\mathrm{df}=1)}=0.004-3.24, p=.07-.95\right)$. In addition, whether the sample was preadolescent, adolescent, or adult significantly moderated the prototype similarity-behaviour $\left(Q M_{(\mathrm{df}=2)}=9.27, p=.009\right)$, prototype favourability-willingness $\left(Q M_{(\mathrm{df}=2)}=8.67, p=.01\right)$, prototypewillingness $\left(Q M_{(\mathrm{df}=2)}=11.97, p=.003\right)$, and willingness-behaviour $\left(Q M_{(\mathrm{df}=2)}=8.75, p=.01\right)$ relationships. Age category was not a significant moderator of the other relationships $\left(Q M_{(\mathrm{df}=2)}=\right.$ 0.28-4.97, $p=.08-.87)$. Given the number of relationships for which age category was a moderator, sub-group analyses were conducted for each of the three age categories, and 


\section{REASONED VERSUS REACTIVE PREDICTION}

significant differences between groups were determined using confidence intervals. These results are displayed in Table 5.

\section{INSERT TABLE 5 HERE}

A series of path analytic models were also conducted to explore the PWM separately for each age group, as with the overall sample. These results are displayed in Table 6. For preadolescents, intention accounted for $6.8 \%$ of variance in behaviour. The addition of willingness accounted for a further $0.2 \%$ of the variance in behaviour, and the addition of prototype accounted for a further $0.9 \%$ of the variance in behaviour (Final $R^{2}=.079$ ). In the final model, intention was the main predictor of behaviour $(\beta=.203$ respectively). Willingness $(\beta=.092)$ and Prototype $(\beta=.062)$ were not strong predictors of behaviour after accounting for intention. Willingness initially explained $24.9 \%$ of the variance in intention, and the addition of prototype accounted for a further $0.6 \%$ of the variance. In the final model, willingness was the main predictor of intention $(\beta=.472)$, and prototype was not a strong predictor $(\beta=.062)$. Prototype accounted for $3.5 \%$ of the variance in willingness in the final model $(\beta=.188)$.

For adolescents, intention accounted for $25.2 \%$ of variance in behaviour. The addition of willingness accounted for a further $7.4 \%$ of the variance in behaviour, and the addition of prototype accounted for a further $0.7 \%$ of the variance in behaviour (Final $R^{2}=.333$ ). In the final model, intention and willingness were the main predictors of behaviour $(\beta=.337, \beta=.287$ respectively). Prototype was not a strong predictor of behaviour $(\beta=.082)$ after accounting for intention and willingness. Willingness initially explained $50.3 \%$ of the variance in intention, and the addition of prototype reduced the variance explained. In the final model, willingness was the main predictor of intention $(\beta=.478)$, and prototype was not a strong predictor $(\beta=.058)$.

Prototype accounted for $15.9 \%$ of the variance in willingness in the final model $(\beta=.399)$. 


\section{REASONED VERSUS REACTIVE PREDICTION}

For adults, intention accounted for $25.4 \%$ of variance in behaviour. The addition of willingness accounted for a further $3.1 \%$ of the variance in behaviour, and the addition of prototype accounted for a further $1.6 \%$ of the variance in behaviour (Final $R^{2}=.301$ ). In the final model, intention and willingness were the main predictors of behaviour $(\beta=.356, \beta=.212$ respectively). Prototype was not a strong predictor of behaviour $(\beta=.099)$ after accounting for intention and willingness. Willingness initially explained $56.5 \%$ of the variance in intention, and the addition of prototype accounted for a further $11.6 \%$ of the variance. In the final model, willingness was the main predictor of intention $(\beta=.519)$, and prototype was not as strong a strong predictor $(\beta=.116)$. Prototype accounted for $11.8 \%$ of the variance in willingness in the final model $(\beta=.343)$.

\section{INSERT TABLE 6 HERE}

\section{Other Sample and Methodological Moderators}

\section{Gender of sample}

Proportion of females in each study was not a significant moderator of any of the relationships tested $\left(Q M_{(\mathrm{df}=1)}=0.02-1.15, p=.28-.89\right)$. Gender category (male, female, or combined) was also not a significant moderator for any of the relationships tested $\left(Q M_{(\mathrm{df}=2)}=0.04\right.$ $5.40, p=.07-.98)$. Separate analyses by gender were therefore not conducted.

\section{Length of follow-up}

Presence or absence of follow-up and length of follow-up moderators were only explored for behaviour relationships, as studies that used follow-ups were most likely to measure prototype, willingness, and intention together, and then behaviour at a later time-point (although this did not apply to cross-sectional studies which measured all constructs simultaneously). Whether or not the study was cross-sectional was a significant moderator of the intention- 


\section{REASONED VERSUS REACTIVE PREDICTION}

behaviour relationship $\left(Q M_{(\mathrm{df}=1)}=4.49, p=.03\right)$, such that this relationship was stronger for prospective studies $(r=.54$, se $=.05,95 \% \mathrm{CI}: .43-.64, k=26)$ compared to cross-sectional studies $(r=.32, \mathrm{se}=.07,95 \% \mathrm{CI}: .18-.46, k=9)$. There was no significant difference in the willingnessbehaviour or prototype-behaviour relationships according to whether the study was prospective or cross-sectional $\left(Q M_{(\mathrm{df}=1)}=0.03-2.03, p=.15-.87\right)$. Average length of follow-up in days was not a significant moderator for any of the PWM-behaviour relationships $\left(Q M_{(\mathrm{df}=1)}=0.004-1.65, p=.19\right.$ $.95)$.

\section{Presence of an intervention}

Presence of an intervention was a significant moderator for the prototype similaritywillingness relationship $\left(Q M_{(\mathrm{df}=1)}=4.21, p=.04\right)$. The relationship was stronger in studies conducted without an intervention $(r=.49, \mathrm{se}=.07,95 \% \mathrm{CI}: .35-.63, k=8)$ than those where an intervention was present $(r=.27, \mathrm{se}=.06,95 \% \mathrm{CI}: .16-.38, k=6)$. The presence of an intervention was not a significant moderator of any of the other PWM relationships $\left(Q M_{(\mathrm{df}=1)}=0.07-3.27\right.$, $p=.07-.78)$.

\section{Overlapping data and samples}

Whether or not the study reported on data from a larger project that overlapped with other studies included in the meta-analysis was not a significant moderator of any of the tested relationships $\left(Q M_{(\mathrm{df}=1)}=0.01-2.17, p=0.14-.94\right)$. Forest plots and funnel plots of 1$)$ all studies and 2) without overlapping studies were created in order to further explore the potential influence of including overlapping data (see Supplementary File 5 and 6). These plots were consistent with the moderator analyses and there were no major differences with or without overlapping studies.

\section{Discussion}




\section{REASONED VERSUS REACTIVE PREDICTION}

The aim of this meta-analysis was to explore the relationships between the heuristic PWM variables of prototypes and willingness, in addition to intention and behaviour, and to determine whether contextual, sample, and study factors influenced the strength of these relationships. The heuristic pathway was supported, as willingness generally added to the prediction of behaviour, and prototype was generally a strong predictor of willingness. As shown in Tables 2, 4, and 6 the addition of willingness to the prediction of behaviour significantly attenuated the intention-behaviour relationship within the overall dataset, within studies of alcohol and cigarette use, and within studies that included adolescent and adult samples. In addition, pathways not specified by the PWM (i.e., from overall prototype to intention and behaviour) received minimal support. Thirdly, there was evidence of differences in the model relationships depending on behaviour type and age. In particular, whilst willingness did not meaningfully add to the prediction of alcohol use above intentions for alcohol use, willingness accounted for a large proportion of variance for cigarette use. In addition, the model explained greater variance in behaviour for adolescents and adults than for pre-adolescents. These results reinforce the utility of the PWM in predicting health behaviour. Intention was generally a stronger predictor of behaviour than was willingness, and prototype similarity was strongly associated with willingness, intention and behaviour; which were both interesting findings that warrant further exploration.

Overall, the analyses indicated that the PWM (willingness and intention) explained $20.5 \%$ of the variance in behaviour. Intention alone explained $15.6 \%$ of the variance in behaviour, which is consistent with previous research; for example, intention was found to explain between $13.8 \%$ and $15.3 \%\left(R^{2}\right)$ of the variance in risk behaviours within a TPB metaanalysis (McEachan et al., 2011). Willingness improved the prediction of behaviour over and 


\section{REASONED VERSUS REACTIVE PREDICTION}

above intention, explaining an additional $4.9 \%$ of variance, supporting the argument that willingness is a meaningful construct with which to further explain health behaviour beyond traditional TRA/TPB constructs (Head \& Noar, 2013).

The relationship between prototype and willingness was stronger than the prototypeintention relationship, which is also consistent with the PWM in which the latter pathway is not specified. Prototype similarity, however, had the strongest relationship with both willingness and intention, and contrary to predictions, it was more strongly associated with intention than willingness. Previous studies investigating organ donation willingness have also found prototype similarity to be a stronger predictor of willingness than prototype favourability (Hyde \& White, 2009), adding further support for the importance of this construct.

The results of this meta-analysis are generally consistent with previous reviews, which have found that the addition of a social reactive or heuristic pathway can further improve the explanation of behaviour above reasoned models such as the TPB (Gerrard et al., 2008; Gibbons et al., 2009). Given the strength of the pathways from prototype similarity to intention and behaviour, this construct may play an important role in predicting and explaining intention and behaviour, perhaps above the role of prototype favourability. This finding may reflect social and peer influences on behaviour that have been found in the literature (Jaccard, Blanton, \& Dodge, 2005; Maxwell, 2002). Although there were insufficient studies to investigate the prototype similarity associations for separate behaviours or age categories, this would be interesting to explore in the future.

\section{Behaviour as a Moderator}

Significant heterogeneity in results was found for all model relationships, and therefore several moderator variables were explored. Using behaviour as a moderator helped to reduce the 


\section{REASONED VERSUS REACTIVE PREDICTION}

unaccounted for variance in most variable relationships, although a significant amount of residual heterogeneity remained. When explored separately, the largest proportion of variance was accounted for in alcohol consumption. Interestingly, for substance use, willingness was a stronger predictor of behaviour than intention, whereas for alcohol use, cigarette use, and sexual behaviours, intention was stronger than willingness. These findings suggest that substance use may be a more socially reactive behaviour than other behaviours, although the overlap between substance use (encompassing all substances including alcohol and cigarettes when measured as part of a composite behaviour) and the separate categories of alcohol and cigarette use (when measured as the sole behaviour) limits the conclusions that can be drawn from this finding, and therefore the results must be interpreted with caution.

\section{Age as a Moderator}

Another important moderator of the PWM relationships was age - that is, whether the sample was pre-adolescent, adolescent, or adult. The PWM was originally designed as a model to explain adolescent risk-taking behaviour, and consistent with predictions, willingness and intention together accounted for the greatest proportion of variance in behaviour for adolescents $\left(R^{2}=.33\right)$, although the proportion of variance explained for adults was close $\left(R^{2}=.29\right)$. These findings suggest that the model may also be of value when applied to adult samples.

Gerrard et al. (2008) have proposed that whilst risk-taking behaviour begins as being governed by social reactions, with time and experience, the intention-behaviour pathway strengthens and takes precedence over the willingness-behaviour relationship. Whilst this tendency has been supported in the literature (Pomery et al., 2009), this was only partially supported in the current meta-analysis. Although the PWM as a whole better accounted for behaviour in adolescents than adults, willingness alone was a stronger predictor for adults, 


\section{REASONED VERSUS REACTIVE PREDICTION}

suggesting that social reactions continue to be important in health behaviour decisions as individuals age. It may therefore be useful to continue applying the PWM within adult populations, as interventions that incorporate willingness in addition to intentions may be as successful for this age group as for adolescents.

In contrast, for pre-adolescents, willingness added less to the model and was much weaker than intention in predicting behaviour, compared to adolescents and adults. Only $7.6 \%$ of the variance in behaviour was accounted for in pre-adolescents, suggesting that the PWM may be of limited value within this age group. However, it is worth noting that it may be generally harder to account for differences in behaviour in pre-adolescents, rather than being specific limitation of the PWM. Increases in risk-taking behaviour have been observed to correspond to the onset of puberty, which has been associated with the development of certain cortical changes that occur during this time (Steinberg, 2008). Prior to this time, it may be that individuals are less willing to engage in risk behaviours. In addition, as it has been found that intentions develop with behavioural experience (Gerrard et al., 2008; Pomery et al., 2009), it is likely that few preadolescents would have developed intentions to smoke, take drugs, consume alcohol, or engage in risky sex that would correspond to actual behavioural engagement. Thus, the predictive ability of intentions may be small within this age group, at least for some behaviours. Other factors may also be important within this age group; for example, parental factors such as parental health cognitions and behaviour, parenting style, and socio-economic status have been found to be related to pre-adolescent behaviour (Cleveland, Gibbons, Gerrard, Pomery, \& Brody, 2005; Gerrard, Gibbons, Stock, Lune, \& Cleveland, 2005).

\section{Other Moderators Investigated}




\section{REASONED VERSUS REACTIVE PREDICTION}

Other study and methodological variables were included in an attempt to explain the variability across studies and thus reduce heterogeneity. Gender of the sample did not significantly moderate any of the PWM relationships, although as most studies tested a mixed gender sample further behaviour-specific research that reports gender results separately would be useful.

Other methodological variables that were investigated included whether or not the study reported an intervention, whether the study was cross-sectional or prospective, the average length of the follow-up, and whether or not the sample was independent from the samples reported in other studies. The presence of an intervention influenced the prototype similarity-willingness relationship, such that the relationship was stronger for studies not reporting an intervention. In addition, of the relationships with behaviour, presence of a follow-up influenced the intentionbehaviour relationship, such that prospective studies found stronger relationships. This is surprising because cross-sectional measures of constructs can be biased (Maxwell \& Cole, 2007; Noar \& Head, 2014), and meta-analytic research has generally found stronger intentionbehaviour relationships over shorter periods of time (McEachan et al., 2011). Indeed, crosssectional research may also overestimate the association of these constructs with behaviour, as other factors that may influence the strength of the association over time (such as the translation of intentions into behaviour over longer periods), do not come into play. In addition, measuring constructs only at a single time point does not show whether changes in constructs are related to behaviour change, which is a criticism of much of the research in this field, and extends beyond the PWM (Sniehotta, Presseau, \& Araújo-Soares, 2014). Whilst prospective studies also have limitations and, unlike experimental research, cannot definitively conclude whether changes in the constructs are responsible for behaviour change, they can at least provide some indication on 


\section{REASONED VERSUS REACTIVE PREDICTION}

whether the relationships between these constructs are reliably tracking behaviour over time. The current findings suggest that PWM constructs continue to predict behaviour over longer time periods. Whether or not the study reported on overlapping data did not, however, influence any of the PWM relationships, and, in general, it appears that these methodological factors have a limited influence on the PWM relationships.

\section{Strengths and Weaknesses}

It is worth noting that the full PWM was not tested. Attitudes and subjective norms, which are proposed to influence both intention and willingness, were not investigated, as these constructs have been more thoroughly investigated within the TRA/TPB literature, and many PWM studies do not measure these constructs. The extent to which the model accounts for intention and willingness was therefore not able to be determined. Nonetheless, the relative contribution of the reasoned and heuristic pathways to health behaviour engagement was able to be determined, and other pathways within the model were explored.

Despite investigating several moderators, significant heterogeneity remained between studies indicating that there are likely to be other factors that influence the strength of the PWM relationships that were not explored within this meta-analysis. It is also likely that part of the residual heterogeneity is due to other moderators included within the meta-analysis but not tested simultaneously (e.g., exploring the effect of behaviour within age category) due to an insufficient number of studies, which has been a difficulty in other meta-analyses (e.g., McEachan et al., 2011). It is likely that, at different age groups, different behaviours may be more relevant and better predicted by the PWM than for other age groups. For example the nature of drug and substance use may change over time (Arnett, 2005; Schulenberg \& Maggs, 2002), and therefore the determinants of behaviour are likely to change too. Nonetheless, that several moderators 


\section{REASONED VERSUS REACTIVE PREDICTION}

from the diverse categories of contextual, sample, and study characteristics were tested in the current study represents a strength. Important moderators such as age and behaviour type were identified, which may help to determine under which circumstances the PWM is most likely to be effective in explaining health behaviour.

There were several health behaviours that could not be compared due to small numbers of studies, and therefore conclusions that can be drawn from these behaviours are limited. In addition, it was not possible to investigate specific sub-classes of behaviours within the behavioural categories, which may have confounded the results. Nonetheless, the application of PWM to a wide range of behaviours and findings in support of the model appears promising, and further research should continue to build upon these studies to create a sound base of research across health behaviours areas such as diet, physical activity, sun protection and risky driving.

Approximately half the studies included reported data from a sample that partially or fully overlapped with the sample of another study. This is problematic as it is likely to have inflated the sample size and therefore reduced the error, which may have led to an inflation of significant effects, and must therefore be taken into consideration when reviewing the current findings. Despite this, the relationships between constructs did not significantly differ between these studies and studies that reported independent samples, as was also found when comparing funnel and forest plots, which suggests that the strength of the effects is unlikely to have been grossly affected by including these studies. Furthermore, often these studies took a different focus or reported different PWM associations, and therefore including them provided opportunity for more comprehensive analyses and results.

It is important to note that constructs were not always measured consistently within a study; for example, health-protective behaviour studies that included willingness items tended to 


\section{REASONED VERSUS REACTIVE PREDICTION}

measure willingness to engage in health-risk behaviours, whereas health-risk behaviour studies that included intention measures often measured intention to engage in health-protective behaviours. These inconsistencies may have reduced the strength of associations between variables, and where possible, future studies should try to match construct items in terms of direction for increased reliability. In addition, that measures of health-risk and health-protective behaviours were often combined or confounded made it impractical to conduct separate analyses on these classes of behaviours. However, it is worth noting that if classed according to whether behaviour action is risky or healthy, the majority of studies included investigated health risk behaviours. It is stipulated in the PWM that the nature of the behaviour is likely to influence the strength of the relationships, with health-risk behaviour being more strongly predicted by willingness, whilst health-protective behaviours are expected to be more strongly predicted by intention. Reviews have supported this distinction (Rivis et al., 2006), although, to date, the influence of health-risk versus health-promoting status within a single behaviour class (e.g., condom use and unsafe sex; healthy eating and unhealthy eating) has only been explored at the single study level, and it remains difficult to distinguish the methodological effects of question framing (e.g., proportion of unprotected sexual encounters compared to proportion of protected sexual encounters) and social desirability (Tversky \& Kahneman, 1981) from true differences in health-risk versus health-promoting behaviours. More research is therefore needed to elucidate the differences in explaining health-risk and health-protective behaviours using models such as the PWM.

The large number of PWM studies that have been published in the literature enabled examination of effects that are likely to be robust, which is a strength of this field of research and of this meta-analysis. By including dissertation theses and by contacting authors for publications 


\section{REASONED VERSUS REACTIVE PREDICTION}

that may have been missed or where necessary data was not presented in the article, the risk of obtaining biased results that favour positive effects was reduced, and is also reflected in the large fail-safe $\mathrm{N}$ reported for each correlation.

\section{Conclusions}

This was the first study to meta-analytically explore the PWM. Overall, support for the PWM was demonstrated, and in particular including willingness as a predictor of behaviour, in addition to intention, appears warranted. The strength of the relationships between prototype similarity and other constructs was surprising, as within the PWM its only direct pathway is to willingness. Research conducted in this area should therefore continue to include both prototype favourability and similarity measures separately, as it appears that these two constructs differentially impact willingness, intentions, and behaviour. Age of the sample and type of behaviour investigated moderated several construct relationships, which may be of particular utility when conducting further research and designing theory-driven interventions that are informed by the literature. Several PWM experiments and interventions have been conducted already in the literature (e.g., Blanton et al., 1997; Brody et al., 2004; Teunissen et al., 2012; Thornton, Gibbons, \& Gerrard, 2002); and a meta-analysis of PWM interventions would also be useful for informing future intervention development. 
REASONED VERSUS REACTIVE PREDICTION

\section{Disclosure Statement}

No funding was received for this study.

\section{Acknowledgements}

Thanks are due to authors who provided correlations for inclusion in this meta-analysis. Thanks are also due to Vanessa Allom and Kirby Sainsbury for assistance in manuscript preparation, and the University of Sydney Health Psychology Lab, for feedback on earlier drafts of this manuscript.

\section{Notes}

${ }^{1}$ The following authors provided additional data upon request, and are thanked for their contributions: Judy Andrews, Maureen Barckley, Frederick Gibbons, Noémi Keresztes, David Lane, Dana Litt, Barbara Kalebić Maglica, Shoji Ohtomo, Melissa Peterson, Renske Spijkerman, Hanneke Teunissen, Friederike Zimmermann. 


\section{REASONED VERSUS REACTIVE PREDICTION}

\section{References}

Ajzen, I. (1991). The theory of planned behavior. Organizational behavior and human decision processes, 50(2), 179-211. doi: 10.1016/0749-5978(91)90020-T

Andrews, J., Hampson, S., \& Barckley, M. (2008). The effect of subjective normative social images of smokers on children's intentions to smoke. Nicotine \& Tobacco Research, 10(4), 589-597. doi: 10.1080/14622200801975819

Armitage, C. J., \& Conner, M. (2001). Efficacy of the theory of planned behaviour: A meta analytic review. British Journal of Social Psychology, 40(4), 471-499. doi:

$10.1348 / 014466601164939$

Arnett, J. J. (2005). The Developmental Context of Substance use in Emerging Adulthood. Journal of Drug Issues, 35(2), 235-254. doi: 10.1177/002204260503500202

Blanton, H., Gibbons, F. X., Gerrard, M., Conger, K. J., \& Smith, G. E. (1997). Role of family and peers in the development of prototypes associated with substance use. Journal of Family Psychology, 11(3), 271-288. doi: 10.1037/0893-3200.11.3.271

Blanton, H., VandenEijnden, R. J., Buunk, B. P., Gibbons, F. X., Gerrard, M., \& Bakker, A. (2001). Accentuate the negative: Social images in the prediction and promotion of condom use. Journal of Applied Social Psychology, 31(2), 274-295. doi: 10.1111/j.15591816.2001.tb00197.x

Brody, G. H., Murry, V. M., Gerrard, M., Gibbons, F. X., Molgaard, V., McNair, L., .. . Luo, Z. (2004). The strong African American families program: Translating research into prevention programming. Child development, 75(3), 900-917. doi: 10.1111/j.14678624.2004.00713.x 


\section{REASONED VERSUS REACTIVE PREDICTION}

Cleveland, M. J., Gibbons, F. X., Gerrard, M., Pomery, E. A., \& Brody, G. H. (2005). The impact of parenting on risk cognitions and risk behavior: A study of mediation and moderation in a panel of African American adolescents. Child development, 76(4), 900916. doi: 10.1111/j.1467-8624.2005.00885.x

Cohen, J. (1960). A Coefficient of Agreement for Nominal Scales. Educational and Psychological Measurement, 20(1), 37-46. doi: 10.1177/001316446002000104

Cohen, J. (1992). Statistical power analysis. Current Directions in Psychological Science, 1(3), 98-101. doi: $10.2307 / 20182143$

Conner, M., \& Norman, P. (1996). The role of social cognition in health behaviours. In M. Conner \& P. Norman (Eds.), Predicting Health Behaviour (1st ed., pp. 1-22). Buckingham, Philadelphia: Open University Press.

Epstein, S. (1985). The implications of cognitive experiential self theory for research in social psychology and personality. Journal for the Theory of Social Behaviour, 15(3), 283-310. doi: 10.1111/j.1468-5914.1985.tb00057.x

Fanelli, D. (2010). "Positive" results increase down the hierarchy of the sciences. PloS one, 5(4), e10068.

Ge, X., Jin, R., Natsuaki, M. N., Gibbons, F. X., Brody, G. H., Cutrona, C. E., \& Simons, R. L. (2006). Pubertal maturation and early substance use risks among African American children. Psychology of Addictive Behaviors, 20(4), 404-414. doi: 10.1037/0893164X.20.4.404

Gerrard, M., Gibbons, F. X., Houlihan, A. E., Stock, M. L., \& Pomery, E. A. (2008). A dualprocess approach to health risk decision making: The prototype willingness model. Developmental Review, 28(1), 29-61. doi: 10.1016/j.dr.2007.10.001 


\section{REASONED VERSUS REACTIVE PREDICTION}

Gerrard, M., Gibbons, F. X., Stock, M. L., Lune, L. S. V., \& Cleveland, M. J. (2005). Images of smokers and willingness to smoke among African American pre-adolescents: An application of the prototype/willingness model of adolescent health risk behavior to smoking initiation. Journal of Pediatric Psychology, 30(4), 305-318. doi: 10.1093/jpepsy/jsi026

Gibbons, F. X., Gerrard, M., Blanton, H., \& Russell, D. W. (1998). Reasoned action and social reaction: Willingness and intention as independent predictors of health risk. Journal of Personality and Social Psychology, 74(5), 1164-1180. doi: 10.1037/0022-3514.74.5.1164

Gibbons, F. X., Gerrard, M., Lando, H. A., \& McGovern, P. G. (1991). Social comparison and smoking cessation: The role of the "typical smoker". Journal of Experimental Social Psychology, 27(3), 239-258. doi: 10.1016/0022-1031(91)90014-W

Gibbons, F. X., Gerrard, M., \& Lane, D. J. (2003). A social reaction model of adolescent health risk. In J. Suls \& K. Wallston (Eds.), Social Psychological Foundations of Health and Illness (pp. 107-136). Oxford, UK: Blackwell Publishing Ltd.

Gibbons, F. X., Gerrard, M., \& McCoy, S. B. (1995). Prototype perception predicts (lack of) pregnancy prevention. Personality and Social Psychology Bulletin, 21(1), 85-93. doi: $10.1177 / 0146167295211009$

Gibbons, F. X., Houlihan, A. E., \& Gerrard, M. (2009). Reason and reaction: The utility of a dual-focus, dual-processing perspective on promotion and prevention of adolescent health risk behaviour. British Journal of Health Psychology, 14(2), 231-248. doi:

$10.1348 / 135910708 \times 376640$ 


\section{REASONED VERSUS REACTIVE PREDICTION}

Hammer, J. H., \& Vogel, D. L. (2013). Assessing the utility of the willingness/prototype model in predicting help-seeking decisions. Journal of Counseling Psychology, 60(1), 83-97. doi: $10.1037 / \mathrm{a} 0030449$

Hampson, S. E., Andrews, J. A., Peterson, M., \& Duncan, S. C. (2007). A cognitive-behavioral mechanism leading to adolescent obesity: children's social images and physical activity. Annals of Behavioral Medicine, 34(3), 287-294. doi: 10.1007/BF02874553

Head, K. J., \& Noar, S. M. (2013). Facilitating progress in health behaviour theory development and modification: the reasoned action approach as a case study. Health Psychology Review, 8(1), 34-52. doi: 10.1080/17437199.2013.778165

Hyde, M. K., \& White, K. M. (2009). Similarity not favourability: The role of donor prototypes in predicting willingness to donate organs while living. Journal of Health Psychology, 14(7), 888-898. doi: 10.1177/1359105309340990

Hyde, M. K., \& White, K. M. (2010). Are organ donation communication decisions reasoned or reactive? A test of the utility of an augmented theory of planned behaviour with the prototype/willingness model. British Journal of Health Psychology, 15(2), 435-452. doi: $10.1348 / 135910709 X 468232$

Jaccard, J., Blanton, H., \& Dodge, T. (2005). Peer influences on risk behavior: an analysis of the effects of a close friend. Developmental psychology, 41(1), 135-147. doi: 10.1037/00121649.41.1.135

Lane, D. J. (2005). Social Comparison with Risk Images. Dissertation Abstracts International: Section B: The Sciences and Engineering, 65(8-B), 35944669. Retrieved from: $\underline{\text { http://gradworks.umi.com/ }}$ 


\section{REASONED VERSUS REACTIVE PREDICTION}

Litt, D. (2011). Social networking sites and adolescent alcohol use: The role of social images, social norms, and social comparison. Dissertation Abstracts International, B: Sciences and Engineering, 71(8), 744091325. Retrieved from: http://gradworks.umi.com/

Maxwell, K. A. (2002). Friends: The Role of Peer Influence Across Adolescent Risk Behaviors. Journal of youth and adolescence, 31(4), 267-277. doi: 10.1023/a:1015493316865

Maxwell, S. E., \& Cole, D. A. (2007). Bias in cross-sectional analyses of longitudinal mediation. Psychological methods, 12(1), 23-44. doi: 10.1037/1082-989X.12.1.23

McAuley, L., Pham, B., Tugwell, P., \& Moher, D. (2000). Does the inclusion of grey literature influence estimates of intervention effectiveness reported in meta-analyses? The Lancet, 356(9237), 1228-1231. doi: 10.1016/S0140-6736(00)02786-0

McEachan, R. R. C., Conner, M., Taylor, N. J., \& Lawton, R. J. (2011). Prospective prediction of health-related behaviours with the theory of planned behaviour: A meta-analysis. Health Psychology Review, 5(2), 97-144. doi: 10.1080/17437199.2010.521684

Noar, S. M., \& Head, K. J. (2014). Mind the gap: Bringing our theories in line with the empirical data-a response to commentaries. Health Psychology Review, 8(1), 65-69. doi: $10.1080 / 17437199.2013 .855593$

Ohtomo, S., \& Hirose, Y. (2007). The dual-process of reactive and intentional decision-making involved in eco-friendly behavior. Journal of Environmental Psychology, 27(2), 117-125. doi: 10.1016/j.jenvp.2007.01.005

Pomery, E. A., Gibbons, F. X., Reis-Bergan, M., \& Gerrard, M. (2009). From willingness to intention: Experience moderates the shift from reactive to reasoned behavior. Personality and Social Psychology Bulletin, 35(7), 894-908. doi: 10.1177/0146167209335166 


\section{REASONED VERSUS REACTIVE PREDICTION}

Rivers, S. E., Reyna, V. F., \& Mills, B. (2008). Risk taking under the influence: A fuzzy-trace theory of emotion in adolescence. Developmental Review, 28(1), 107-144. doi: 10.1016/j.dr.2007.11.002

Rivis, A., Sheeran, P., \& Armitage, C. J. (2006). Augmenting the theory of planned behaviour with the prototype/willingness model: Predictive validity of actor versus abstainer prototypes for adolescents' health-protective and health-risk intentions. British Journal of Health Psychology, 11(3), 483-501. doi: 10.1348/135910705X70327

Rosenthal, R. (1979). The file drawer problem and tolerance for null results. Psychological bulletin, 86(3), 638-641. doi: 10.1037/0033-2909.86.3.638

Schulenberg, J. E., \& Maggs, J. L. (2002). A developmental perspective on alcohol use and heavy drinking during adolescence and the transition to young adulthood. Journal of Studies on Alcohol and Drugs(14), 54-70. Retrieved from: http://www.jsad.com/

Sheeran, P. (2002). Intention-behavior relations: A conceptual and empirical review. European review of social psychology, 12(1), 1-36. doi: 10.1080/14792772143000003

Silver, N. C., \& Dunlap, W. P. (1987). Averaging correlation coefficients: Should Fisher's Z transformation be used? Journal of Applied Psychology, 72(1), 146-148. doi: $10.1037 / 0021-9010.72 .1 .146$

Sniehotta, F. F., Presseau, J., \& Araújo-Soares, V. (2014). Time to retire the theory of planned behaviour. Health Psychology Review, 8(1), 1-7. doi: 10.1080/17437199.2013.869710

Spijkerman, R., van den Eijnden, R., Vitale, S., \& Engels, R. (2004). Explaining adolescents' smoking and drinking behavior: The concept of smoker and drinker prototypes in relation to variables of the theory of planned behavior. Addictive behaviors, 29(8), 1615-1622. doi: 10.1016/j.addbeh.2004.02.030 


\section{REASONED VERSUS REACTIVE PREDICTION}

Steinberg, L. (2008). A social neuroscience perspective on adolescent risk-taking. Developmental Review, 28(1), 78-106. doi: 10.1016/j.dr.2007.08.002

Teunissen, H. A., Spijkerman, R., Larsen, H., Kremer, K. A., Kuntsche, E., Gibbons, F. X., . . . Engels, R. C. M. E. (2012). Stereotypic information about drinkers and students' observed alcohol intake: An experimental study on prototype-behavior relations in males and females in a naturalistic drinking context. Drug and Alcohol Dependence, 125(3), 301-306. doi: 10.1016/j.drugalcdep.2012.03.007

Thornton, B., Gibbons, F. X., \& Gerrard, M. (2002). Risk perception and prototype perception: Independent processes predicting risk behavior. Personality and Social Psychology Bulletin, 28(7), 986-999. doi: 10.1177/014616720202800711

Tversky, A., \& Kahneman, D. (1981). The framing of decisions and the psychology of choice. Science, 211(4481), 453-458. doi: 10.2307/1685855

Viechtbauer, W. (2010). Conducting meta-analyses in R with the metafor package. Journal of Statistical Software, 36(3), 1-48. Retrieved from: http://www.jstatsoft.org/v36/i03/

Wills, T. A., Murry, V. M., Brody, G. H., Gibbons, F. X., Gerrard, M., Walker, C., \& Ainette, M. G. (2007). Ethnic pride and self-control related to protective and risk factors: Test of the theoretical model for the strong African American families program. Health Psychology, 26(1), 50-59. doi: 10.1037/0278-6133.26.1.50

World Health Organization: WHO. (2009). Global Health Risks: Mortality and Burden of Disease Attributable to Selected Major Risks. Retrieved 9th May, 2011, Retrieved from http://www.who.int/healthinfo/global_burden_disease/GlobalHealthRisks_report_full.pdf 


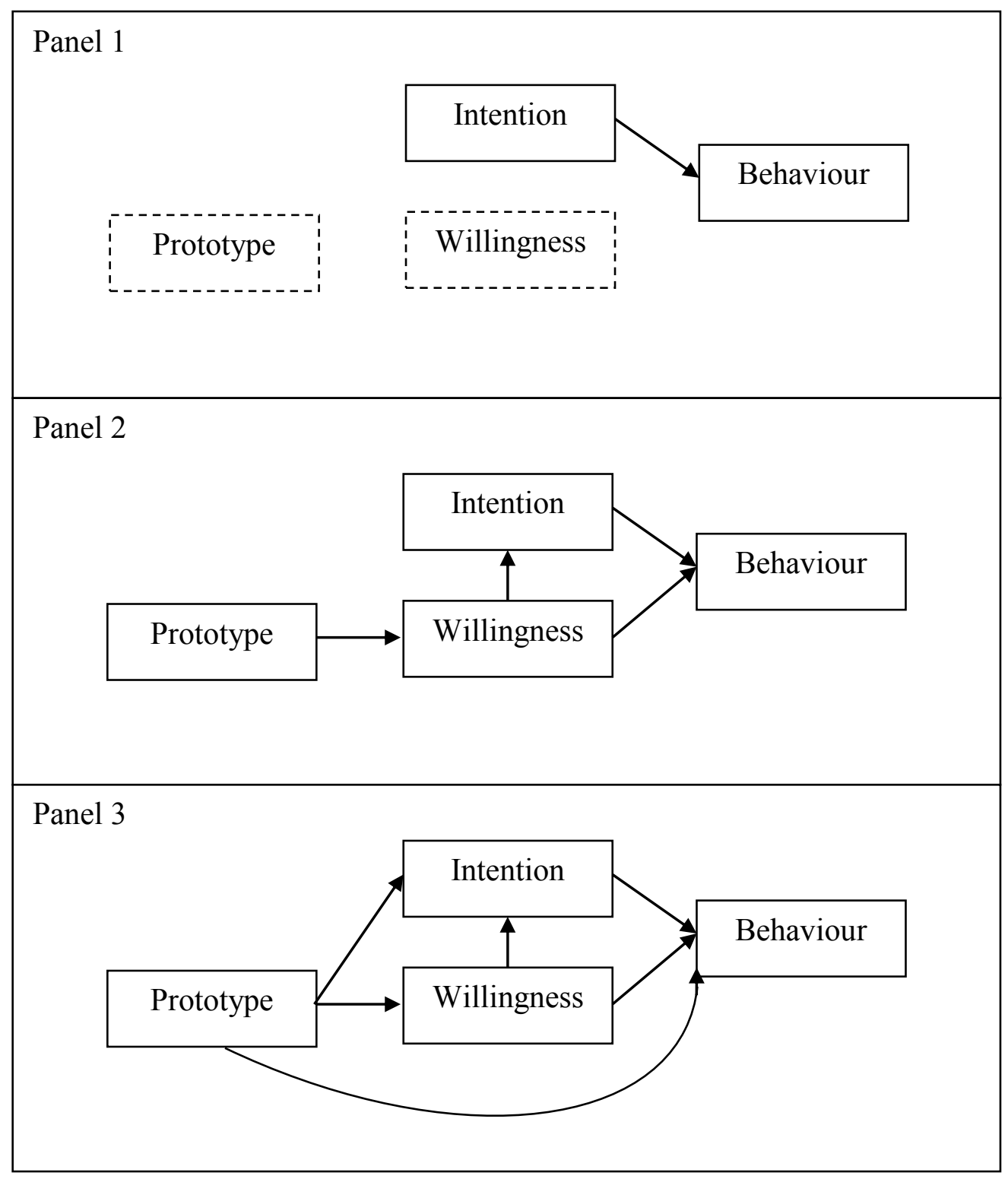

Figure 1. Prototype Willingness Model Pathways, Tested with Path Analysis Modelling.

Notes. Panel 1= partial test of the reasoned pathway (excluding attitudes and subjective norms); Panel 2= addition of the social reactive pathway; Panel 3= including additional relationships not specified within the model. 
REASONED VERSUS REACTIVE PREDICTION

Table 1. General Prototype Willingness Model Correlations

\begin{tabular}{llll}
\hline & Willingness & Intention & Behaviour \\
\hline Prototype & $.343[.30, .39] k=51, \mathrm{FSN}=47471$ & $.255[.20, .31] k=40, \mathrm{FSN}=11957$ & $.255[.20, .31] k=51, \mathrm{FSN}=25775$ \\
Proto Similarity & $.406[.30, .51] k=14, \mathrm{FSN}=1899$ & $.466[.31, .62] k=12, \mathrm{FSN}=3740$ & $.408[.32, .50] k=12, \mathrm{FSN}=2381$ \\
Proto Favourability & $.313[.24, .38] k=17, \mathrm{FSN}=2559$ & $.227[.13, .32] k=15, \mathrm{FSN}=1815$ & $.286[.20, .37] k=12, \mathrm{FSN}=1238$ \\
Willingness & & $.535[.43, .64] k=44, \mathrm{FSN}=62821$ & $.438[.38, .50] k=57, \mathrm{FSN}=92075$ \\
Intention & & & $.481[.39, .57] k=35, \mathrm{FSN}=32963$
\end{tabular}

Notes. Reported: correlations [95\% Confidence Interval], number of studies (k), fail-safe N (FSN). Fail-safe N is an estimate of the number of missed studies necessary to obtain a null result, and is used as an indicator of bias with higher numbers suggesting lower risk of bias. Correlations $\geq 0.1,0.3$ and 0.5 can be interpreted as small, medium, and large effect sizes, respectively, according to Cohen's (1992) guidelines. 
REASONED VERSUS REACTIVE PREDICTION

Table 2. Path Analysis of the Prototype Willingness Model: Reasoned, Heuristic, and Additional Pathways

\begin{tabular}{|c|c|c|c|}
\hline & Model 1 & Model 2 & Model 3 \\
\hline Total R ${ }^{2}$ (behaviour) & .156 & .205 & .217 \\
\hline Total $\mathrm{R}^{2}$ (intention) & & .216 & .221 \\
\hline Total $\mathrm{R}^{2}$ (willingness) & & .107 & .103 \\
\hline Intention $\rightarrow$ behaviour & $.394[0.34 ; 0.45]$ & $.254[0.19 ; 0.32]$ & $.263[0.20 ; 0.33]$ \\
\hline Willingness $\rightarrow$ behaviour & & $.274[0.21 ; 0.33]$ & $.235[0.17 ; 0.30]$ \\
\hline Willingness $\rightarrow$ intention & & $.465[0.41 ; 0.52]$ & $.429[0.37 ; 0.49]$ \\
\hline Prototype $\rightarrow$ willingness & & $.328[0.27 ; 0.39]$ & $.321[0.26 ; 0.38]$ \\
\hline Prototype $\rightarrow$ intention & & & $.100[0.04 ; 0.16]$ \\
\hline Prototype $\rightarrow$ behaviour & & & $.096[0.04 ; 0.15]$ \\
\hline
\end{tabular}

Notes. Values are standardised Beta regression coefficients [95\% confidence intervals], except where indicated as $\mathrm{R}^{2}$ (proportion of variance

explained). Fit statistics are reported in supplementary file 7.

Model 1= reasoned pathway (intention to behaviour); Model 2= addition of the social reactive pathway (prototype to willingness, willingness to intention, intention to behaviour); Model 3= addition of relationships not specified within the model (prototype to intention, prototype to behaviour). 
REASONED VERSUS REACTIVE PREDICTION

Table 3. Average Prototype Willingness Model Correlations, by Behaviour Type

\begin{tabular}{|c|c|c|c|c|c|c|c|c|c|c|}
\hline & & $r$ & $\mathrm{Se}$ & $\mathrm{Z}$ & CI- & $\mathrm{CI}+$ & $\mathrm{k}$ & $\mathrm{N}$ & FSN & Diffs \\
\hline \multirow[t]{4}{*}{ P-W } & A. Alcohol & .440 & 0.05 & 9.05 & .34 & .53 & 15 & 12324 & 8711 & $\mathrm{D}$ \\
\hline & B. Cigs & .262 & 0.08 & 3.32 & .11 & .42 & 5 & 5841 & 430 & \\
\hline & C. Subs & .335 & 0.06 & 5.77 & .22 & .45 & 5 & 3627 & 746 & \\
\hline & D. Sex & .281 & 0.03 & 10.64 & .23 & .33 & 17 & 5638 & 2339 & A \\
\hline \multirow[t]{4}{*}{ P-I } & A. Alcohol & .373 & 0.06 & 6.30 & .26 & .49 & 9 & 2111 & 830 & $\mathrm{D}$ \\
\hline & B. Cigs & .184 & 0.06 & 3.06 & .07 & .30 & 8 & 5604 & 350 & \\
\hline & C. Subs & .318 & 0.03 & 11.32 & .26 & .37 & 3 & 1274 & 131 & D \\
\hline & D. Sex & .131 & 0.03 & 4.17 & .07 & .19 & 14 & 3493 & 239 & $\mathrm{~A}, \mathrm{C}$ \\
\hline \multirow[t]{4}{*}{ P-B } & A. Alcohol & .376 & 0.05 & 7.48 & .28 & .47 & 20 & 13425 & 8789 & C, D \\
\hline & B. Cigs & .169 & 0.08 & 2.23 & .02 & .32 & 5 & 3916 & 83 & \\
\hline & C. Subs & .184 & 0.03 & 5.37 & .12 & .25 & 8 & 4953 & 447 & A \\
\hline & D. Sex & .166 & 0.03 & 6.41 & .12 & .22 & 10 & 3994 & 374 & A \\
\hline \multirow[t]{3}{*}{ W-B } & A. Alcohol & .535 & 0.05 & 9.76 & .43 & .64 & 18 & 13148 & 17549 & \\
\hline & B. Cigs & .465 & 0.10 & 4.82 & .28 & .65 & 9 & 3622 & 2153 & \\
\hline & C. Subs & .398 & 0.07 & 5.60 & .26 & .54 & 10 & 4867 & 1899 & \\
\hline
\end{tabular}


REASONED VERSUS REACTIVE PREDICTION

\begin{tabular}{|c|c|c|c|c|c|c|c|c|c|c|}
\hline & D. Sex & .334 & 0.06 & 5.60 & .22 & .45 & 10 & 3436 & 1290 & \\
\hline \multirow[t]{4}{*}{ I-B } & A. Alcohol & .643 & 0.10 & 6.45 & .45 & .84 & 9 & 2214 & 2804 & \\
\hline & B. Cigs & .491 & 0.12 & 4.24 & .26 & .72 & 7 & 2690 & 1397 & \\
\hline & C. Subs & .289 & 0.12 & 2.46 & .06 & .52 & 3 & 2125 & 192 & \\
\hline & D. Sex & .411 & 0.11 & 3.90 & .20 & .62 & 6 & 1773 & 699 & \\
\hline \multirow[t]{4}{*}{ W-I } & A. Alcohol & .749 & 0.12 & 6.445 & .52 & .98 & 12 & 2609 & 6423 & C, D \\
\hline & B. Cigs & .695 & 0.10 & 6.90 & .50 & .89 & 6 & 4131 & 3171 & C, D \\
\hline & C. Subs & .184 & 0.03 & 5.37 & .12 & .25 & 8 & 4953 & 447 & A, B \\
\hline & D. Sex & .266 & 0.06 & 4.65 & .15 & .38 & 16 & 4119 & 1480 & A, B \\
\hline
\end{tabular}

Note. $\mathrm{P}=$ prototype, $\mathrm{W}=$ willingness, $\mathrm{I}=$ intention, $\mathrm{B}=$ behaviour, Cigs=cigarette use, Subs=substance use, $\mathrm{FSN}=$ fail-safe $\mathrm{N}$, Diffs $=$ significant differences between confidence intervals 
REASONED VERSUS REACTIVE PREDICTION

Table 4. Path Analysis of the Prototype Willingness Model by Behaviour

\begin{tabular}{|c|c|c|c|c|}
\hline Behaviour Type & & Model 1 & Model 2 & Model 3 \\
\hline \multirow[t]{9}{*}{ Alcohol } & Total $\mathrm{R}^{2}$ (behaviour) & .413 & .425 & .436 \\
\hline & Total $\mathrm{R}^{2}$ (intention) & & .564 & .564 \\
\hline & Total R² (willingness) & & .204 & .193 \\
\hline & Intention $\rightarrow$ behaviour & $.643[0.6 ; 0.69]$ & $.535[0.45 ; 0.59]$ & $.537[0.47 ; 0.61]$ \\
\hline & Willingness $\rightarrow$ behaviour & & $.147[0.07 ; 0.21]$ & $.069[0.09 ; 0.20]$ \\
\hline & Willingness $\rightarrow$ intention & & $.751[0.71 ; 0.79]$ & $.725[0.68 ; 0.77]$ \\
\hline & Prototype $\rightarrow$ willingness & & $.452[0.41 ; 0.52]$ & $.440[0.39 ; 0.49]$ \\
\hline & Prototype $\rightarrow$ intention & & & $.054[0.01 ; 0.10]$ \\
\hline & Prototype $\rightarrow$ behaviour & & & $.145[0.00 ; 0.14]$ \\
\hline \multirow[t]{6}{*}{ Cigarette } & Total $\mathrm{R}^{2}$ (behaviour) & .241 & .272 & .273 \\
\hline & Total $\mathrm{R}^{2}$ (intention) & & .483 & .483 \\
\hline & Total R² (willingness) & & .069 & .069 \\
\hline & Intention $\rightarrow$ behaviour & $.491[0.44 ; 0.55]$ & $.324[0.25 ; 0.40]$ & $.323[0.25 ; 0.40]$ \\
\hline & Willingness $\rightarrow$ behaviour & & $.241[0.17 ; 0.32]$ & $.227[0.15 ; 0.30]$ \\
\hline & Willingness $\rightarrow$ intention & & $.695[0.65 ; 0.74]$ & $.695[0.65 ; 0.74]$ \\
\hline
\end{tabular}


REASONED VERSUS REACTIVE PREDICTION

Prototype $\rightarrow$ willingness

Prototype $\rightarrow$ intention

$.002[-0.05 ; 0.05]$

Prototype $\rightarrow$ behaviour

.050 [0.00; 0.10$]$

\begin{tabular}{|c|c|c|c|c|}
\hline \multirow[t]{9}{*}{ Substance Use } & Total $\mathrm{R}^{2}$ (behaviour) & .083 & .202 & .207 \\
\hline & Total $\mathrm{R}^{2}$ (intention) & & .039 & .108 \\
\hline & Total R² (willingness) & & .129 & .112 \\
\hline & Intention $\rightarrow$ behaviour & $.289[0.23 ; 0.35]$ & $.211[0.16 ; 0.29]$ & $.225[0.17 ; 0.28]$ \\
\hline & Willingness $\rightarrow$ behaviour & & $.357[0.30 ; 0.41]$ & $.360[0.30 ; 0.42]$ \\
\hline & Willingness $\rightarrow$ intention & & $.198[0.12 ; 0.24]$ & $.087[0.02 ; 0.15]$ \\
\hline & Prototype $\rightarrow$ willingness & & $.359[0.32 ; 0.45]$ & $.335[0.28 ; 0.39]$ \\
\hline & Prototype $\rightarrow$ intention & & & $.289[0.23 ; 0.35]$ \\
\hline & Prototype $\rightarrow$ behaviour & & & $-.008[-0.07 ; 0.05]$ \\
\hline \multirow[t]{5}{*}{ Sex } & Total $\mathrm{R}^{2}$ (behaviour) & .169 & .221 & .226 \\
\hline & Total $\mathrm{R}^{2}$ (intention) & & .071 & .074 \\
\hline & Total R² (willingness) & & .080 & .079 \\
\hline & Intention $\rightarrow$ behaviour & $.411[0.35 ; 0.47]$ & $.341[0.28 ; 0.40]$ & $.343[0.29 ; 0.40]$ \\
\hline & Willingness $\rightarrow$ behaviour & & $.245[0.19 ; 0.30]$ & $.226[0.17 ; 0.28]$ \\
\hline
\end{tabular}


REASONED VERSUS REACTIVE PREDICTION

$$
\begin{aligned}
& \text { Willingness } \rightarrow \text { intention } \\
& \text { Prototype } \rightarrow \text { willingness } \\
& \text { Prototype } \rightarrow \text { intention } \\
& \text { Prototype } \rightarrow \text { behaviour }
\end{aligned}
$$

$.267[0.21 ; 0.32]$

$.283[0.22 ; 0.35]$

$.249[0.19 ; 0.31]$

$.281[0.22 ; 0.34]$

$.061[0.00 ; 0.12]$

.058 [0.00; 0.11$]$

Notes. Values are standardised Beta regression coefficients [95\% confidence intervals], except where indicated as $\mathrm{R}^{2}$ (proportion of variance explained). Fit statistics are reported in supplementary file 7.

Model 1= reasoned pathway (intention to behaviour); Model 2= addition of the social reactive pathway (prototype to willingness, willingness to intention, intention to behaviour); Model 3= addition of relationships not specified within the model (prototype to intention, prototype to behaviour). 
REASONED VERSUS REACTIVE PREDICTION

Table 5. Average Prototype Willingness Model Correlations, by Age Category

\begin{tabular}{|c|c|c|c|c|c|c|c|c|c|c|}
\hline & & $\mathrm{r}$ & $\mathrm{Se}$ & $\mathrm{Z}$ & CI- & $\mathrm{CI}+$ & $\mathrm{k}$ & $\mathrm{N}$ & FSN & diffs \\
\hline \multirow[t]{3}{*}{ P-W } & A. Pre-adoles. & 0.188 & 0.03 & 5.85 & 0.12 & 0.25 & 7 & 6078 & 479 & $\mathrm{~B}$ \\
\hline & B. Adolescent & 0.399 & 0.04 & 10.60 & 0.33 & 0.47 & 20 & 17661 & 15208 & A \\
\hline & C. Adult & 0.343 & 0.03 & 11.77 & 0.29 & 0.40 & 24 & 6027 & 5241 & \\
\hline \multirow[t]{3}{*}{ P-I } & A. Pre-adoles. & 0.198 & 0.04 & 5.35 & 0.13 & 0.27 & 10 & 5844 & 873 & \\
\hline & B. Adolescent & 0.250 & 0.06 & 4.13 & 0.13 & 0.37 & 13 & 4165 & 612 & \\
\hline & C. Adult & 0.294 & 0.05 & 6.20 & 0.20 & 0.39 & 17 & 5850 & 2991 & \\
\hline \multirow[t]{3}{*}{ P-B } & A. Pre-adoles. & 0.119 & 0.03 & 3.83 & 0.06 & 0.18 & 7 & 4665 & 167 & B \\
\hline & B. Adolescent & 0.281 & 0.04 & 6.42 & 0.20 & 0.37 & 25 & 18632 & 9034 & A \\
\hline & C. Adult & 0.276 & 0.04 & 7.70 & 0.21 & 0.35 & 19 & 5784 & 2695 & A \\
\hline \multirow[t]{3}{*}{ W-B } & A. Pre-adoles. & 0.204 & 0.067 & 3.11 & 0.08 & 0.33 & 6 & 3919 & 359 & $\mathrm{~B}, \mathrm{C}$ \\
\hline & B. Adolescent & 0.489 & 0.05 & 9.97 & 0.39 & 0.59 & 25 & 17310 & 28710 & \\
\hline & C. Adult & 0.445 & 0.04 & 11.52 & 0.37 & 0.52 & 26 & 7480 & 13183 & \\
\hline \multirow[t]{3}{*}{ I-B } & A. Pre-adoles. & 0.261 & 0.09 & 2.85 & 0.08 & 0.44 & 4 & 2115 & 221 & \\
\hline & B. Adolescent & 0.524 & 0.10 & 5.28 & 0.33 & 0.72 & 11 & 3801 & 3401 & \\
\hline & C. Adult & 0.504 & 0.05 & 9.21 & 0.40 & 0.61 & 20 & 6639 & 11698 & \\
\hline
\end{tabular}


REASONED VERSUS REACTIVE PREDICTION

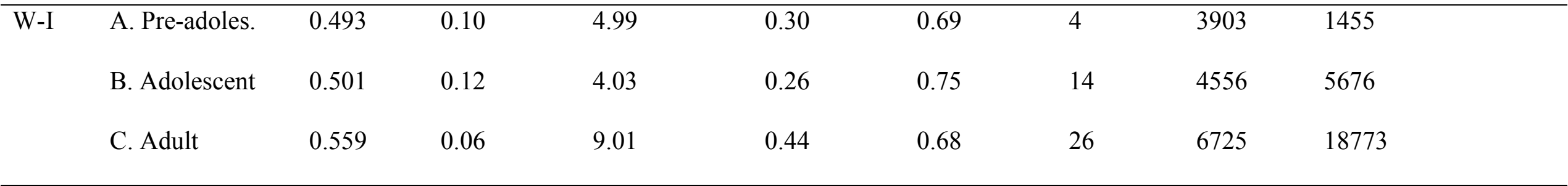

Note. $\mathrm{P}=$ prototype, $\mathrm{W}=$ willingness, $\mathrm{I}=$ intention, $\mathrm{B}=$ behaviour, Pre-adoles.= pre-adolescent less than 13 years, Adolescent $=13-17$ years, Adult $=18+$ years, FSN= fail-safe N, Diffs= significant differences between confidence intervals 
REASONED VERSUS REACTIVE PREDICTION

Table 6. Path Analysis of the Prototype Willingness Model by Age Group

\begin{tabular}{|c|c|c|c|c|}
\hline Behaviour Type & & Model 1 & Model 2 & Model 3 \\
\hline \multirow[t]{9}{*}{ Pre-adolescent } & Total $\mathrm{R}^{2}$ (behaviour) & .068 & .070 & .079 \\
\hline & Total $\mathrm{R}^{2}$ (intention) & & .249 & .255 \\
\hline & Total R² (willingness) & & .037 & .035 \\
\hline & Intention $\rightarrow$ behaviour & $.261[0.2 ; 0.32]$ & $.193[0.12 ; 0.26]$ & $.203[0.13 ; 0.27]$ \\
\hline & Willingness $\rightarrow$ behaviour & & $.109[0.04 ; 0.18]$ & $.092[0.02 ; 0.16]$ \\
\hline & Willingness $\rightarrow$ intention & & $.499[0.44 ; 0.55]$ & $.472[0.42 ; 0.53]$ \\
\hline & Prototype $\rightarrow$ willingness & & $.191[0.13 ; 0.26]$ & $.188[0.06 ; 0.18]$ \\
\hline & Prototype $\rightarrow$ intention & & & $.109[0.05 ; 0.16]$ \\
\hline & Prototype $\rightarrow$ behaviour & & & $.062[0.00 ; 0.12]$ \\
\hline \multirow[t]{6}{*}{ Adolescent } & Total $\mathrm{R}^{2}$ (behaviour) & .252 & .326 & .333 \\
\hline & Total $\mathrm{R}^{2}$ (intention) & & .253 & .254 \\
\hline & Total $\mathrm{R}^{2}$ (willingness) & & .162 & .159 \\
\hline & Intention $\rightarrow$ behaviour & $.502[0.45 ; 0.55]$ & $.334[0.27 ; 0.39]$ & $.337[0.28 ; 0.40]$ \\
\hline & Willingness $\rightarrow$ behaviour & & $.325[0.26 ; 0.38]$ & $.287[0.22 ; 0.35]$ \\
\hline & Willingness $\rightarrow$ intention & & $.503[0.45 ; 0.55]$ & $.478[0.42 ; 0.54]$ \\
\hline
\end{tabular}


REASONED VERSUS REACTIVE PREDICTION

Prototype $\rightarrow$ willingness

Prototype $\rightarrow$ intention $.058[0.00 ; 0.12]$

Prototype $\rightarrow$ behaviour

\begin{tabular}{|c|c|c|c|c|}
\hline \multirow[t]{9}{*}{ Adult } & Total R ${ }^{2}$ (behaviour) & .254 & .285 & .301 \\
\hline & Total $\mathrm{R}^{2}$ (intention) & & .320 & .324 \\
\hline & Total R² (willingness) & & .124 & .118 \\
\hline & Intention $\rightarrow$ behaviour & $.504[0.45 ; 0.56]$ & $.343[0.28 ; 0.41]$ & $.356[0.29 ; 0.42]$ \\
\hline & Willingness $\rightarrow$ behaviour & & $.259[0.19 ; 0.32]$ & $.212[0.15 ; 0.28]$ \\
\hline & Willingness $\rightarrow$ intention & & $.565[0.51 ; 0.61]$ & $.519[0.46 ; 0.57]$ \\
\hline & Prototype $\rightarrow$ willingness & & $.352[0.30 ; 0.42]$ & $.343[0.28 ; 0.40]$ \\
\hline & Prototype $\rightarrow$ intention & & & $.116[0.06 ; 0.17]$ \\
\hline & Prototype $\rightarrow$ behaviour & & & $.099[0.04 ; 0.15]$ \\
\hline
\end{tabular}

Notes. Values are standardised Beta regression coefficients [95\% confidence intervals], except where indicated as $\mathrm{R}^{2}$ (proportion of variance

explained). Fit statistics are reported in supplementary file 7. Pre-adolescent $=$ up to 13 years; Adolescent $=13-17$ years; Adult $=18$ or more years

Model 1= reasoned pathway (intention to behaviour); Model 2= addition of the social reactive pathway (prototype to willingness, willingness to intention, intention to behaviour); Model 3= addition of relationships not specified within the model (prototype to intention, prototype to behaviour). 


\section{SUPPLEMENTARY FILE 1}

\section{The Prototype Willingness Model}

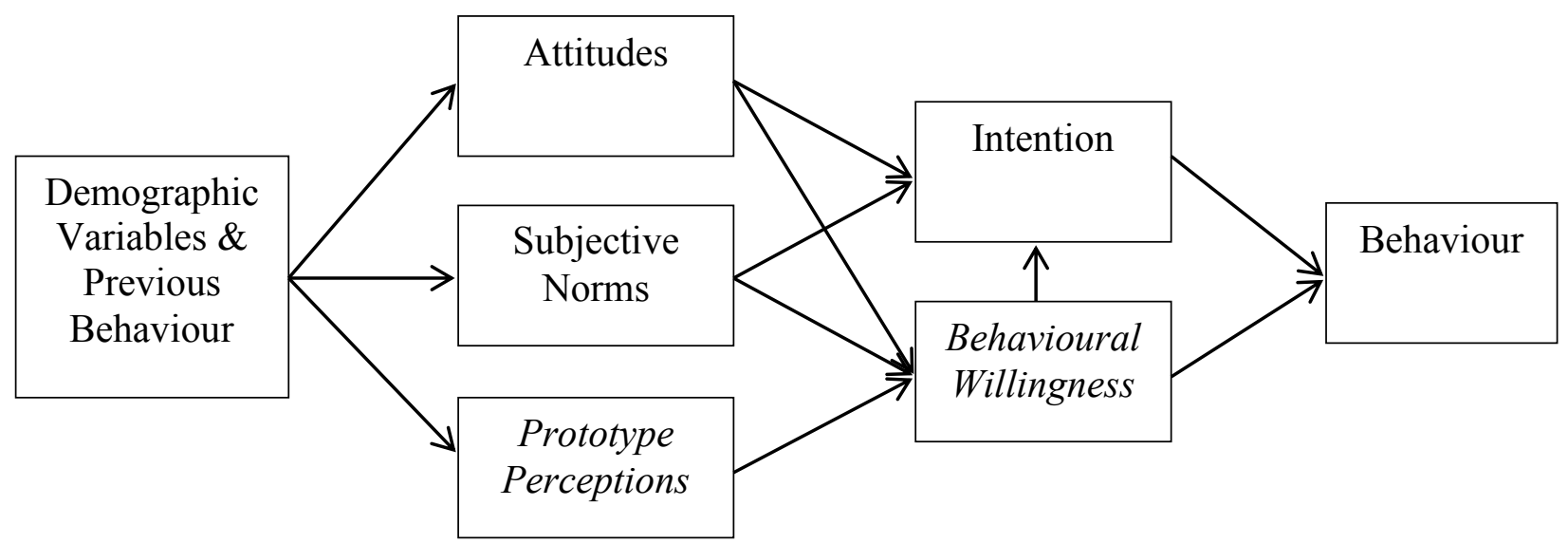

(Gibbons, Gerrard, Blanton, \& Russell, 1998a; Gibbons, Gerrard, \& Lane, 2003).

Notes. The reasoned path is represented by attitude, subjective norms, and intention. The heuristic path is represented by prototype perceptions and willingness (italicised). 


\section{SUPPLEMENTARY FILE 2}

\section{Study Selection Flow Diagram}

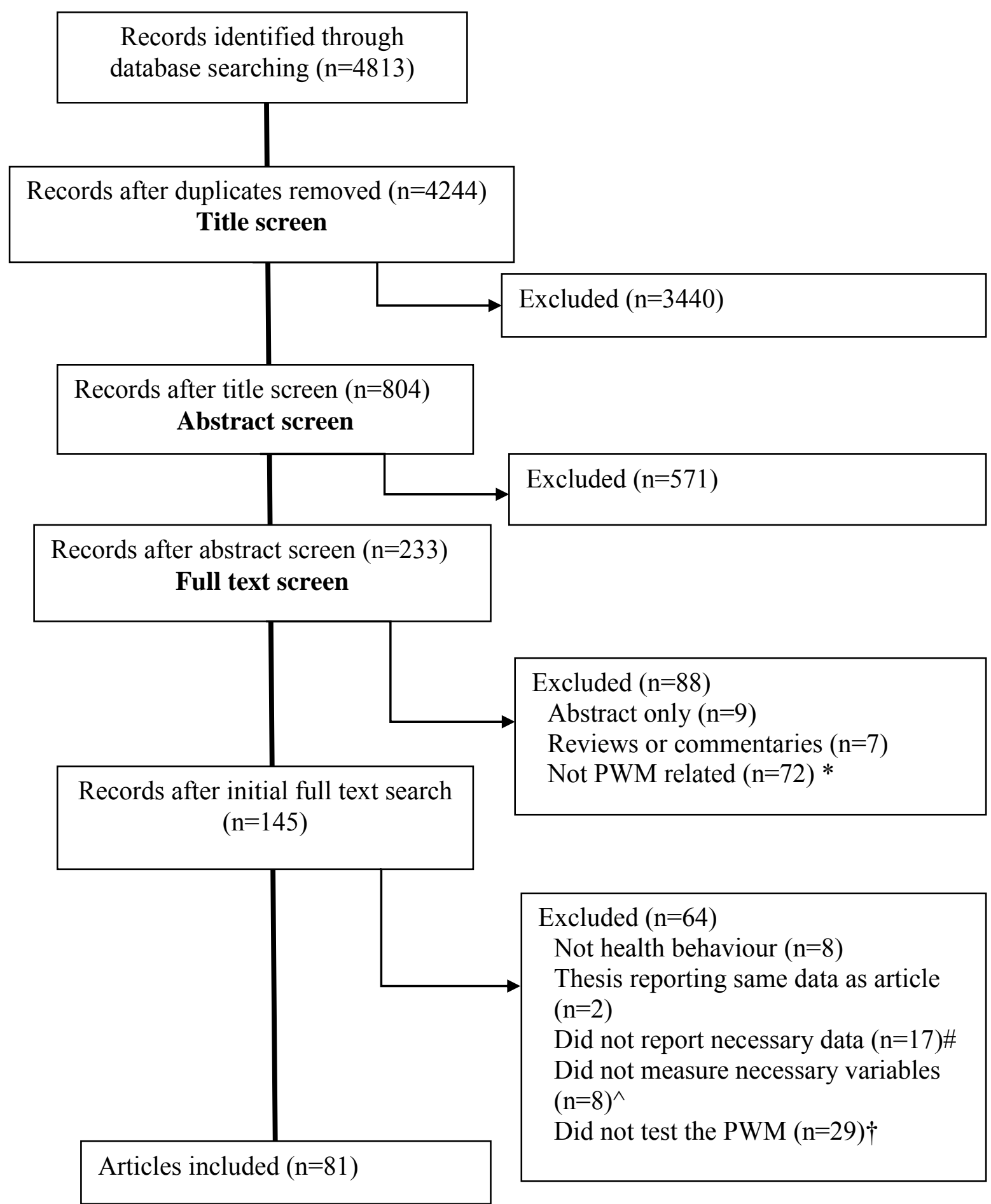


Notes.

*Not PWM related: Did not include 'prototype' 'willingness' 'Gibbons' or 'Gerrard' in the text, or included only as additional information in the introduction or discussion \#Did not report necessary data: Variables measured, but correlational relationships not reported (and unable to be obtained from authors), or were measured across an intervention without being measured cross-sectionally

${ }^{\wedge}$ Did not measure necessary variables: Key variables needed to calculate relationships of interest between prototypes or willingness not included $\uparrow$ Did not test the PWM: Made reference to the PWM but was not explicitly testing it and was therefore missing necessary variables and data (e.g., exploring willingness to engage in a behaviour but nothing elseno other constructs) 


\section{SUPPLEMENTARY FILE 4}

Individual Study Data

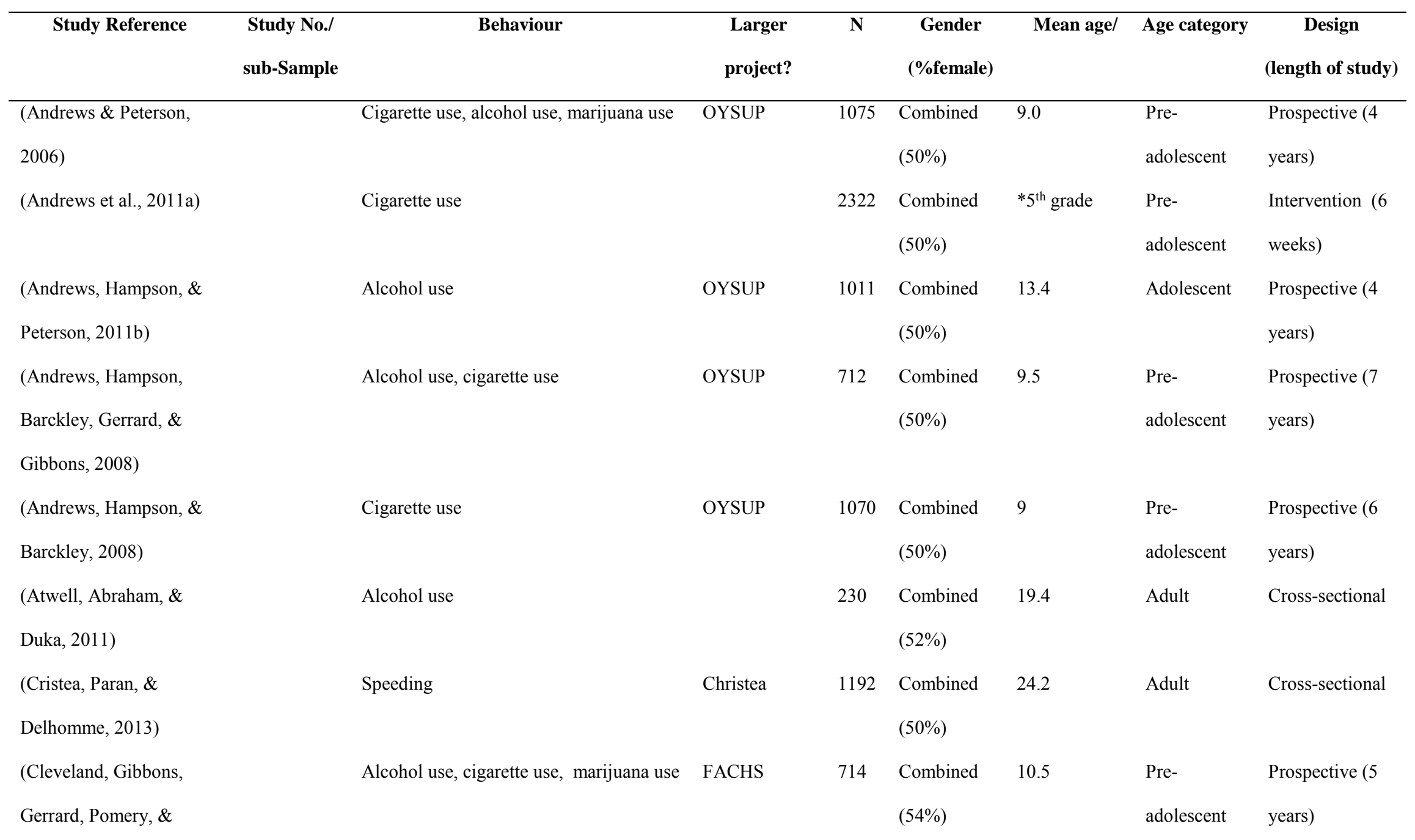


Brody, 2005)

(Dal Cin et al., 2009)

(Delhomme, Cristea, \&

Paran, In press)

(Dodge, Stock, \& Litt,

2013)

(Eggleston, 1997)

(Gebhardt, Van Empelen,

\& Van Beurden, 2009)

(Gerrard et al., 2006)

Study 2

Alcohol use

Alcohol use

Cigarette use

Lune, \& Cleveland,

2005)

(Gerrard, Gibbons, Vande

Lune, Pexa, \& Gano,

2002b)

Alcohol use

Speeding
Performance enhancing substances

Unsafe sex, condom use

Condom preparation

SAAF

IOWA

Alcohol use, cigarette use, illegal drugs

FACHS
(siblings)

34 Combined 13.5
12 Female

18.7

234

6522 Combined

12.1

$(49 \%)$

1192 Combined

22

(50\%)

132 Male

$230 \quad$ Female

19

Combined

308

Combined

742

Combined

10.5

(53\%) adolescents

$\begin{array}{ll}\text { Adolescent } & \begin{array}{l}\text { Prospective (2 } \\ \text { years) }\end{array} \\ \text { Adult } & \text { Prospective (2 } \\ & \text { years) } \\ \text { Adult } & \text { Cross-sectional }\end{array}$

Adult

Pre-

adolescent

Adolescents

years)

Prospective (20

months)

Adolescent

Prospective (20

months) 


\begin{tabular}{|c|c|c|c|c|c|c|c|c|}
\hline (Gerrard, Gibbons, Zhao, & & Alcohol use & & 266 & Combined & $* 15-17$ & Adolescent & Prospective ( 3 \\
\hline Russell, \& Reis-Bergan, & & & & & & & & years) \\
\hline 1999) & & & & & & & & \\
\hline (Gerrits, de Ridder, de & Study 3 & Unhealthy eating & & 97 & Combined & 15.9 & Adolescent & Prospective (5 \\
\hline Wit, \& Kuijer, 2009) & & & & & $(66 \%)$ & & & days) \\
\hline (Gibbons et al., 2010a) & & Substance use & FACHS & 897 & Combined & 10.5 & Pre- & Prospective (5 \\
\hline & & & & & $(54 \%)$ & & adolescent & years) \\
\hline (Gibbons, Gerrard, & Study 1 & Cigarette use & IOWA & 470 & Combined & $* 13-15$ & Adolescent & Prospective (2 \\
\hline Blanton, \& Russell, & & & & & $(51 \%)$ & & & years) \\
\hline 1998) & Study 2 & Unsafe sex & & 628 & Combined & 18.0 & Adult & Prospective (1 \\
\hline & & & & & $(56 \%)$ & & & year) \\
\hline & Study 3 & Unsafe sex & & 297 & Combined & 21.0 & Adult & Cross-sectional \\
\hline & & & & & $(59 \%)$ & & & \\
\hline (Gibbons, Gerrard, Lane, & Study 1 & Tanning bed use & & 70 & Combined & *University & Adult & Intervention (4 \\
\hline Mahler, \& Kulik, 2005) & & & & & $(49 \%)$ & students & & weeks) \\
\hline & Study 2 & Tanning bed use & & 134 & Combined & *University & Adult & Intervention (3 \\
\hline & & & & & $(54 \%)$ & students & & weeks) \\
\hline (Gibbons, Gerrard, & & Substance use & FACHS & 684 & Combined & 10.5 & Pre- & Prospective $(20$ \\
\hline Cleveland, Wills, \& & & & & & $(54 \%)$ & & adolescent & months) \\
\hline Brody, 2004a) & & & & & & & & \\
\hline (Gibbons et al., 2004b) & & Alcohol use, drug use, cigarette use & FACHS & 746 & Combined & 10.5 & Pre- & Prospective $(20$ \\
\hline & & & & & $(54 \%)$ & & adolescent & months) \\
\hline
\end{tabular}




\begin{tabular}{|c|c|c|c|c|c|c|c|c|}
\hline \multirow{3}{*}{$\begin{array}{l}\text { (Gibbons, Gerrard, \& } \\
\text { McCoy, 1995) }\end{array}$} & Study 1 & Unsafe sex & & 226 & Combined & *13-15 & Adolescent & Cross-sectional \\
\hline & & & & & $(68 \%)$ & & & \\
\hline & Study 2 & Unsafe sex & IOWA & 432 & $\begin{array}{l}\text { Combined } \\
(51 \%)\end{array}$ & $* 13-15$ & Adolescent & Cross-sectional \\
\hline $\begin{array}{l}\text { (Gibbons, Gerrard, } \\
\text { Ouellette, \& Burzette, }\end{array}$ & Study 1 & Cigarette use & IOWA & 470 & $\begin{array}{l}\text { Combined } \\
(51 \%)\end{array}$ & $* 13-15$ & Adolescent & $\begin{array}{l}\text { Prospective ( } 2 \\
\text { years })\end{array}$ \\
\hline 1998) & Study 2 & Drink driving & IOWA & 519 & $\begin{array}{l}\text { Combined } \\
(56 \%)\end{array}$ & $\begin{array}{l}* \text { College } \\
\text { students }\end{array}$ & Adult & $\begin{array}{l}\text { Prospective (2 } \\
\text { years) }\end{array}$ \\
\hline $\begin{array}{l}\text { (Gibbons, Helweg- } \\
\text { Larsen, \& Gerrard, 1995) }\end{array}$ & American & Condom use, unsafe sex & IOWA & 500 & $\begin{array}{l}\text { Combined } \\
(51 \%)\end{array}$ & 14.4 & Adolescent & Cross-sectional \\
\hline & Danish & Condom use, unsafe sex & & 224 & $\begin{array}{l}\text { Combined } \\
(48 \%)\end{array}$ & 14.2 & Adolescent & Cross-sectional \\
\hline (Gibbons et al., 2010b) & $\begin{array}{l}\text { African } \\
\text { American }\end{array}$ & Alcohol use & Dartmouth & 704 & $\begin{array}{l}\text { Combined } \\
(49 \%)\end{array}$ & 12.1 & Adolescent & $\begin{array}{l}\text { Prospective (28 } \\
\text { months) }\end{array}$ \\
\hline & $\begin{array}{l}\text { European } \\
\text { American }\end{array}$ & Alcohol use & Dartmouth & 4036 & $\begin{array}{l}\text { Combined } \\
(49 \%)\end{array}$ & 12.1 & Adolescent & $\begin{array}{l}\text { Prospective (28 } \\
\text { months) }\end{array}$ \\
\hline (Gibbons et al., 2012) & & Substance use, unsafe sex & FACHS & 889 & Combined & 10.5 & $\begin{array}{l}\text { Pre- } \\
\text { adolescent }\end{array}$ & $\begin{array}{l}\text { Prospective (11 } \\
\text { years) }\end{array}$ \\
\hline (Hampson, Andrews, \& & & Cigarette use & OYSUP & 809 & Combined & 9 & Pre- & Prospective (4 \\
\hline Barckley, 2007) & & & & & $(50 \%)$ & & adolescent & years) \\
\hline (Hampson, Andrews, \& & & Marijuana use & OYSUP & 420 & Combined & $* 4^{\text {th }}-5^{\text {th }}$ grade & Pre- & Prospective (7 \\
\hline Barckley, 2008) & & & & & $(47 \%)$ & & adolescent & years) \\
\hline
\end{tabular}




\begin{tabular}{|c|c|c|c|c|c|c|c|c|}
\hline (Houlihan et al., 2008) & & Unsafe sex & FACHS & 889 & $\begin{array}{l}\text { Combined } \\
(54 \%)\end{array}$ & 10.5 & $\begin{array}{l}\text { Pre- } \\
\text { adolescent }\end{array}$ & $\begin{array}{l}\text { Prospective (5 } \\
\text { years) }\end{array}$ \\
\hline $\begin{array}{l}\text { (Hukkelberg \& Dykstra, } \\
\text { 2009) }\end{array}$ & & Cigarette use & & 760 & $\begin{array}{l}\text { Combined } \\
(50 \%)\end{array}$ & 13.9 & Adolescent & $\begin{array}{l}\text { Prospective (1 } \\
\text { year) }\end{array}$ \\
\hline (Kalebić Maglica, 2011) & & Alcohol use, cigarette use & & 341 & $\begin{array}{l}\text { Combined } \\
(61 \%)\end{array}$ & 16.4 & Adolescent & Cross-sectional \\
\hline $\begin{array}{l}\text { (Keresztes, Piko, } \\
\text { Gibbons, \& Spielberger, }\end{array}$ & & Physical Activity & & 541 & $\begin{array}{l}\text { Combined } \\
(58 \%)\end{array}$ & 16.5 & Adolescent & Cross-sectional \\
\hline 2009) & & & & & & & & \\
\hline (Kogan et al., 2011) & & Unsafe sex, condom use & $\begin{array}{l}\text { FACHS } \\
\text { (siblings) }\end{array}$ & 195 & Combined & 13.0 & Adolescent & $\begin{array}{l}\text { Prospective (6 } \\
\text { years) }\end{array}$ \\
\hline $\begin{array}{l}\text { (Lane, Gibbons, O'Hara, } \\
\& \text { Gerrard, 2011) }\end{array}$ & Study 1 & Alcohol use & & 217 & $\begin{array}{l}\text { Combined } \\
(55 \%)\end{array}$ & 19.4 & Adult & $\begin{array}{l}\text { Intervention } \\
\text { (same day) }\end{array}$ \\
\hline & Study 2 & Alcohol use & & 55 & $\begin{array}{l}\text { Combined } \\
(60 \%)\end{array}$ & 19.5 & Adult & $\begin{array}{l}\text { Intervention } \\
\text { (same day) }\end{array}$ \\
\hline (Litt et al., 2013) & & Alcohol use & & 275 & $\begin{array}{l}\text { Combined } \\
(56 \%)\end{array}$ & 20.1 & Adult & $\begin{array}{l}\text { Prospective (10 } \\
\text { day) }\end{array}$ \\
\hline (Litt \& Stock, 2011) & & Alcohol use & & 189 & $\begin{array}{l}\text { Combined } \\
(51 \%)\end{array}$ & 14.5 & Adolescent & $\begin{array}{l}\text { Intervention } \\
\text { (same day) }\end{array}$ \\
\hline $\begin{array}{l}\text { (Litt, Stock, \& Lewis, } \\
\text { 2012) }\end{array}$ & & Alcohol use & & 346 & $\begin{array}{l}\text { Combined } \\
(57 \%)\end{array}$ & 19.4 & Adult & Cross-sectional \\
\hline (Matterne, Diepgen, \& & & Sun protection & & 150 & Combined & 44.1 & Adult & Intervention $(7+$ \\
\hline
\end{tabular}


Weisshaar, 2011)

(Murry et al., 2011)

(Myklestad \& Rise, 2007)

Male

Contraception use

Female

(Myklestad \& Rise, 2008)

(Norman, Armitage, \&

Quigley, 2007)

(O'Hara, 2012)

(Ohtomo, 2013)

(Ohtomo, Hirose, \&

Midden, 2011)

Japanese

(Ouellette, Gerrard,

Gibbons, \& Reis-Bergan,

1999)

(Peterson, 2013)
Unhealthy eating

Unsafe sex, condom use

Contraception use

Contraception use

Alcohol use

Alcohol use, flu vaccination

Unhealthy eating

Unhealthy eating

Alcohol use

Sex following alcohol use
$(39 \%)$

weeks)

\begin{tabular}{|c|c|c|c|c|c|}
\hline \multirow[t]{7}{*}{ SAAF } & 332 & $\begin{array}{l}\text { Combined } \\
(54 \%)\end{array}$ & 11.2 & $\begin{array}{l}\text { Pre- } \\
\text { adolescent }\end{array}$ & $\begin{array}{l}\text { Intervention (65 } \\
\text { months) }\end{array}$ \\
\hline & 88 & Male & $14.5 * *$ & Adolescent & Cross-sectional \\
\hline & 108 & Female & $14.5^{* *}$ & Adolescent & Cross-sectional \\
\hline & 154 & $\begin{array}{l}\text { Combined } \\
(55 \%)\end{array}$ & 14.5 & Adolescent & Cross-sectional \\
\hline & 94 & $\begin{array}{l}\text { Combined } \\
(86 \%)\end{array}$ & 20.1 & Adult & $\begin{array}{l}\text { Prospective (7 } \\
\text { days) }\end{array}$ \\
\hline & 986 & $\begin{array}{l}\text { Combined } \\
(68 \%)\end{array}$ & 19.3 & Adult & $\begin{array}{l}\text { Prospective (3 } \\
\text { months) }\end{array}$ \\
\hline & 286 & Female & 19.0 & Adult & $\begin{array}{l}\text { Prospective (2 } \\
\text { weeks) }\end{array}$ \\
\hline \multirow{4}{*}{ IOWA } & 277 & $\begin{array}{l}\text { Combined } \\
(20 \%)\end{array}$ & 21.8 & Adult & Cross-sectional \\
\hline & 321 & $\begin{array}{l}\text { Combined } \\
(67 \%)\end{array}$ & 19.1 & Adult & Cross-sectional \\
\hline & 357 & $\begin{array}{l}\text { Combined } \\
(51 \%)\end{array}$ & 15.0 & Adolescent & $\begin{array}{l}\text { Prospective (4 } \\
\text { years) }\end{array}$ \\
\hline & 193 & $\begin{array}{l}\text { Combined } \\
(65 \%)\end{array}$ & 19.3 & Adult & $\begin{array}{l}\text { Intervention } \\
\text { (same day) }\end{array}$ \\
\hline
\end{tabular}




\begin{tabular}{|c|c|c|c|c|c|c|c|c|}
\hline \multirow{2}{*}{ (Pomery, 2008) } & & \multicolumn{2}{|l|}{ Unsafe sex } & \multirow[t]{2}{*}{109} & Combined & *College & \multirow[t]{2}{*}{ Adult } & Intervention \\
\hline & & & & & $(29 \%)$ & students & & (same day) \\
\hline \multirow{2}{*}{\multicolumn{2}{|c|}{ (Pomery et al., 2005) }} & Alcohol use, cigarette use, marijuana use & FACHS & 225 & Combined & 10.5 & Pre- & Prospective $(20$ \\
\hline & & & & & $(55 \%)$ & & adolescent & months) \\
\hline \multirow{4}{*}{$\begin{array}{l}\text { (Pomery, Gibbons, Reis- } \\
\text { Bergan, \& Gerrard, 2009) }\end{array}$} & Study $2 \mathrm{a}$ & Alcohol use & IOWA & 344 & Combined & 14.4 & Adolescent & Prospective (5 \\
\hline & & & & & & & & years) \\
\hline & Study $2 b$ & Cigarette use & IOWA & 186 & Combined & 14.4 & Adolescent & Prospective (5 \\
\hline & & & & & & & & years) \\
\hline \multirow[t]{4}{*}{ (Reimer, 2009) } & Study 1 & Alcohol use, casual sex & & 139 & Combined & 20.1 & Adult & Intervention \\
\hline & & & & & $(51 \%)$ & & & (same day) \\
\hline & Study 2 & Alcohol use, casual sex & & 204 & Combined & 19.4 & Adult & Intervention \\
\hline & & & & & $(70 \%)$ & & & (same day) \\
\hline (Rivis, Abraham, \& & Young & Drink driving & & 100 & male & 23.3 & Adult & Cross-sectional \\
\hline Snook, 2011) & Older & Drink driving & & 100 & male & 46.3 & Adult & Cross-sectional \\
\hline \multirow[t]{2}{*}{ (Rivis \& Sheeran, 2003) } & & Physical activity & & 333 & Combined & *University & Adult & Prospective (2 \\
\hline & & & & & & students & & weeks) \\
\hline \multicolumn{2}{|l|}{ (Rivis, Sheeran, \& } & Cigarette use & & 272 & Combined & 16.4 & Adolescent & Prospective (2 \\
\hline \multicolumn{2}{|l|}{ Armitage, 2010) } & & & & $(57 \%)$ & & & weeks) \\
\hline \multicolumn{2}{|l|}{ (Rivis, Sheeran, \& } & 14 health related behaviours & & 136 & Combined & 16.4 & Adolescent & Prospective (2 \\
\hline \multicolumn{2}{|l|}{ Armitage, 2011) } & & & & $(65 \%)$ & & & weeks) \\
\hline \multicolumn{2}{|l|}{ (Scott-Parker, Hyde, } & Speeding & & 1190 & Combined & 17.9 & Adult & Prospective (6 \\
\hline \multicolumn{2}{|l|}{ Watson, \& King, 2013) } & & & & $(61 \%)$ & & & months) \\
\hline
\end{tabular}




\begin{tabular}{|c|c|c|c|c|c|c|c|c|}
\hline \multicolumn{2}{|l|}{$\begin{array}{l}\text { (Spijkerman, van den } \\
\text { Eijnden, \& Engels, 2005) }\end{array}$} & \multicolumn{2}{|l|}{ Cigarette use } & & $\begin{array}{l}\text { Combined } \\
(54 \%)\end{array}$ & 12.8 & Adolescent & $\begin{array}{l}\text { Prospective }(1 \\
\text { year) }\end{array}$ \\
\hline $\begin{array}{l}\text { (Spijkerman, Larsen, } \\
\text { Gibbons, \& Engels, }\end{array}$ & & Alcohol use & & 200 & $\begin{array}{l}\text { Combined } \\
(51 \%)\end{array}$ & 21.5 & Adult & Cross-sectional \\
\hline 2010) & & & & & & & & \\
\hline (Stock et al., 2013a) & & Substance use & FACHS & 720 & $\begin{array}{l}\text { Combined } \\
(53 \%)\end{array}$ & 15.6 & Adolescent & $\begin{array}{l}\text { Prospective ( } 4 \\
\text { years } 8 \text { months) }\end{array}$ \\
\hline $\begin{array}{l}\text { (Stock, Gibbons, } \\
\text { Peterson, \& Gerrard, }\end{array}$ & Study 1 & $\begin{array}{l}\text { Alcohol use, marijuana, other drugs, } \\
\text { unsafe sex }\end{array}$ & FACHS & 833 & $\begin{array}{l}\text { Combined } \\
(54 \%)\end{array}$ & 18.8 & Adult & $\begin{array}{l}\text { Prospective }(8 \\
\text { years) }\end{array}$ \\
\hline 2013b) & Study 2 & Substance use, unsafe sex & & 110 & $\begin{array}{l}\text { Combined } \\
(52 \%)\end{array}$ & 22.1 & Adult & $\begin{array}{l}\text { Intervention } \\
\text { (same day) }\end{array}$ \\
\hline $\begin{array}{l}\text { (Stock, Litt, Arlt, } \\
\text { Peterson, \& Sommerville, } \\
\text { 2013c) }\end{array}$ & & Nonmedical stimulant & & 555 & $\begin{array}{l}\text { Combined } \\
(56 \%)\end{array}$ & 19.4 & Adult & Cross-sectional \\
\hline (Stock, 2007) & & Condom use & & 222 & $\begin{array}{l}\text { Combined } \\
(60 \%)\end{array}$ & 20.5 & Adult & $\begin{array}{l}\text { Intervention } \\
\text { (same day) }\end{array}$ \\
\hline $\begin{array}{l}\text { (Stock, Gibbons, Walsh, } \\
\text { \& Gerrard, 2011) }\end{array}$ & Study 1 & Substance use & FACHS & 64 & $\begin{array}{l}\text { Combined } \\
(66 \%)\end{array}$ & 18.0 & Adult & Cross-sectional \\
\hline (Teunissen et al., 2014) & & Alcohol use & & 599 & Male & 17.0 & Adolescent & $\begin{array}{l}\text { Intervention } \\
\text { (same day) }\end{array}$ \\
\hline (Teunissen et al., 2012) & & Alcohol use & & 192 & $\begin{array}{l}\text { Combined } \\
(57 \%)\end{array}$ & 20.7 & Adult & $\begin{array}{l}\text { Intervention } \\
\text { (same day) }\end{array}$ \\
\hline
\end{tabular}




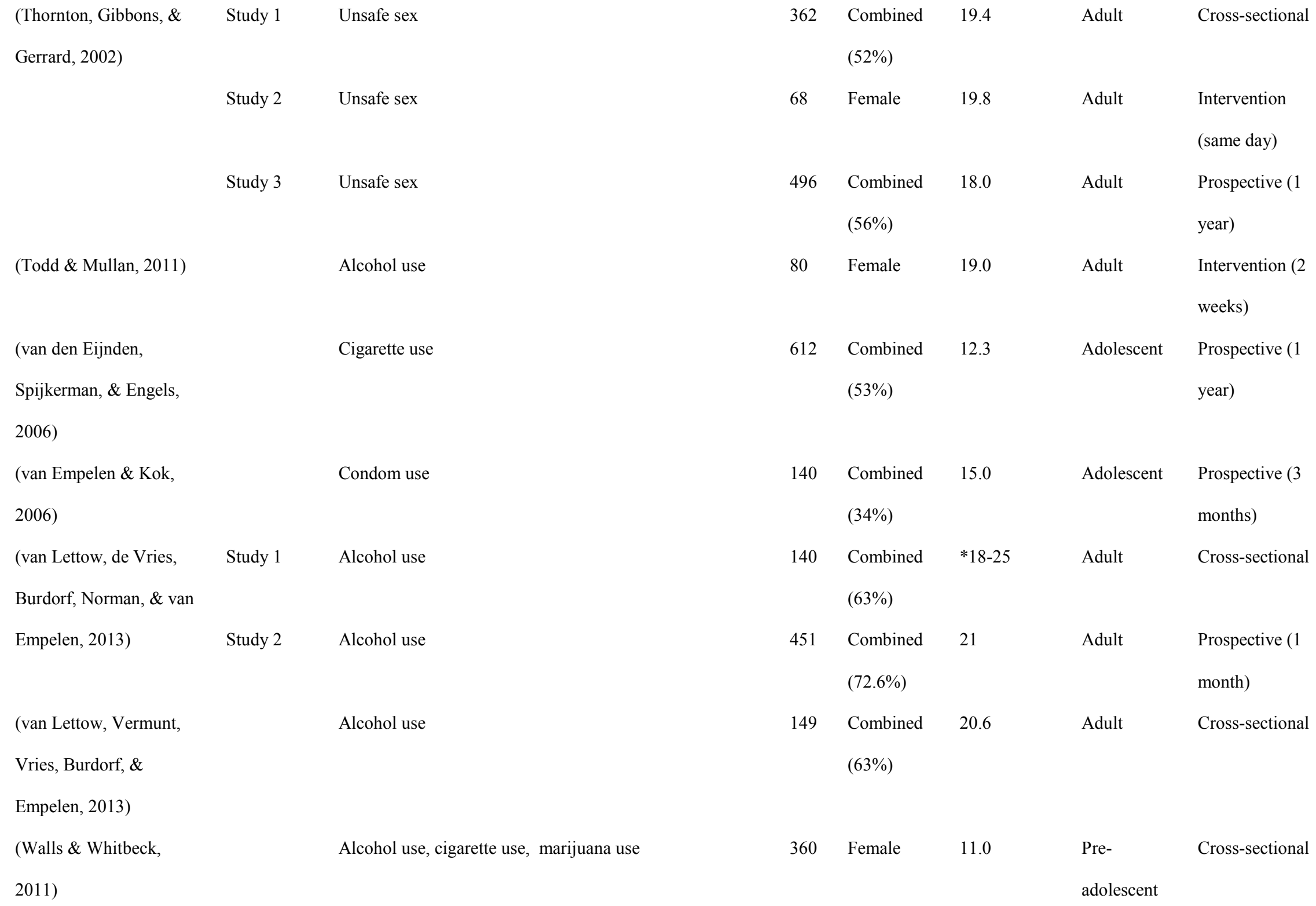


(Walsh \& Stock, 2012)

(Wills, Gibbons, Gerrard,

Murry, \& Brody, 2003

(Whitaker, Long,

Petróczi, \& Backhouse,

2013)

(Zimmermann \&

(Zimmermann \&

Sieverding, 2010)

(Zimmermann \&

Sieverding, 2011b)
Sun protection

Unsafe sex, substance use

Performance enhancing substances

\section{Alcohol use}

Male Alcohol use

Female

Alcohol use

Alcohol use
Male

SAAF

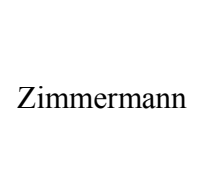

$147 \quad$ Female

Zimmermann

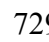

\section{Combined}

Sieverding, 2011a)

Zimmermann

Note: Information descriptive info relevant to the

** Where age was given for entire sample but data was divided, the stated age was used across both samples. 


\section{SUPPLEMENTARY FILES 5 AND 6}

\section{Key for Funnel and Forest Plots}

\section{Constructs:}

$\mathrm{IB}=$ intention - behaviour relationship

$\mathrm{PB}=$ prototype - behaviour relationship

$\mathrm{PFB}=$ prototype favourability - behaviour relationship

$\mathrm{PSB}=$ prototype similarity - behaviour relationship

$\mathrm{PI}=$ prototype-intention relationship

$\mathrm{PFI}=$ prototype favourability-intention relationship

$\mathrm{PSI}=$ prototype similarity-intention relationship

$\mathrm{PW}=$ prototype-willingness relationship

$\mathrm{PFW}=$ prototype favourability-willingness relationship

$\mathrm{PSW}=$ prototype similarity-willingness relationship

$\mathrm{WB}=$ willingness - behaviour relationship

$\mathrm{WI}=$ willingness - intention relationship

\section{Studies included:}

All $=$ for all included studies

No-overlap $=$ overlapping studies excluded 
IB - All

IB - No Overlap

PB - All

PB - No Overlap

PFB - All

PFB - No Overlap

PFI - All

PFI - No overlap

PFW - All

PWF - No Overlap

$\mathrm{PI}$ - All

$\mathrm{PI}$ - No overlap

PSB - All

PSB - No overlap

PSI - All

PSI - No overlap

PSW - All

PSW - No overlap

PW - All

PW - No overlap

WB - All

WB - No Overall

WI-All

WI - No overlap 


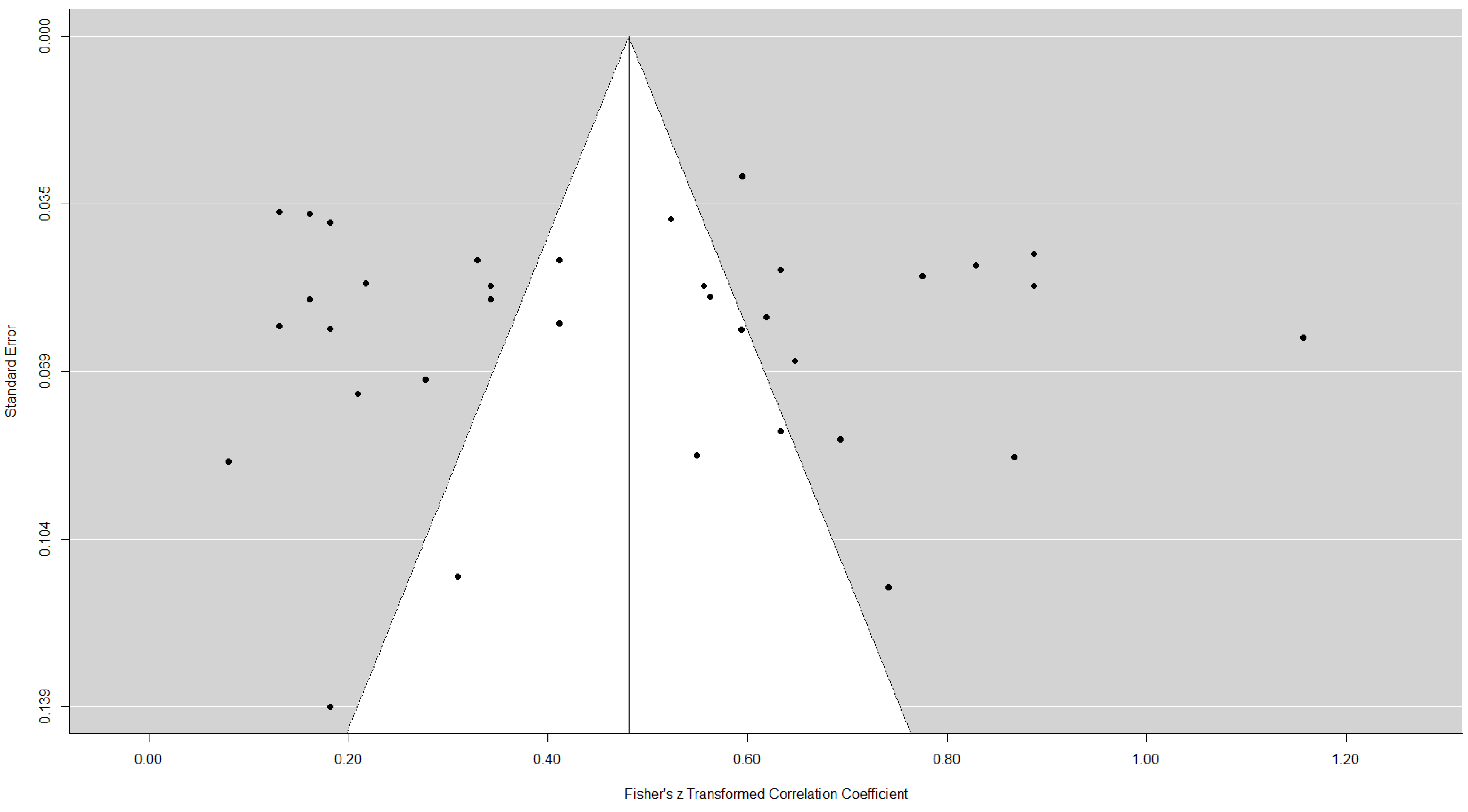




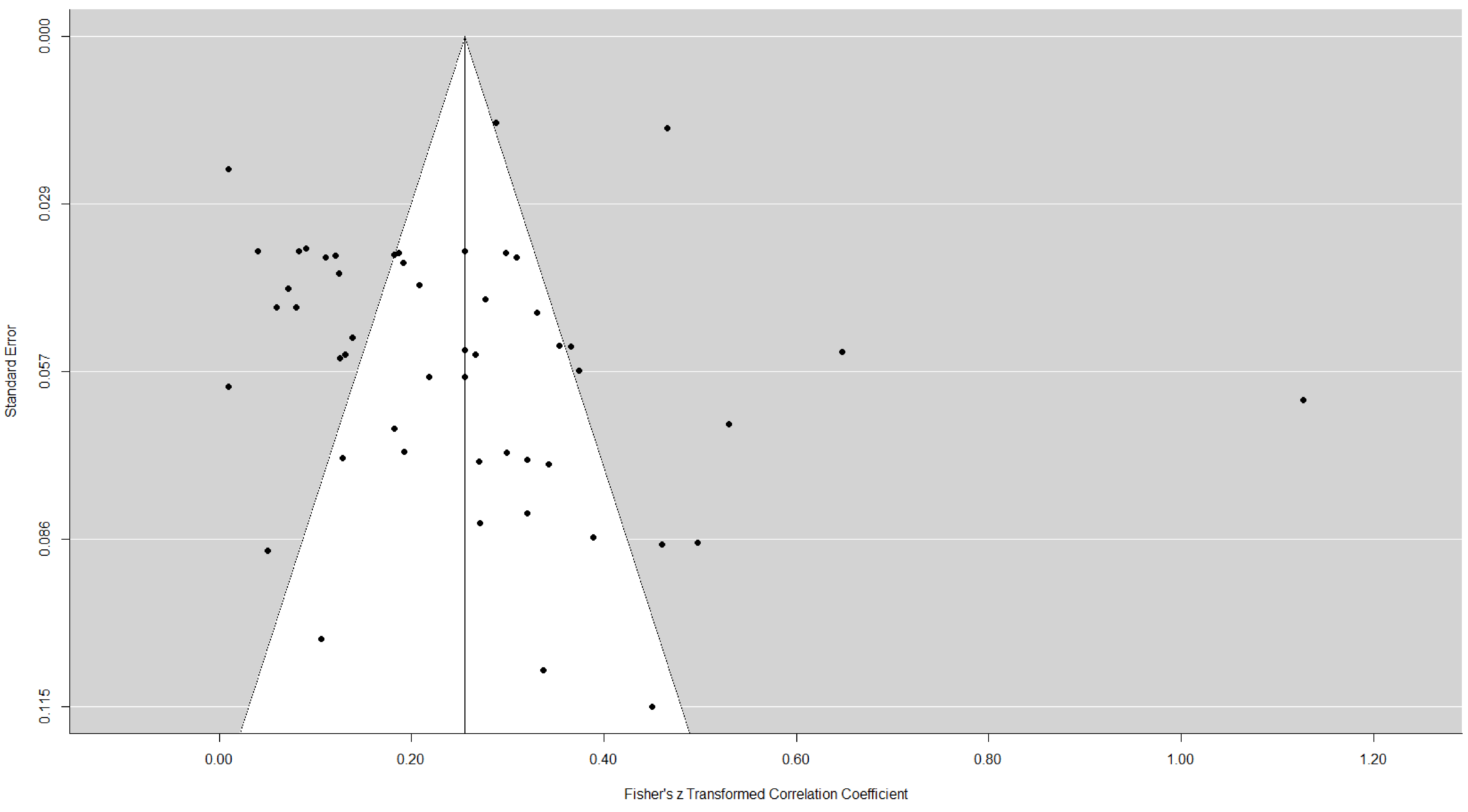




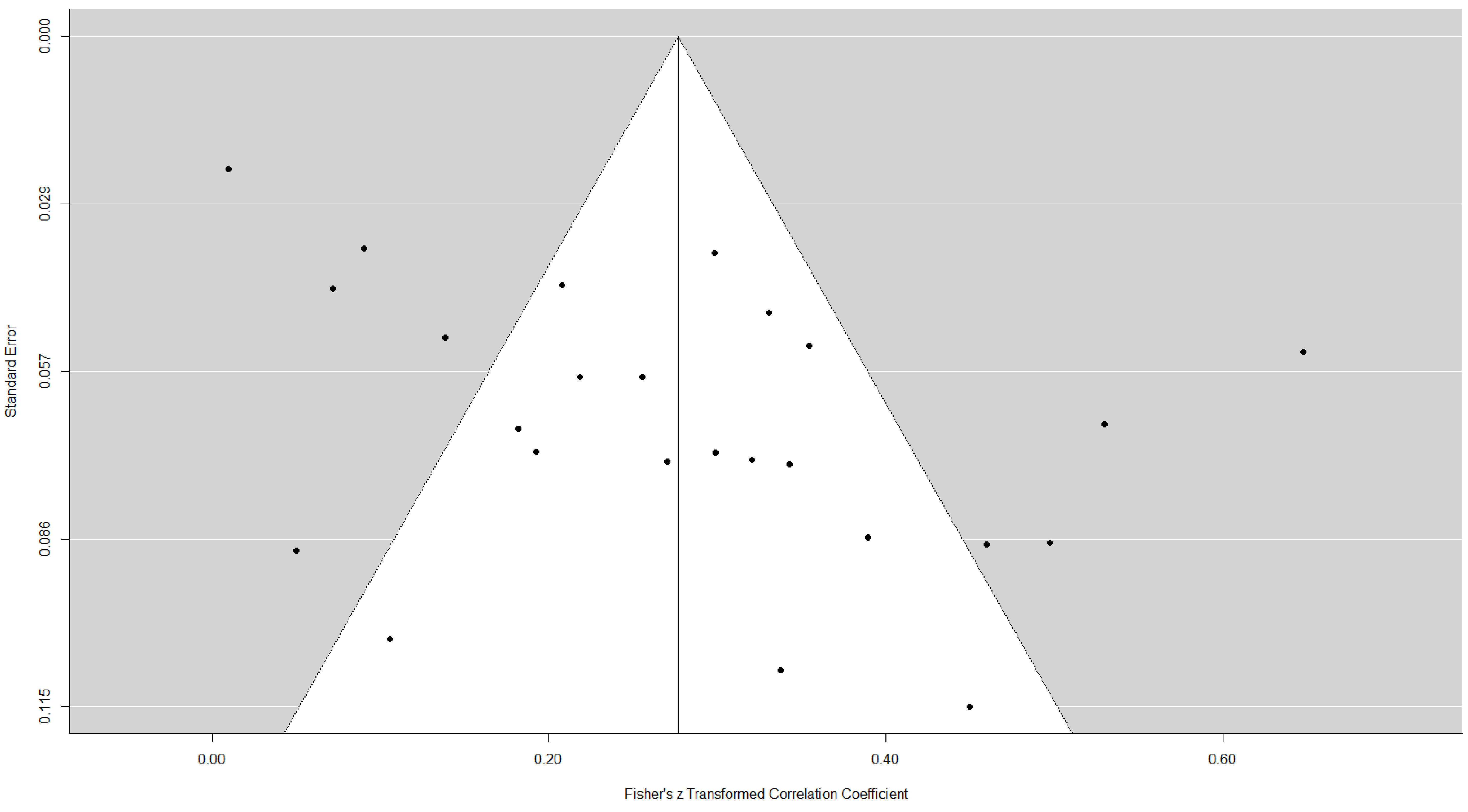




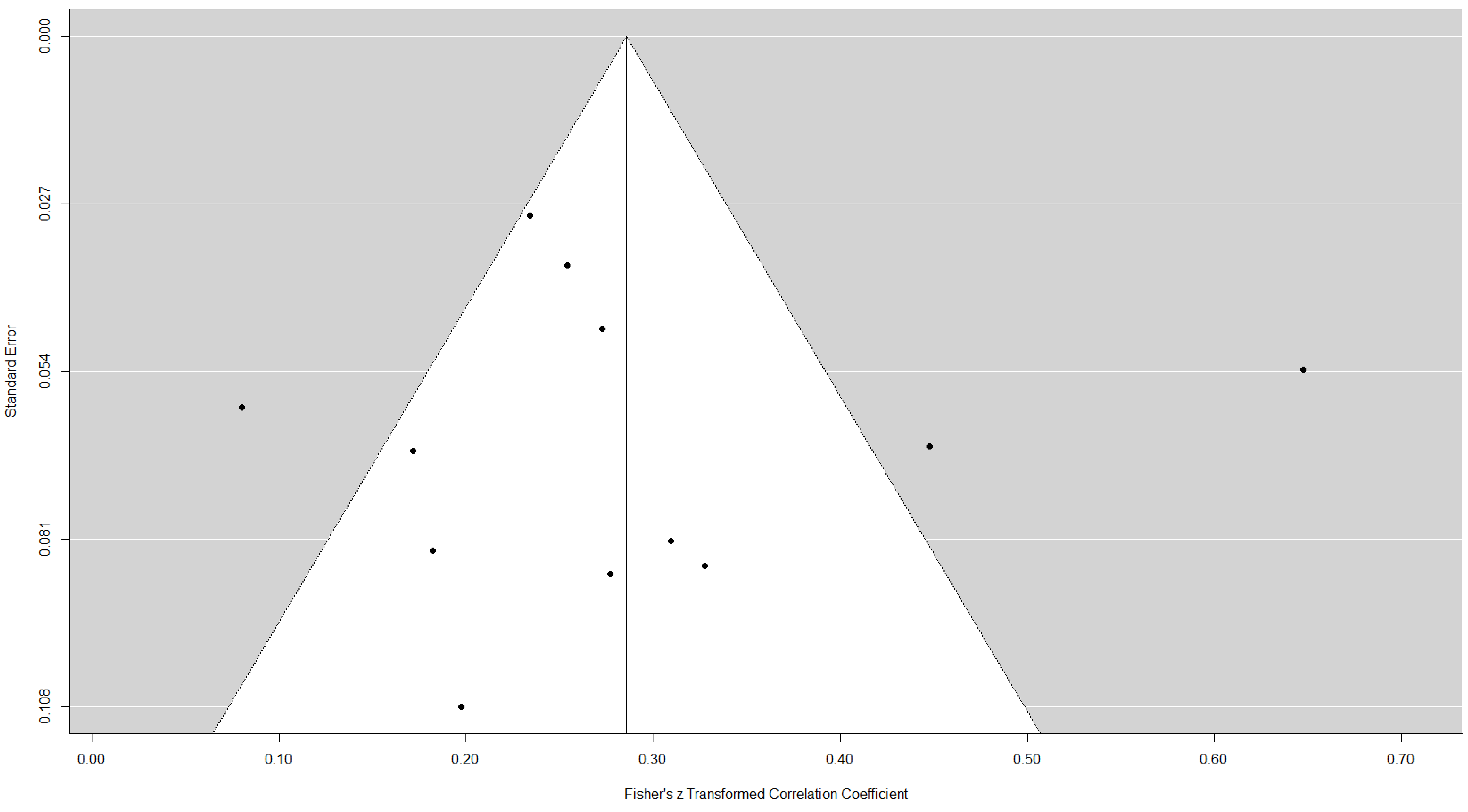




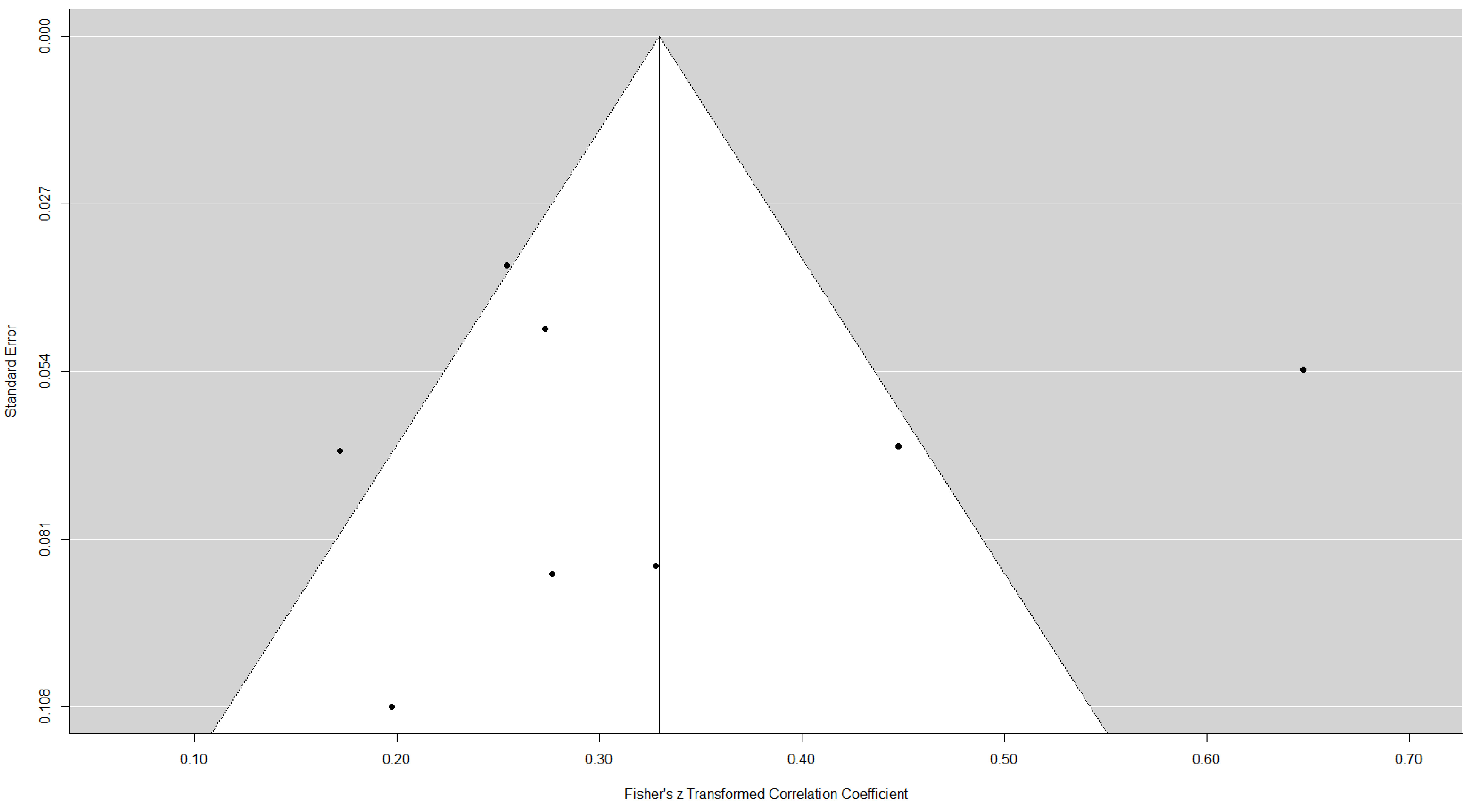




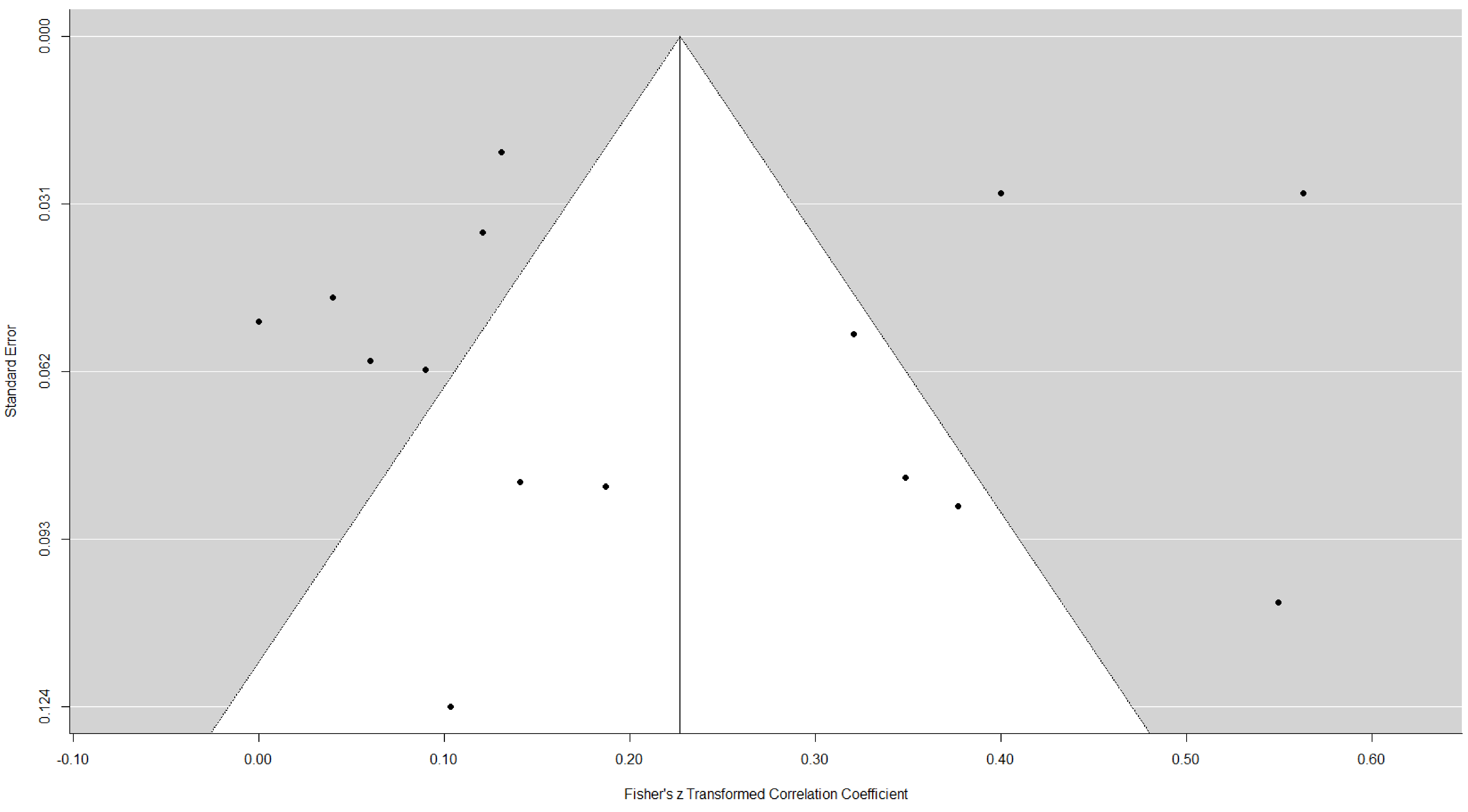




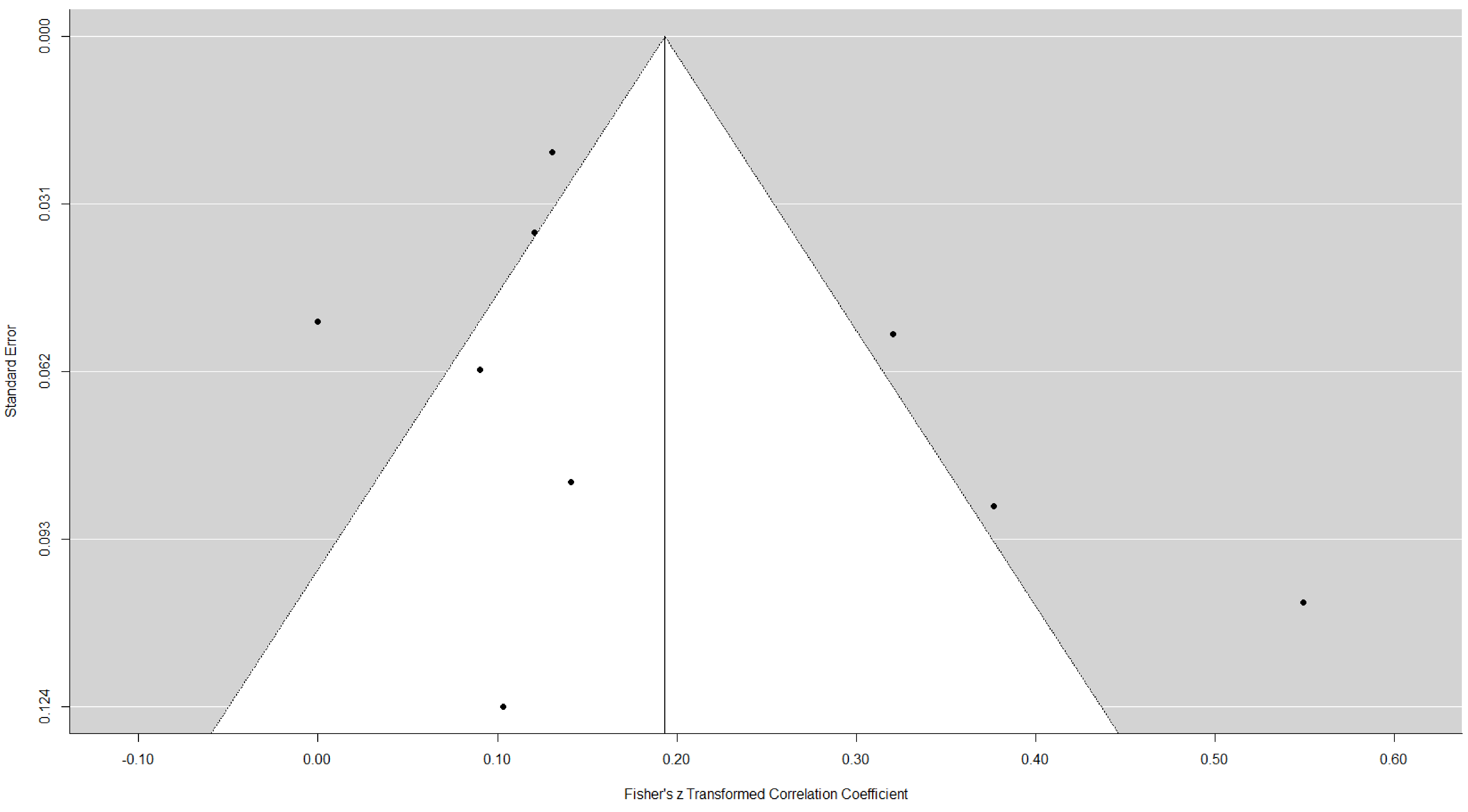




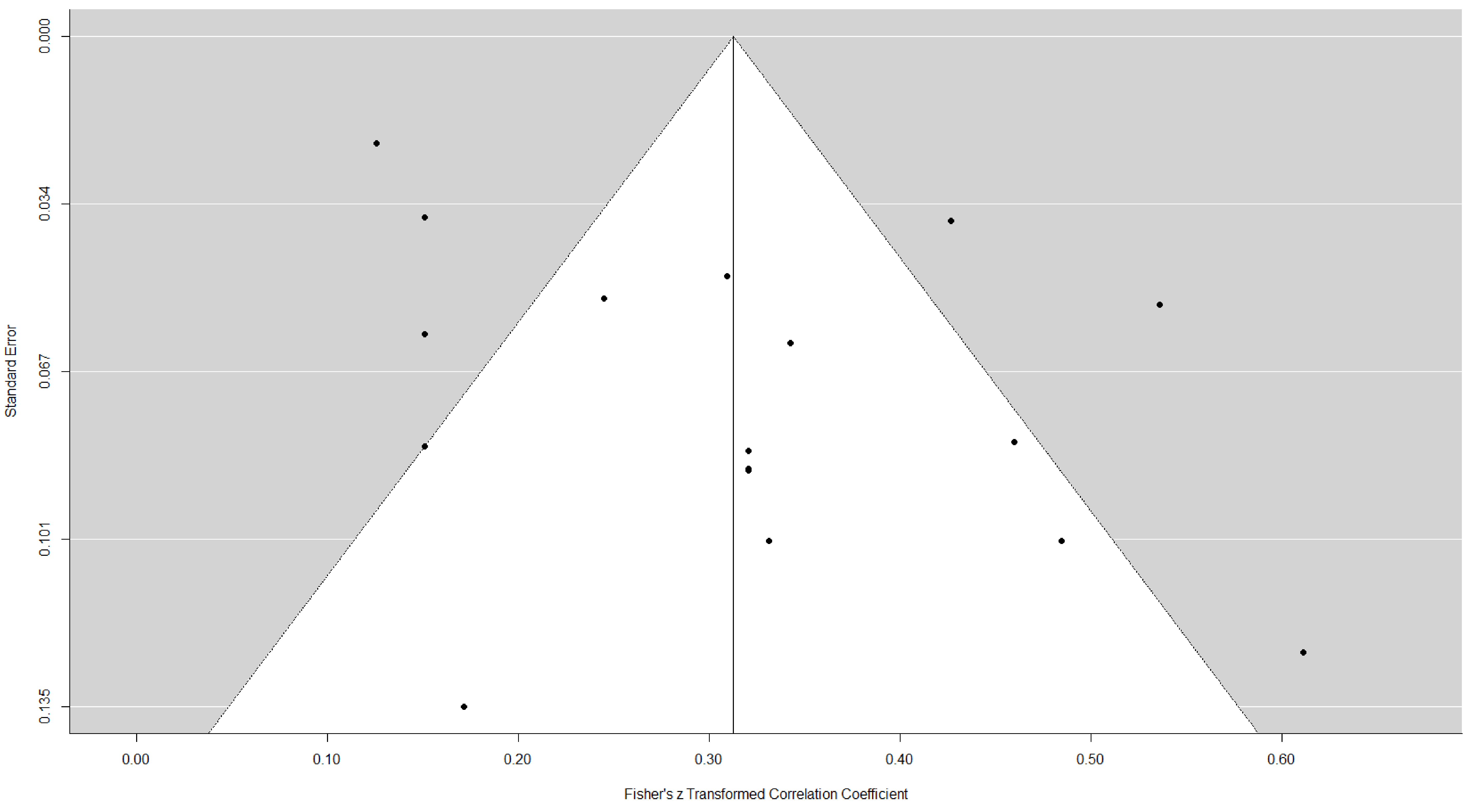




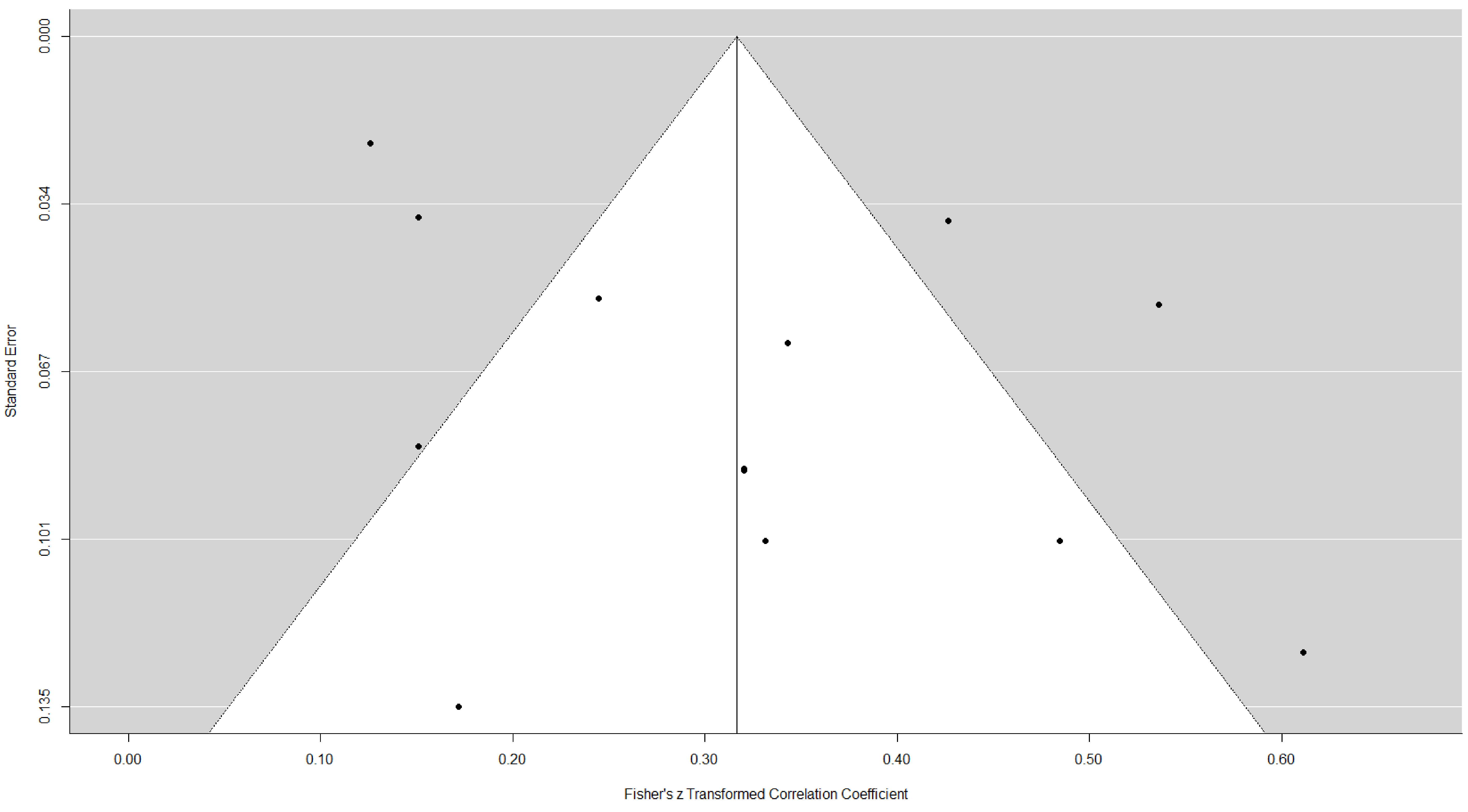




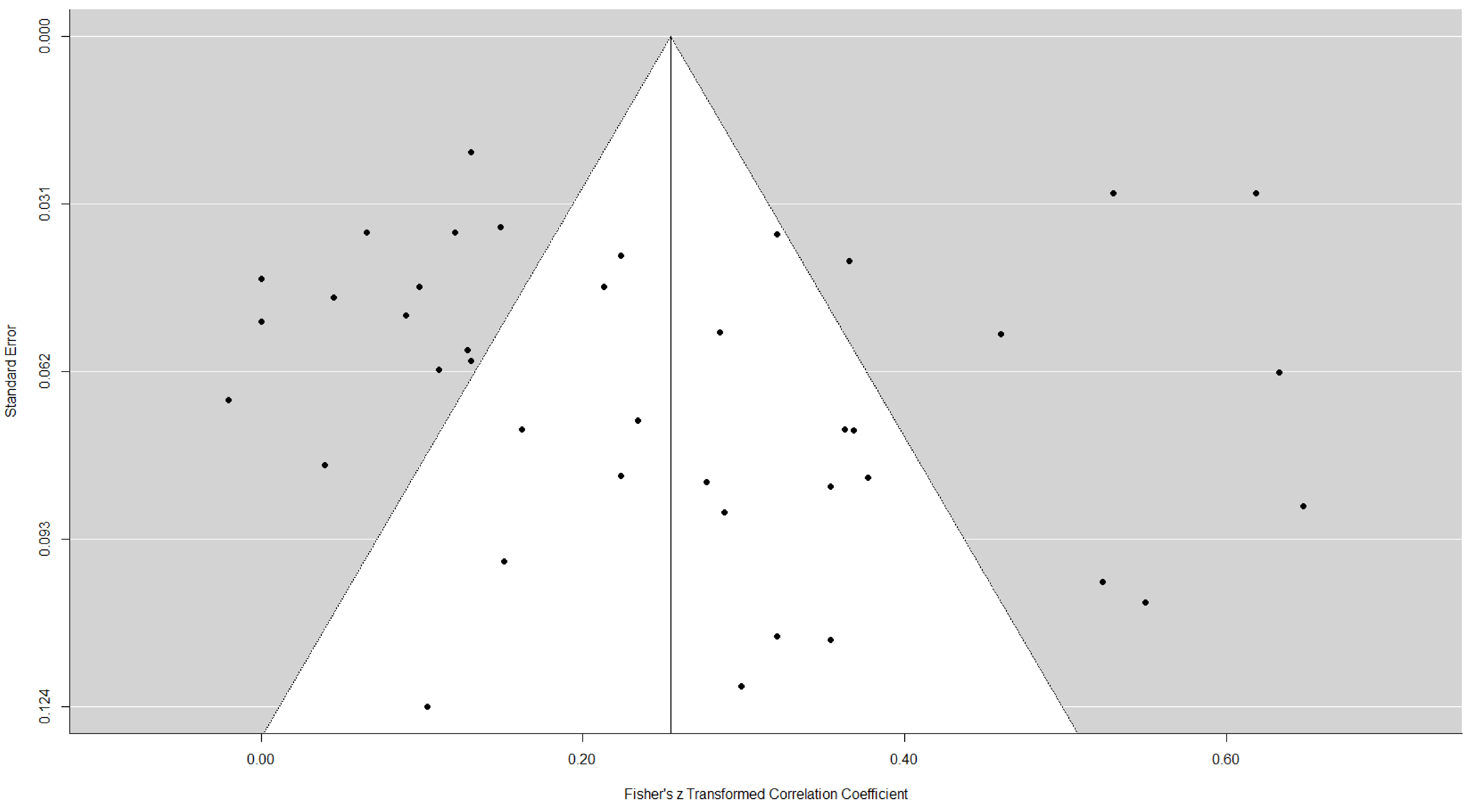




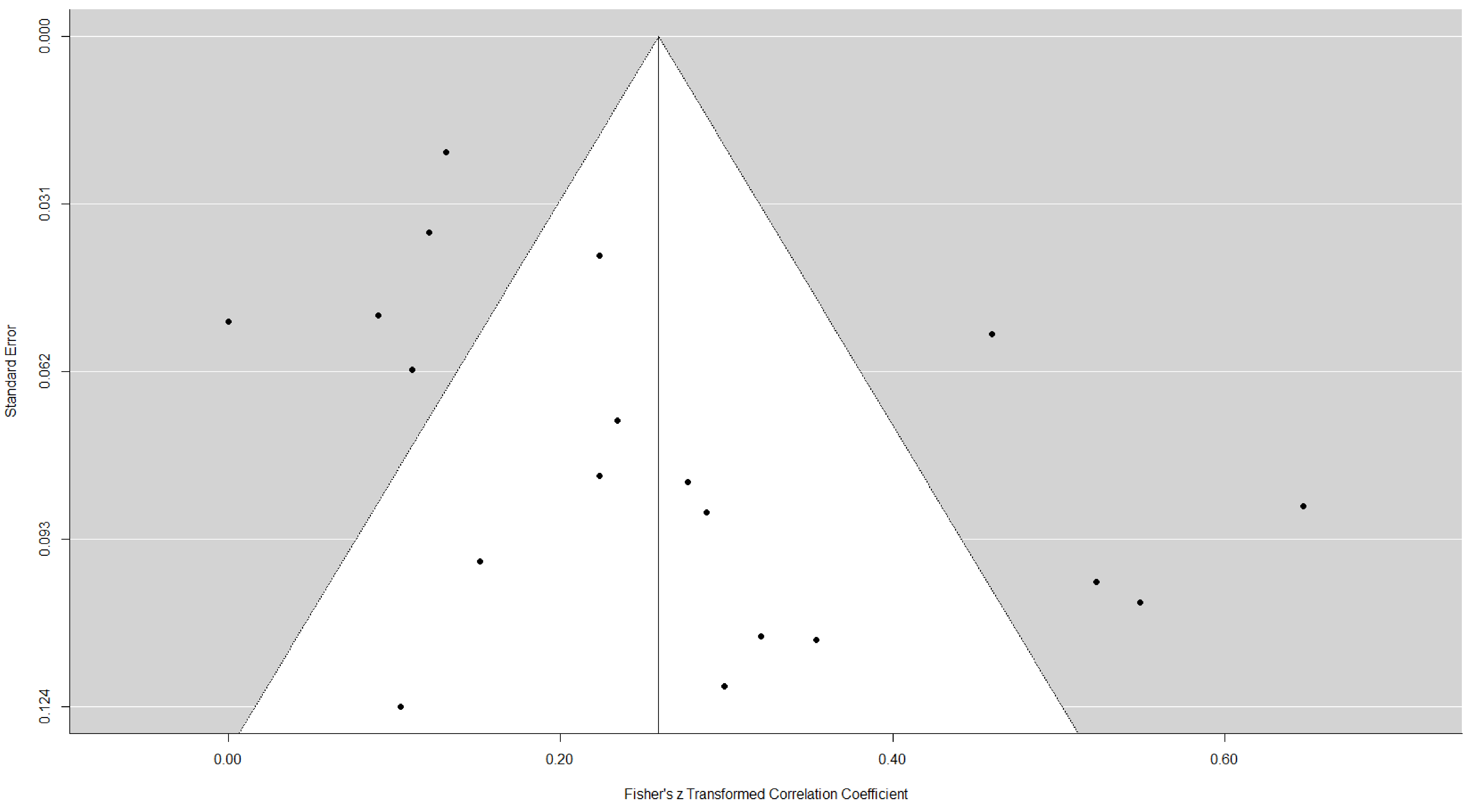




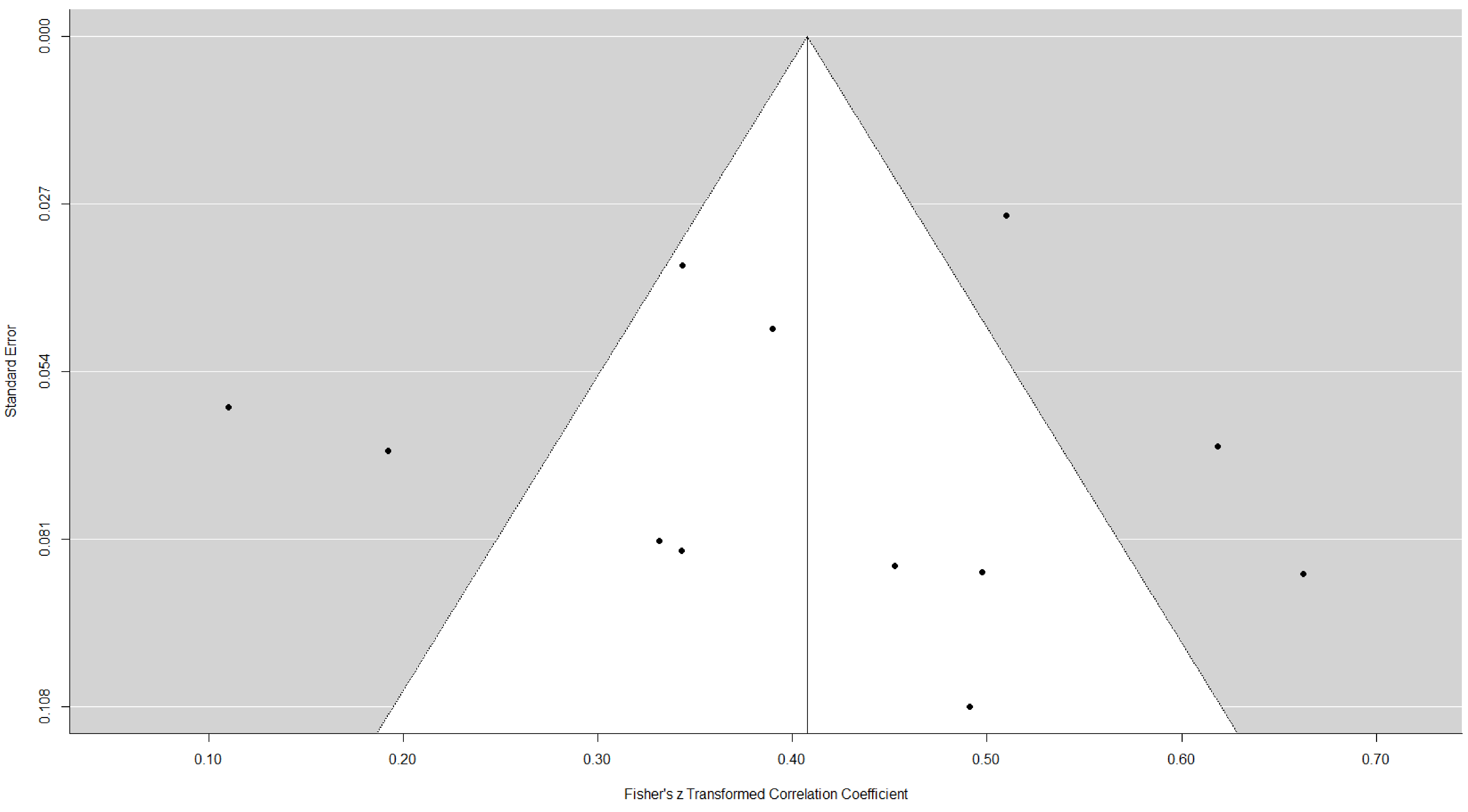




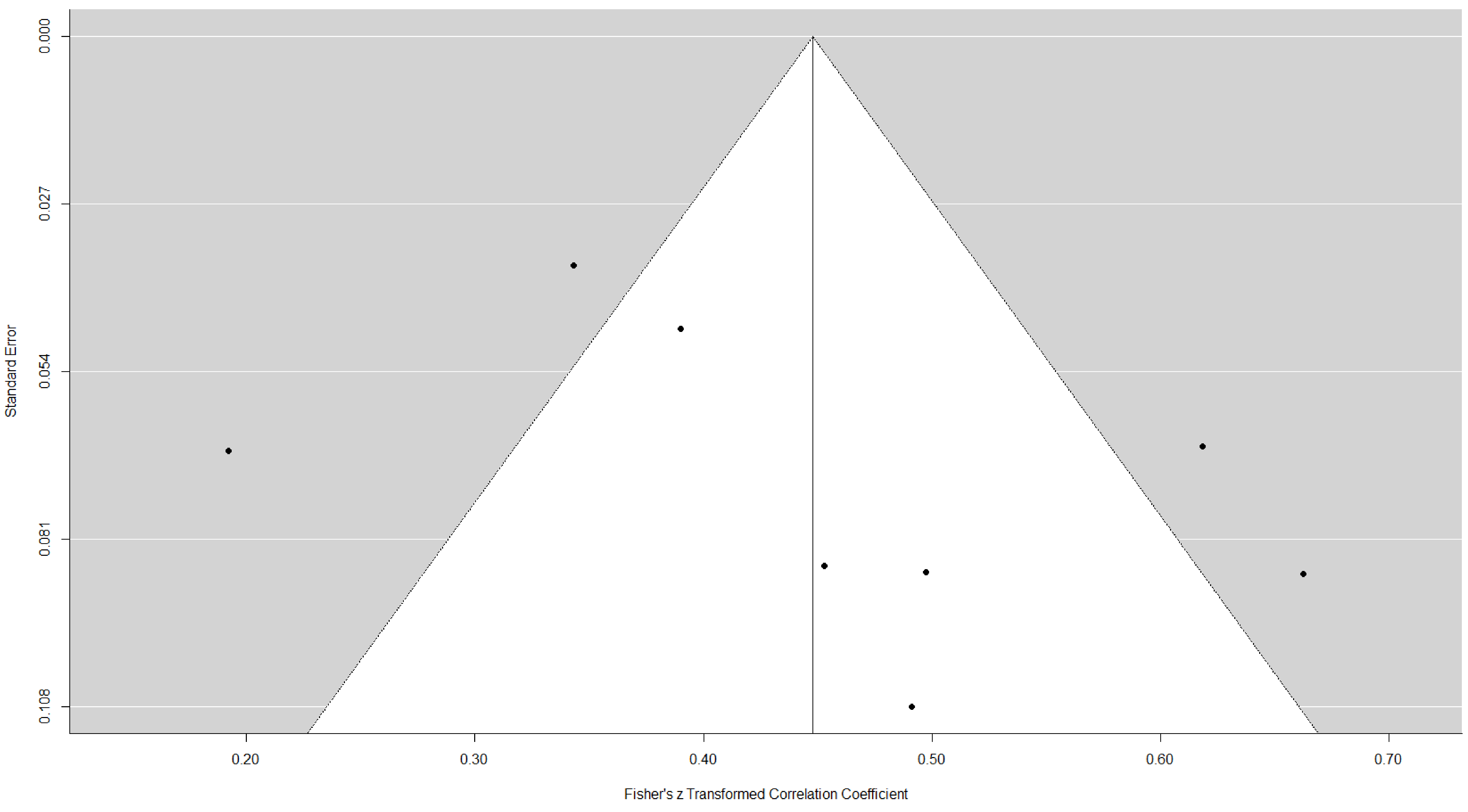




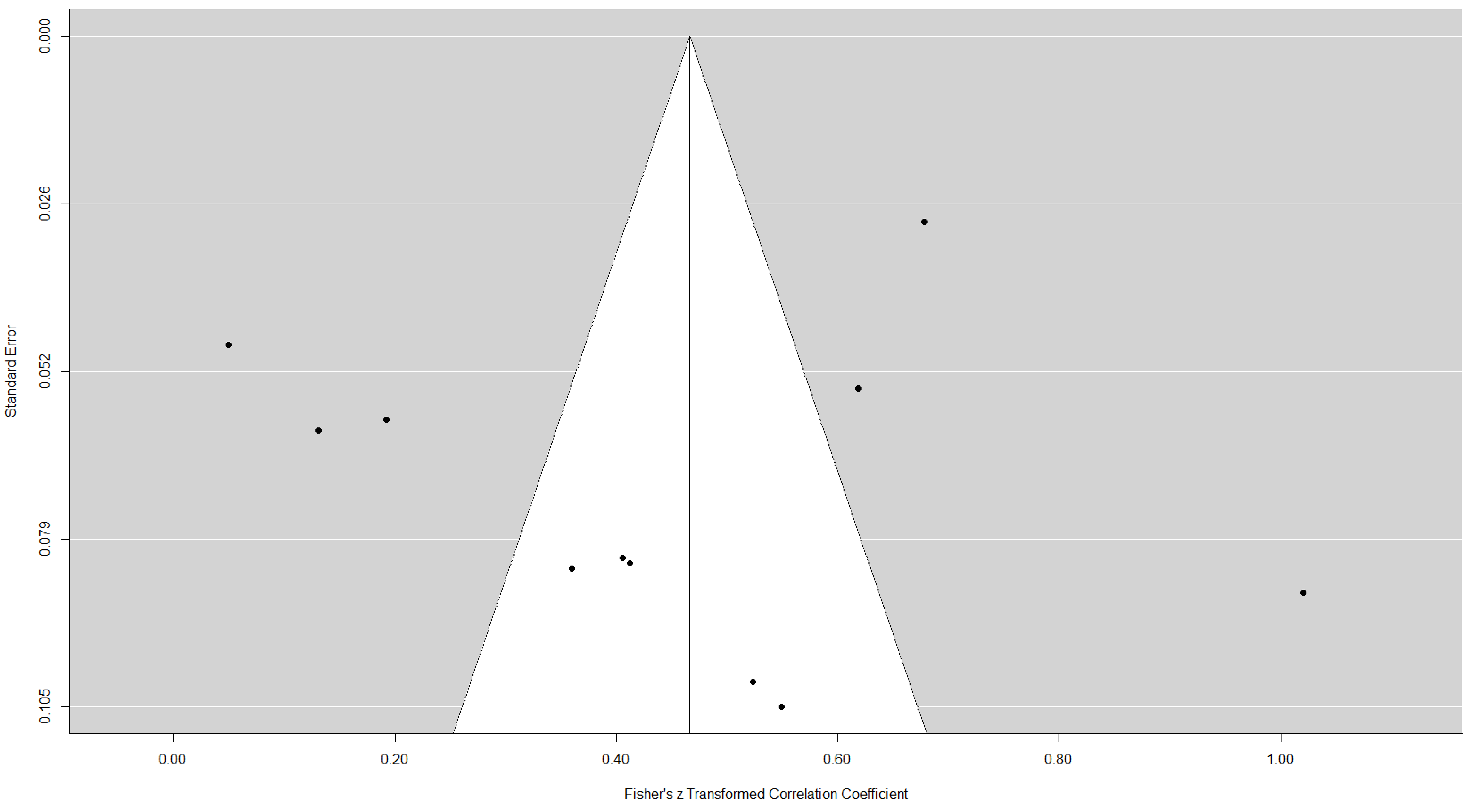




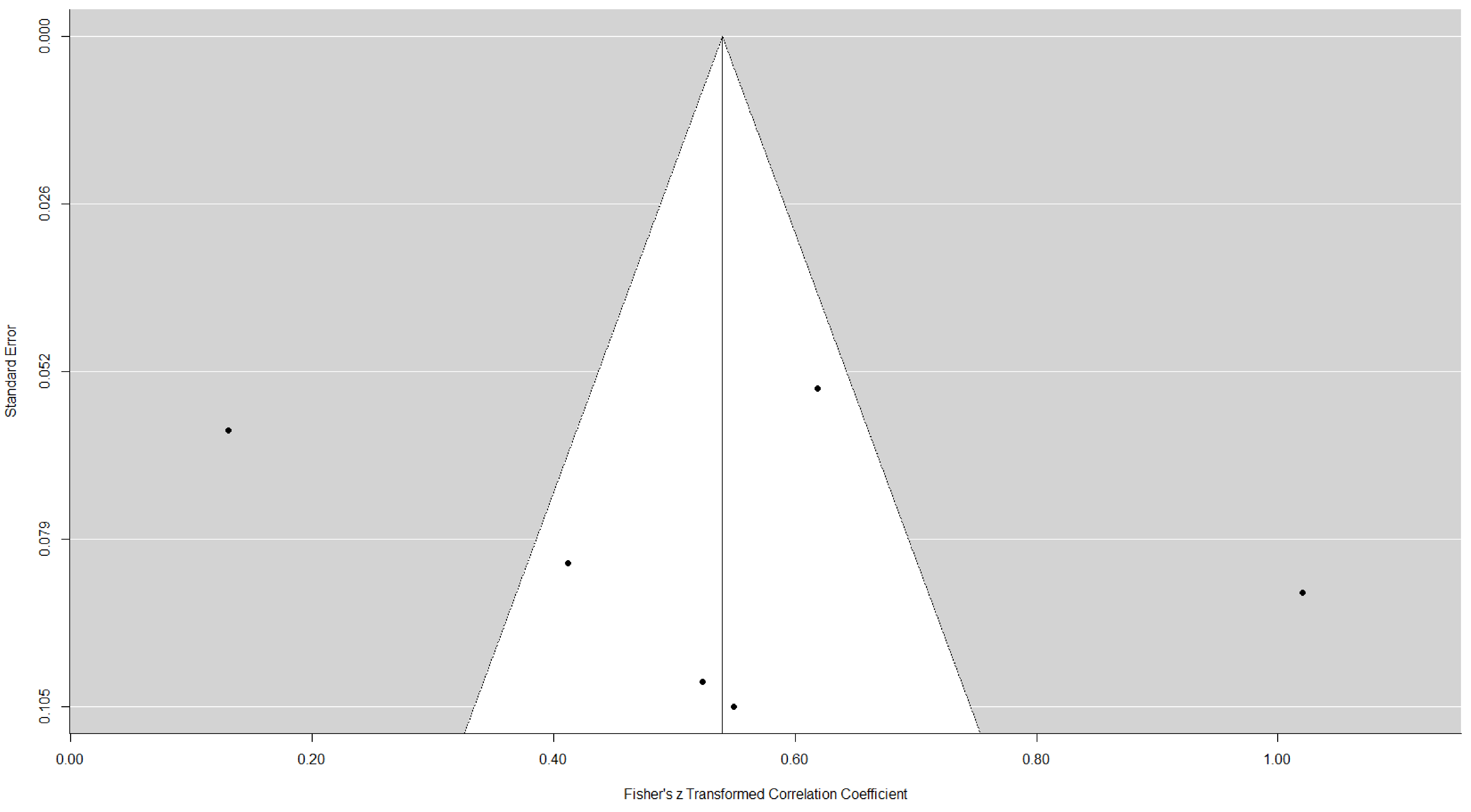




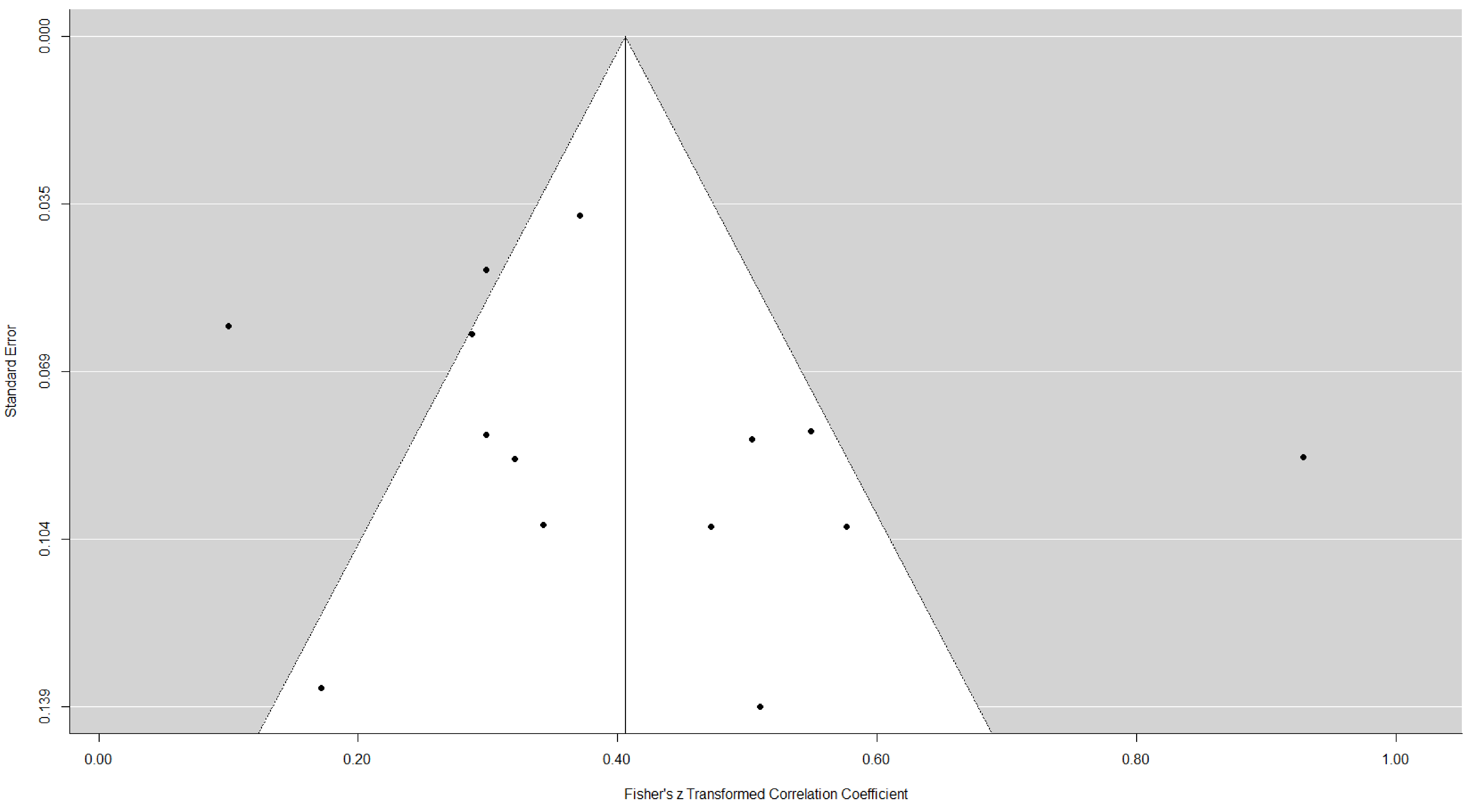




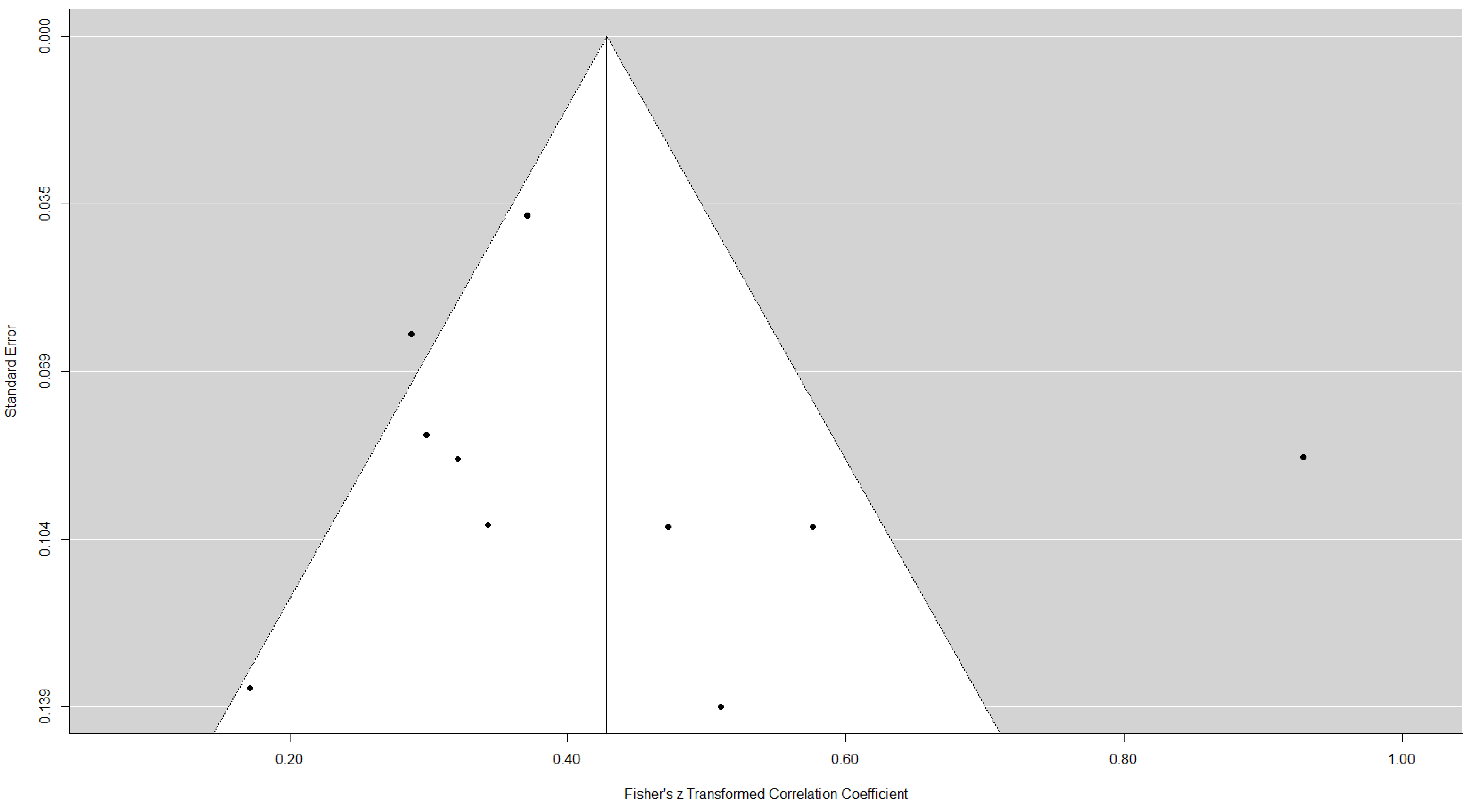




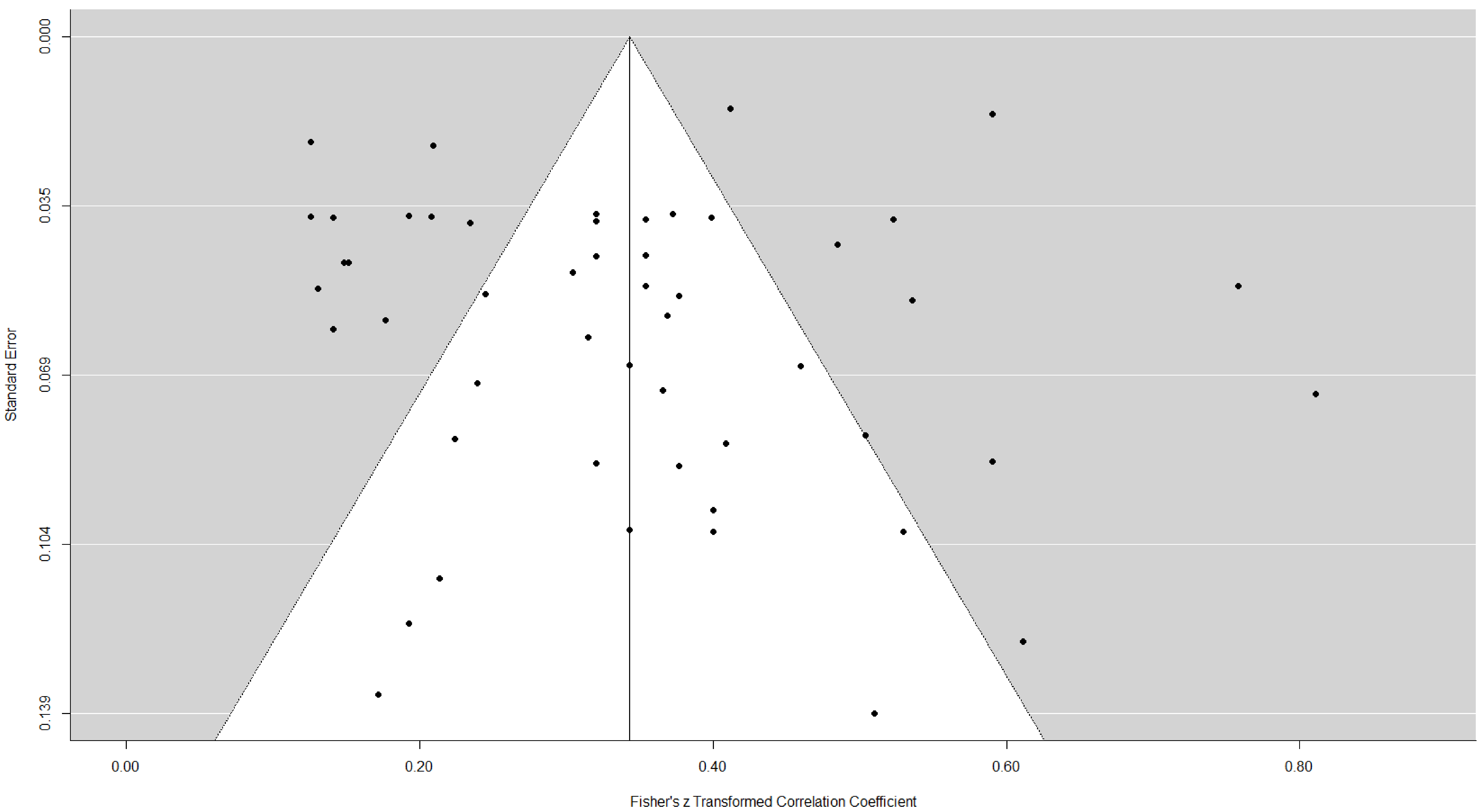




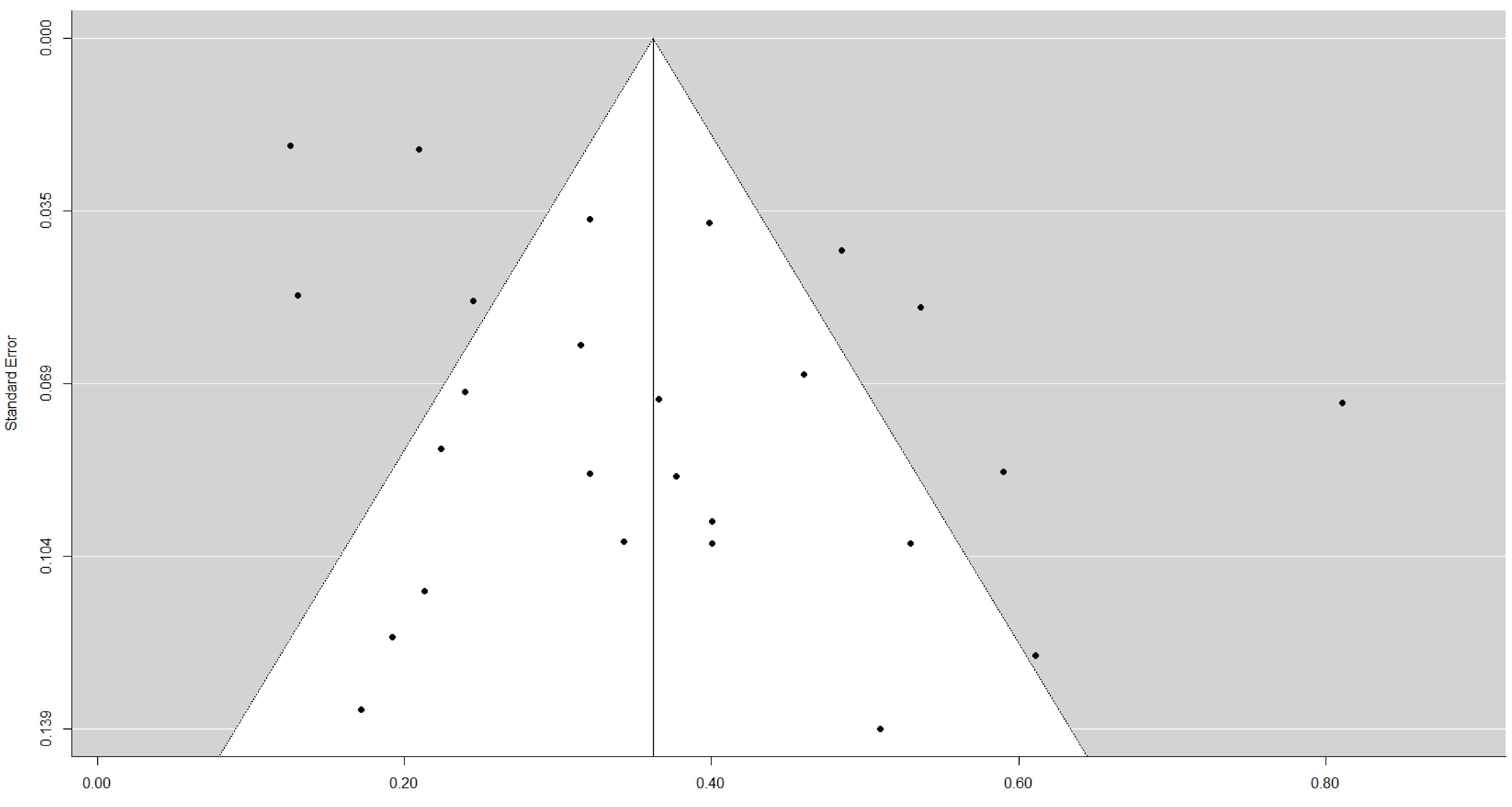




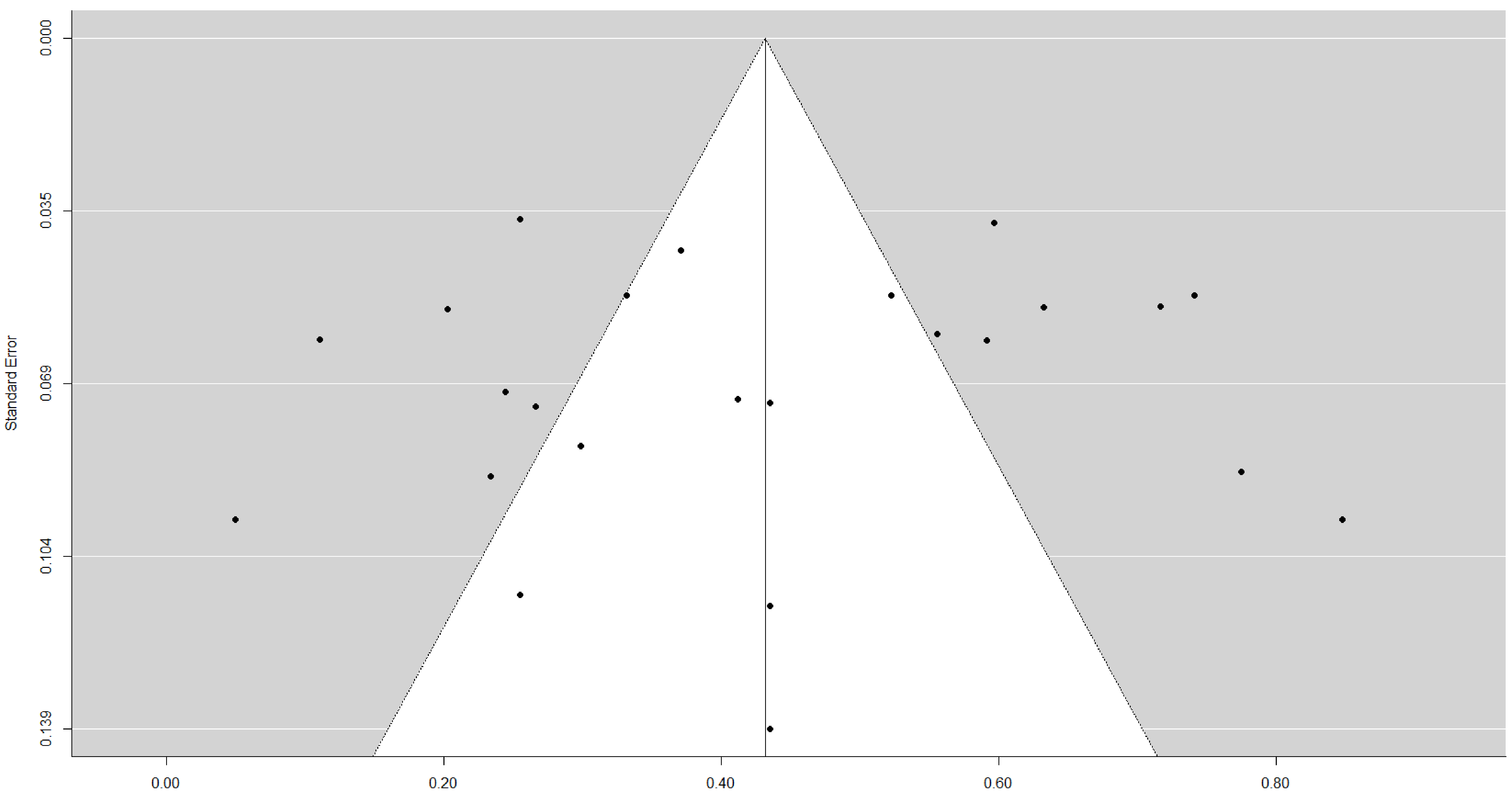




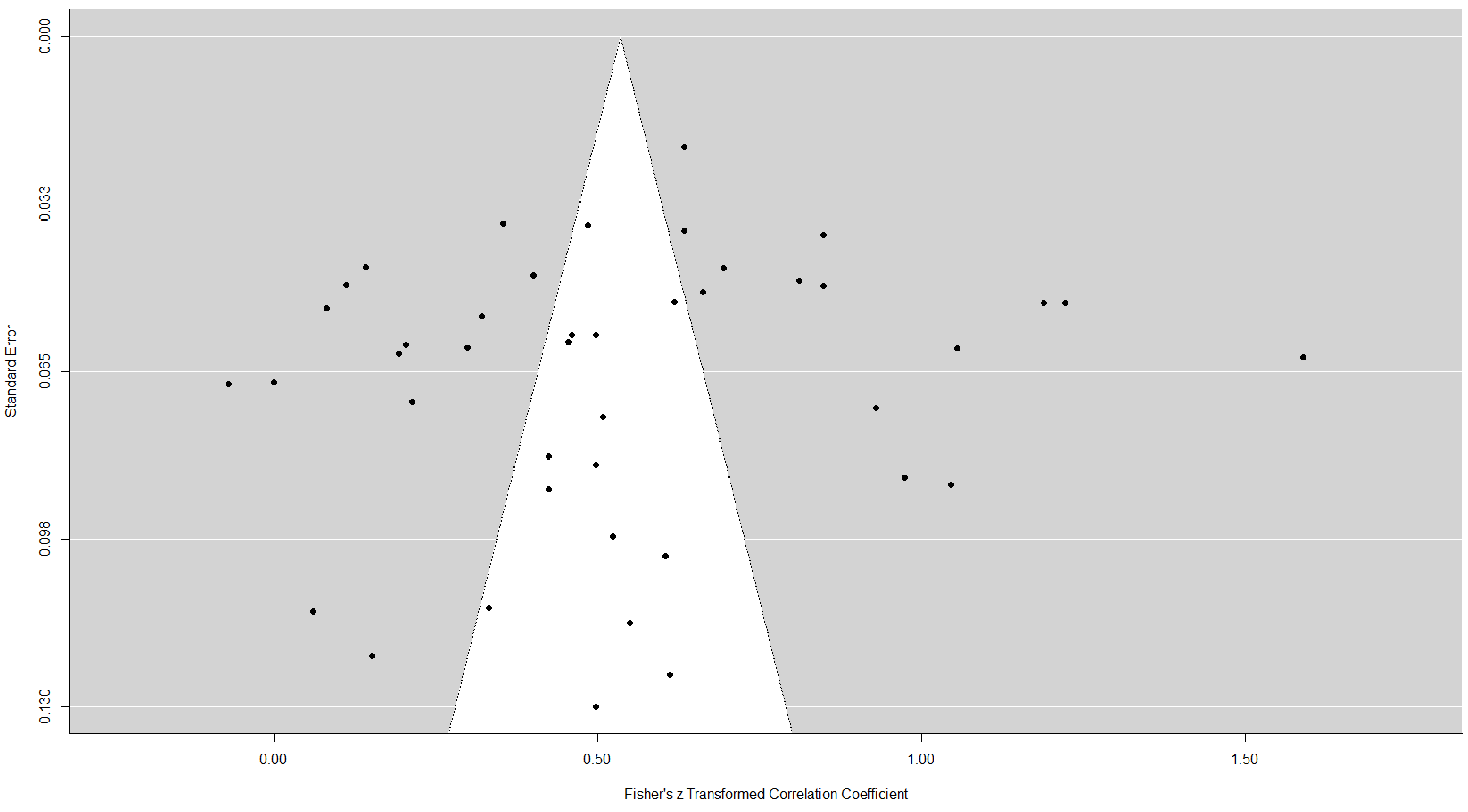


IB - All

IB - No Overlap

PB - All

PB - No Overlap

PFB - All

PFB - No Overlap

PFI - All

PFI - No overlap

PFW - All

PWF - No Overlap

$\mathrm{PI}-\mathrm{All}$

$\mathrm{PI}$ - No overlap

PSB - All

PSB - No overlap

PSI - All

PSI - No overlap

PSW - All

PSW - No overlap

PW - All

PW - No overlap

WB - All

WB - No Overall

WI-All

WI - No overlap 
Dodge, Stock, \& Litt, 2013

ggleston, 1997

ebhardt, Van Empelen, \& Van Beurden, 2009

Hukkelberg \& Dykstra, 2009

Litt et al., 2013

O'Hara, 2012

O'Hara, 2012 (vaccination)

Ohtomo, 2013

Ohtomo, Hirose, \& Midden, 2011 (Dutch)

Ohtomo, Hirose, \& Midden, 2011 (Japanese)

Pomery et al., 2009 (All participants)

Pomery et al., 2009 (Non-smokers)

Rivis \& Sheeran, 2003

Rivis, Sheeran, \& Armitage, 2010

Rivis, Sheeran, \& Armitage, 2011b

Scott-Parker, Hyde, Watson, \& King, 2013

Todd \& Mullan, 2011

an Empelen \& Kok, 2006

Gerrard, Gibbons, Zhao, Russell, \& Reis-Bergan, 1999

Thornton et al., 2002 (Study 3 )

Cristea, Paran, \& Delhomme, 2013

Gibbons et al., 2004b

Gibbons et al., 2010a

Gibbons et al., 1998a (Study 1)

Gibbons et al., 1998a (Study 2)

Gibbons et al., 1998a (Study 3 )

Gibbons et al., 1998b (Study 1)

Gibbons et al., 1998b (Study 2)

Andrews et al., 2008b

Andrews, Hampson, \& Peterson, 2011b

Gerrard et al., 2006

Zimmermann \& Sieverding, 2010 (Male)

Zimmermann \& Sieverding, 2010 (Female)

Zimmermann \& Sieverding, 2011

E Mode

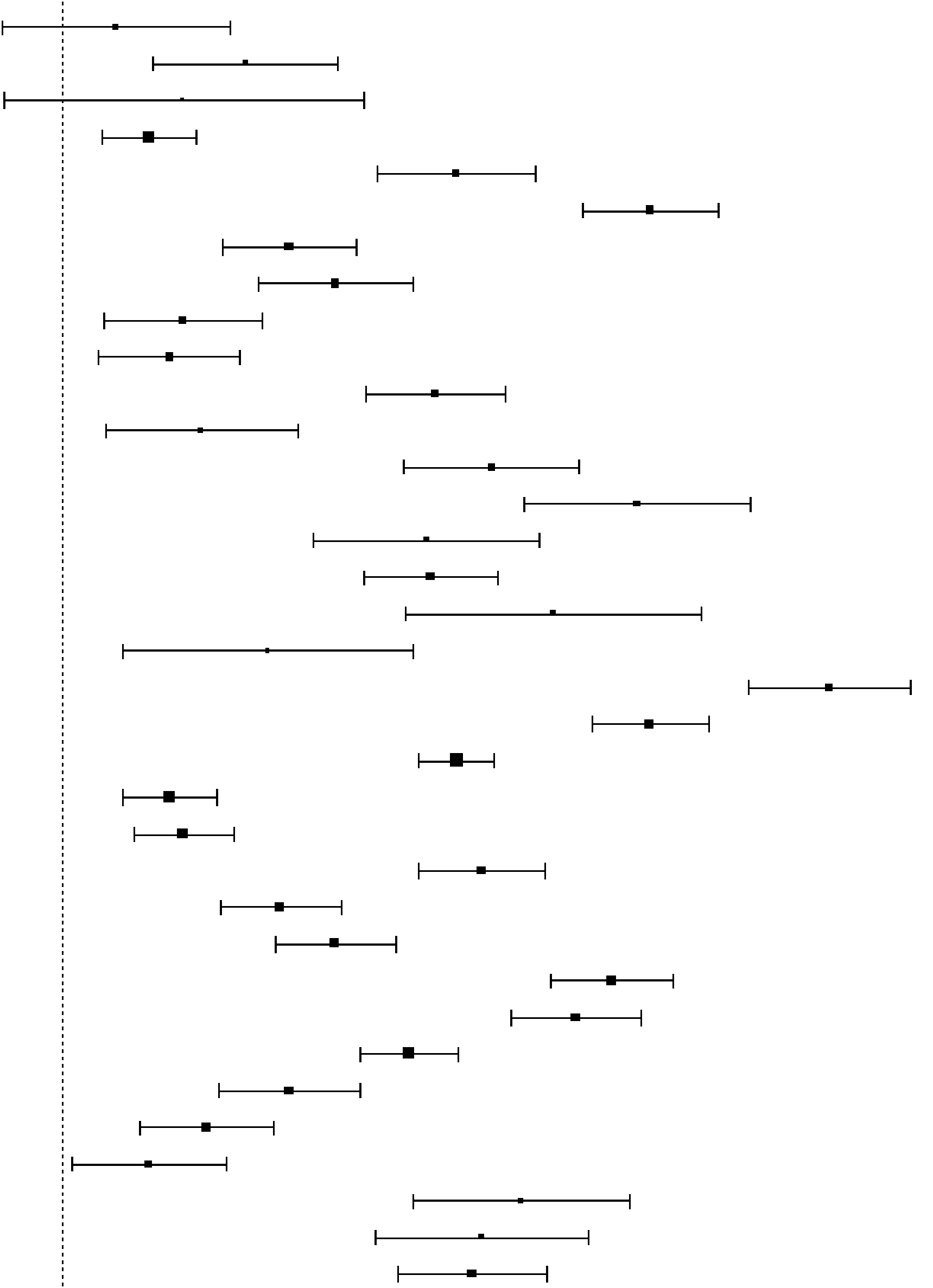

$0.08[-0.09,0.25]$ $0.28[0.14,0.42]$

$0.18[-0.09,0.45]$

$0.13[0.06,0.20]$

$0.59[0.47,0.71]$

$0.89[0.79,0.99]$

$0.34[0.24,0.44$

$0.41[0.30,0.53]$

$0.18[0.06,0.30]$

$0.16[0.05,0.27]$

$0.56[0.46,0.67$

$0.21[0.06,0.35]$

$0.65[0.52,0.78]$

$0.87[0.70,1.04]$

$0.55[0.38,0.72]$

$0.56[0.45,0.66$

$0.74[0.52,0.96]$

$0.31[0.09,0.53$

$1.16[1.03,1.28$

$0.89[0.80,0.98]$

$0.59[0.54,0.65]$

$0.16[0.09,0.23]$

$0.18[0.11,026]$

$0.33[0.24,0.42$

$0.41[0.32,0.50]$

$0.83[0.74,0.92]$

$0.78[0.68,0.87]$

$0.52[0.45,0.60]$

$0.34[0.24,0.45]$

$0.22[0.12,0.32]$

$0.13[0.01,0.25]$

$0.69[0.53,0.86]$

$0.63[0.47,0.79]$

$0.48[0.39,0.57]$ 


\section{Dodge, Stock, \& Litt, 2013}

Eggleston, 1997

Gebhardt, Van Empelen, \& Van Beurden, 2009 Hukkelberg \& Dykstra, 2009

Litt et al., 2013

O'Hara, 2012

O'Hara, 2012 (vaccination)

Ohtomo, 2013

Ohtomo, Hirose, \& Midden, 2011 (Dutch)

Ohtomo, Hirose, \& Midden, 2011 (Japanese)

Pomery et al., 2009 (All participants)

Pomery et al., 2009 (Non-smokers)

Rivis \& Sheeran, 2003

Rivis, Sheeran, \& Armitage, 2010

Rivis, Sheeran, \& Armitage, 2011b

Scott-Parker, Hyde, Watson, \& King, 2013

Todd \& Mullan, 2011

van Empelen \& Kok, 2006

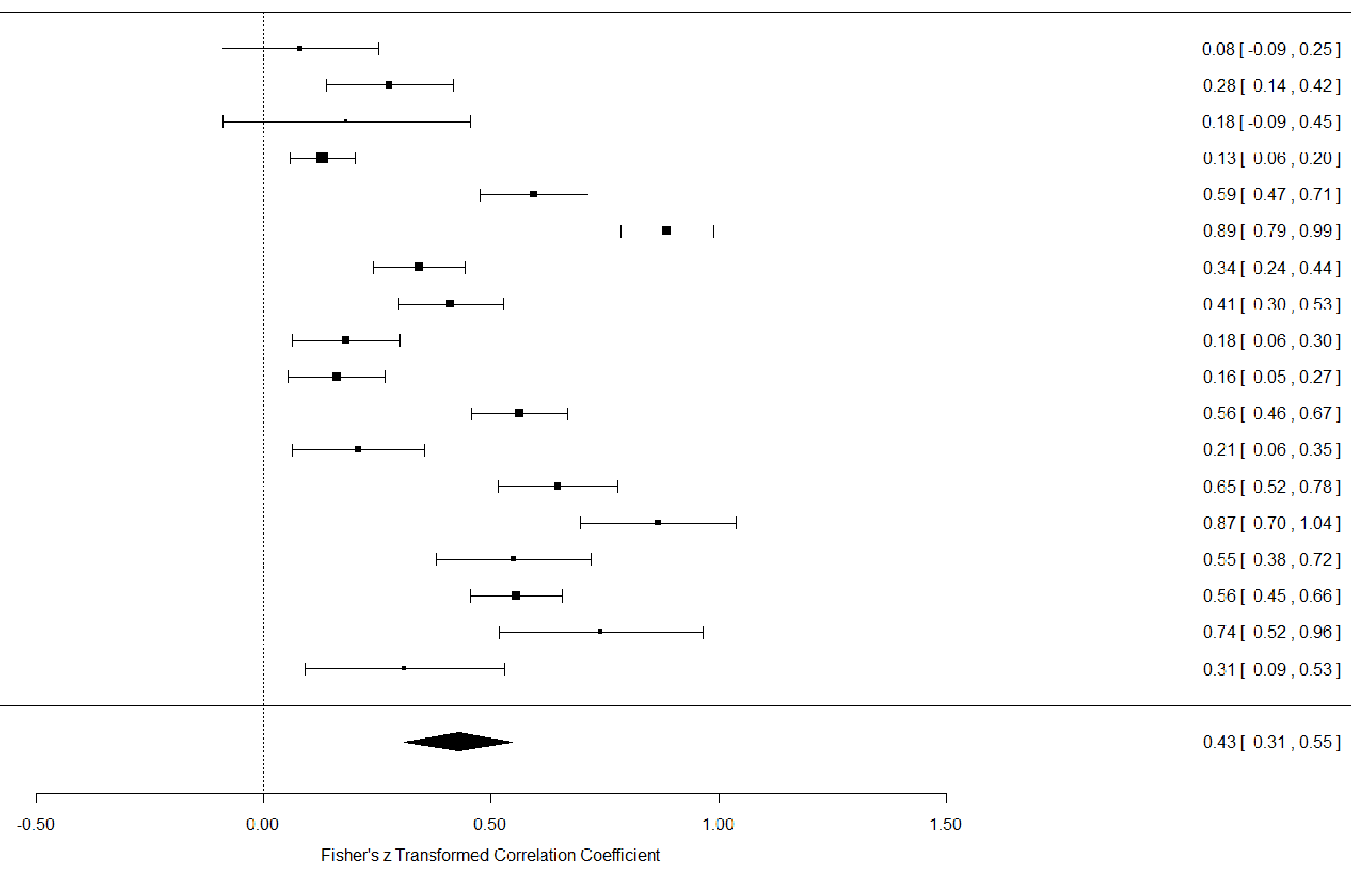




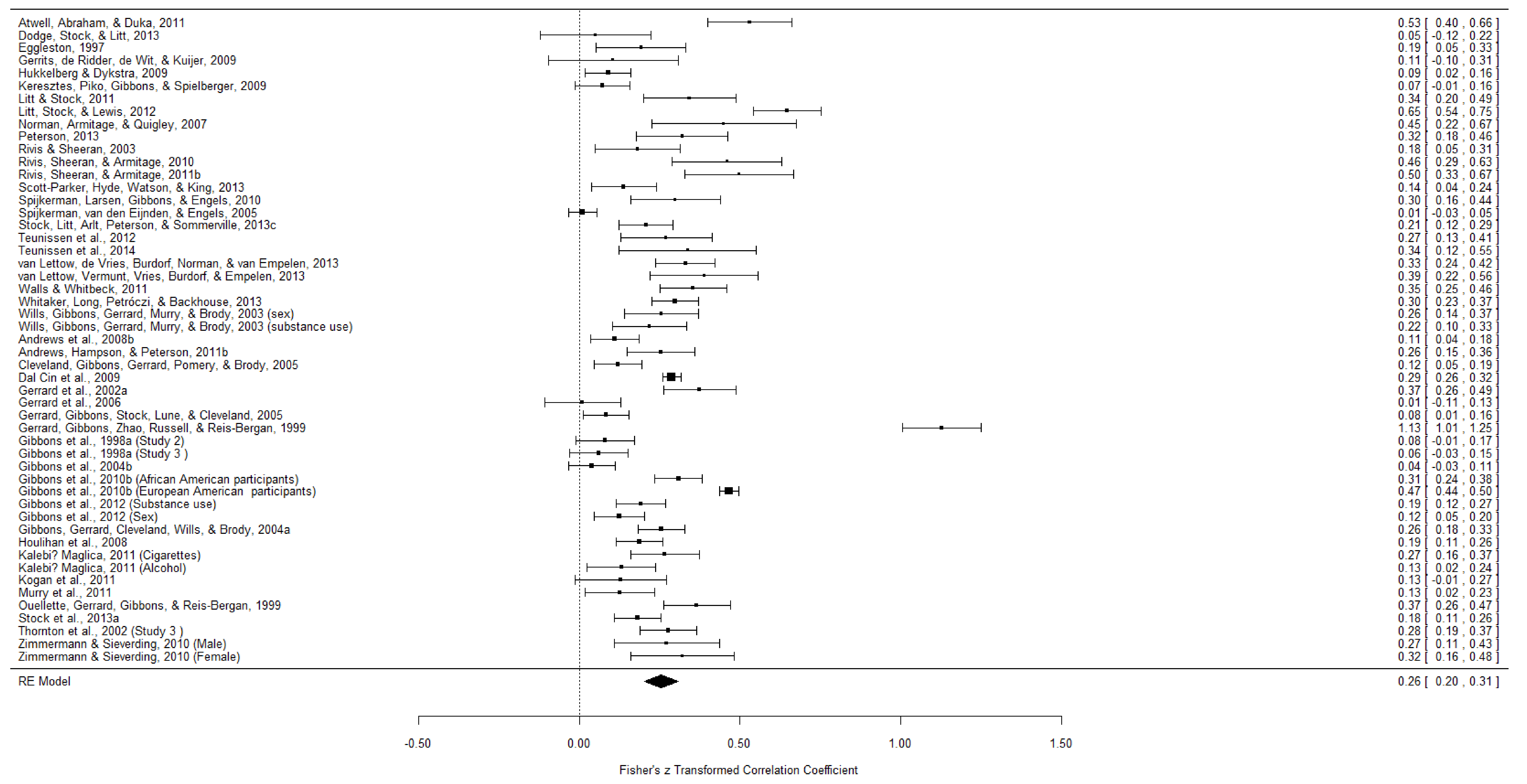




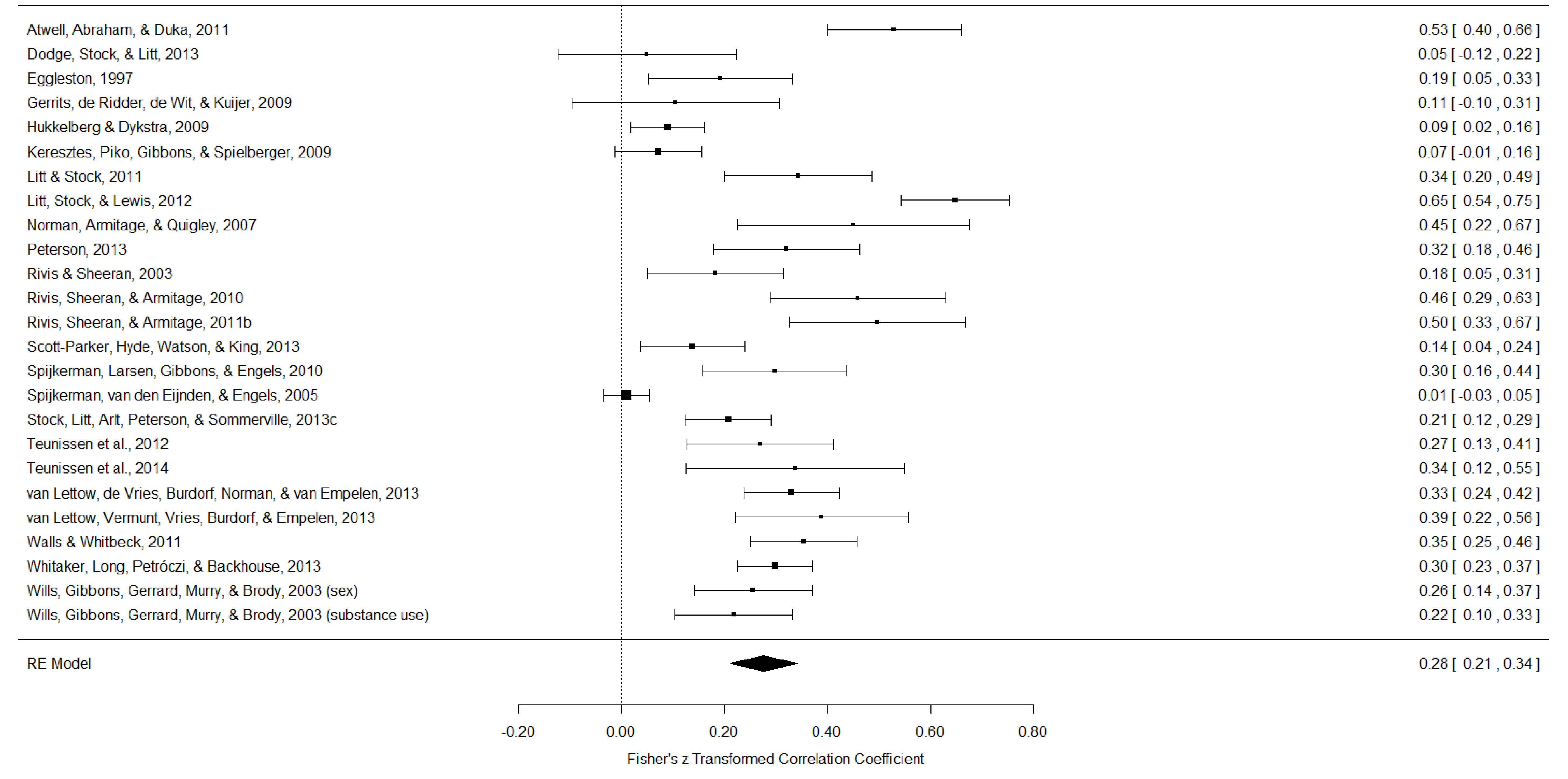




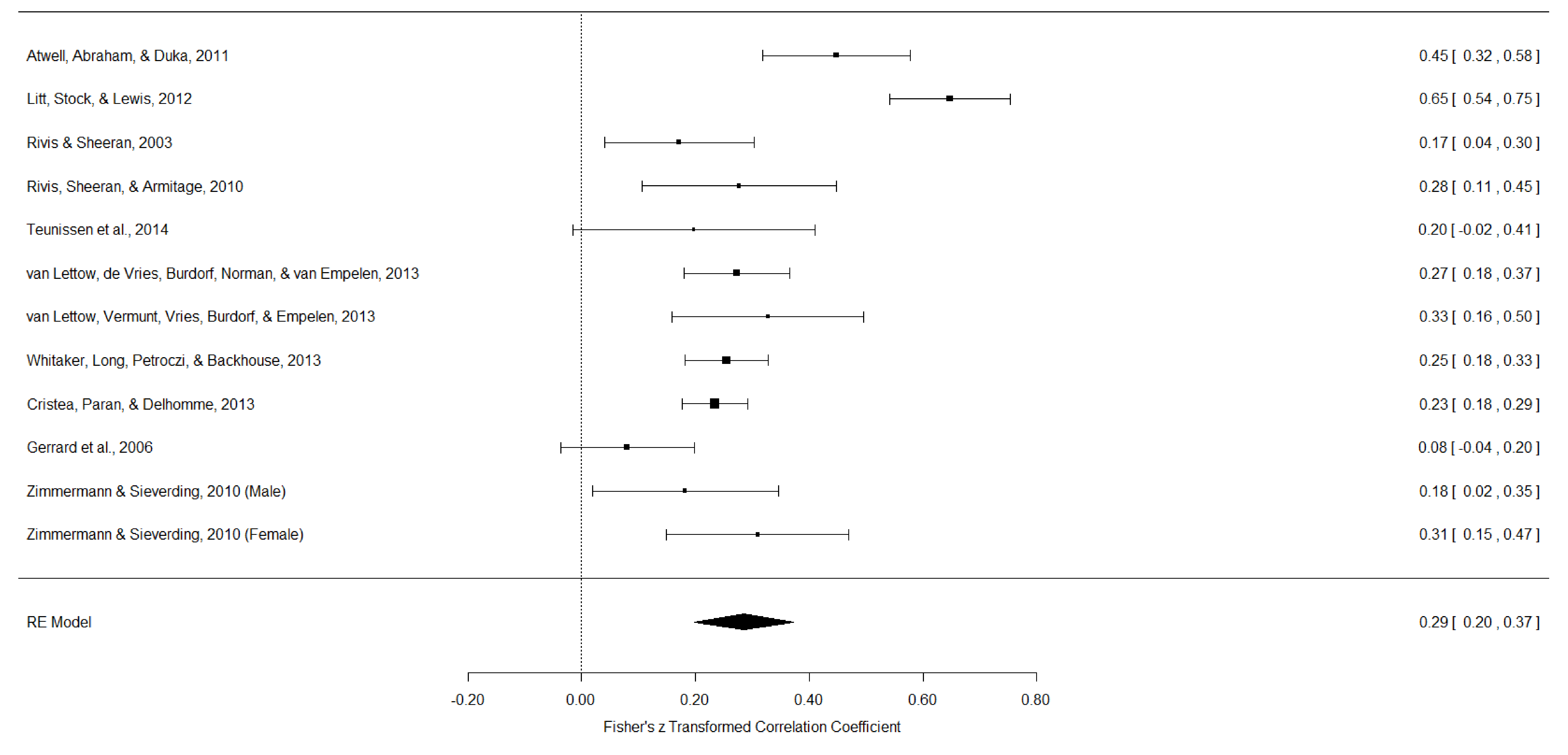




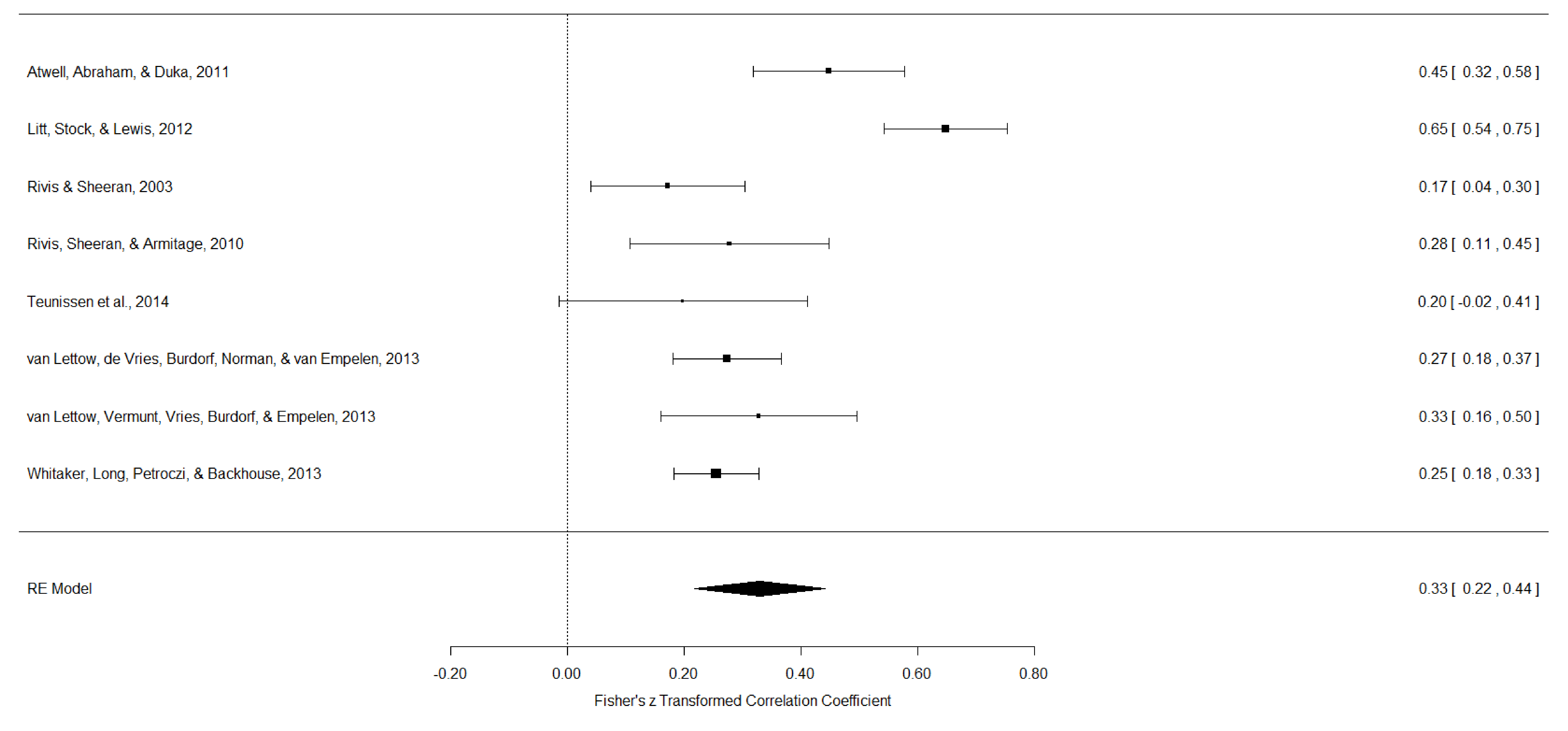


Andrews et al., 2011a

Gibbons et al., 1995a (Study 1 )

Hukkelberg \& Dykstra, 2009

Matterne et al., 2011

Norman, Armitage, \& Quigley, 2007

Rivis \& Sheeran, 2003

Rivis, Sheeran, \& Armitage, 2010

Thornton et al., 2002 (study 1)

Thornton et al., 2002 (Study 2)

Cristea, Paran, \& Delhomme, 2013

Delhomme, Cristea, \& Paran, In press

Gerrard et al., 2006

Gibbons et al., 1995a (Study 2)

Zimmermann \& Sieverding, 2010 (Male)

Zimmermann \& Sieverding, 2010 (Female)

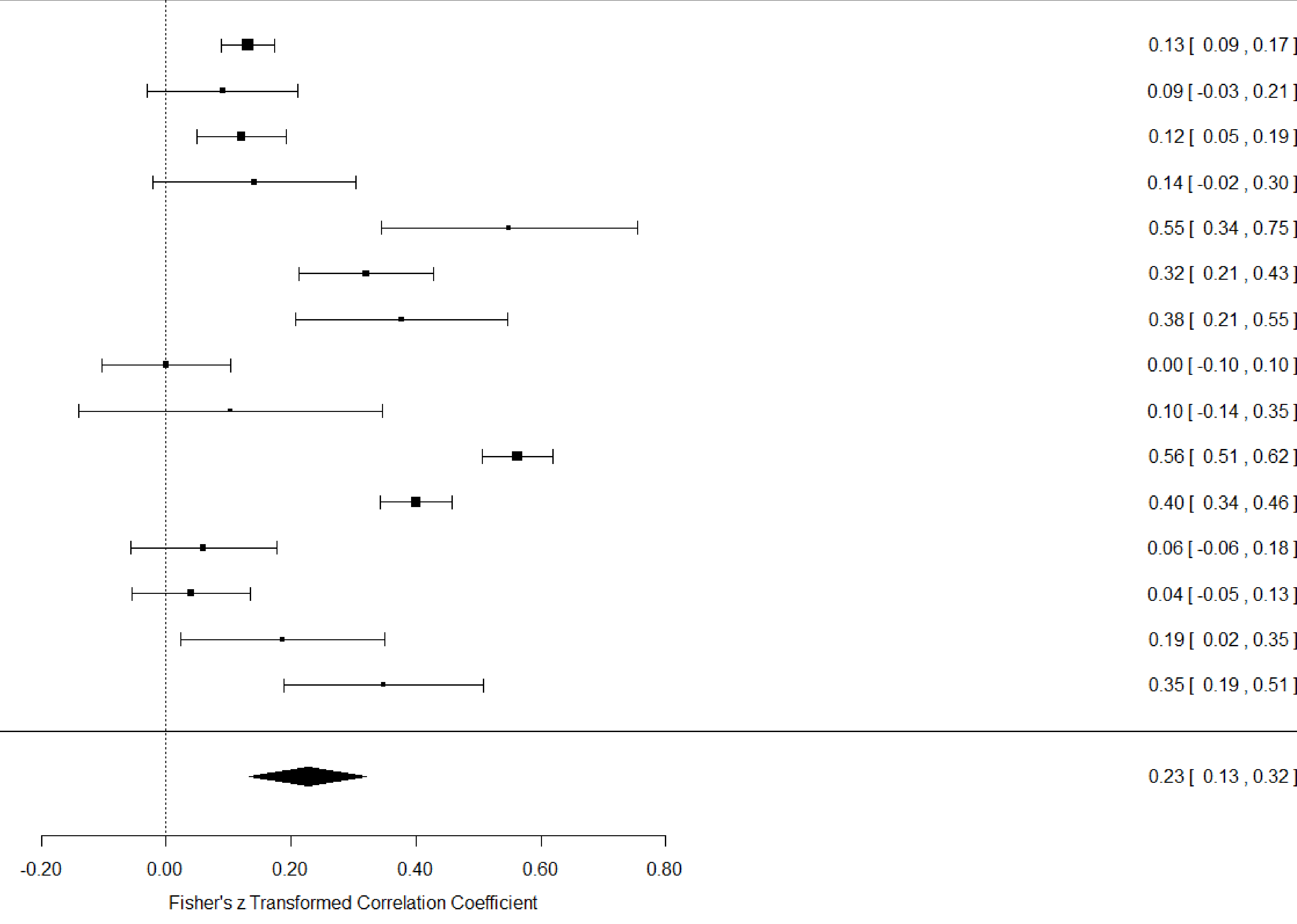


Andrews et al., 2011a

Gibbons et al., 1995a (Study 1 )

Hukkelberg \& Dykstra, 2009

Matterne et al., 2011

Norman, Armitage, \& Quigley, 2007

Rivis \& Sheeran, 2003

Rivis, Sheeran, \& Armitage, 2010

Thornton et al., 2002 (study 1)

Thornton et al., 2002 (Study 2)

RE Model
$0.13[0.09,0.17]$

$0.09[-0.03,0.21]$

$0.12[0.05,0.19]$

$0.14[-0.02,0.30]$

$0.55[0.34,0.75]$

$0.32[0.21,0.43]$

$0.38[0.21,0.55]$

$0.00[-0.10,0.10]$

$0.10[-0.14,0.35]$

$0.19[0.09,0.30]$

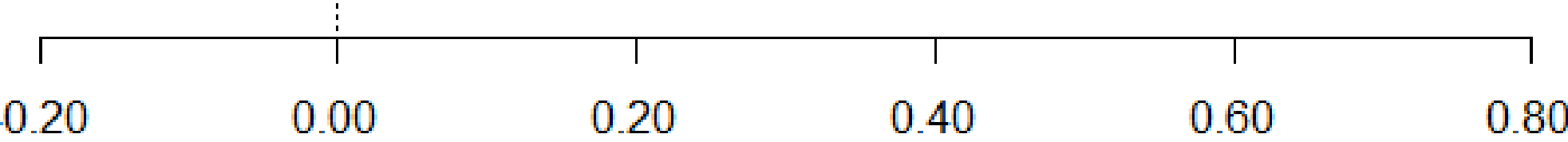

Fisher's z Transformed Correlation Coefficient 


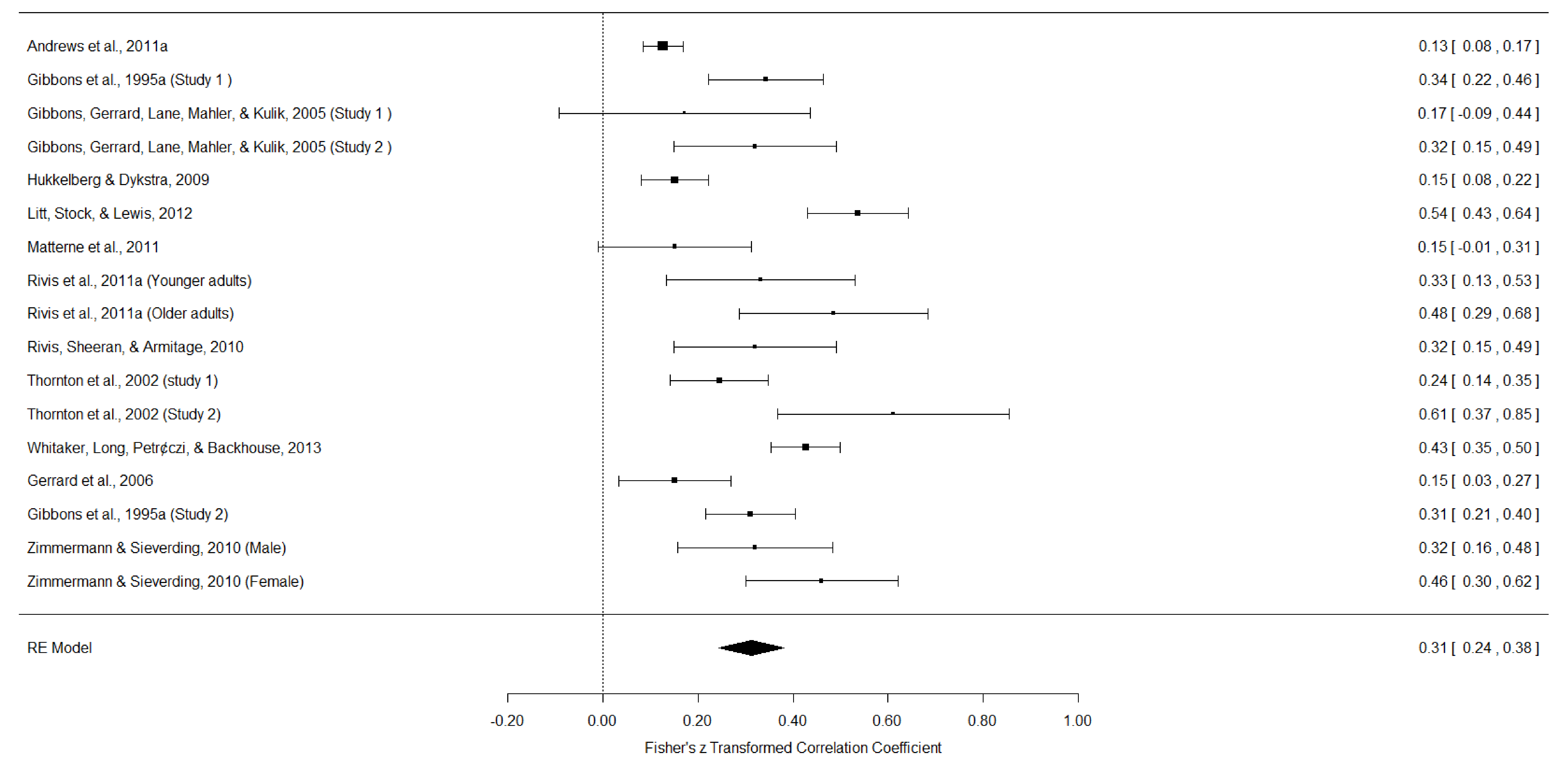




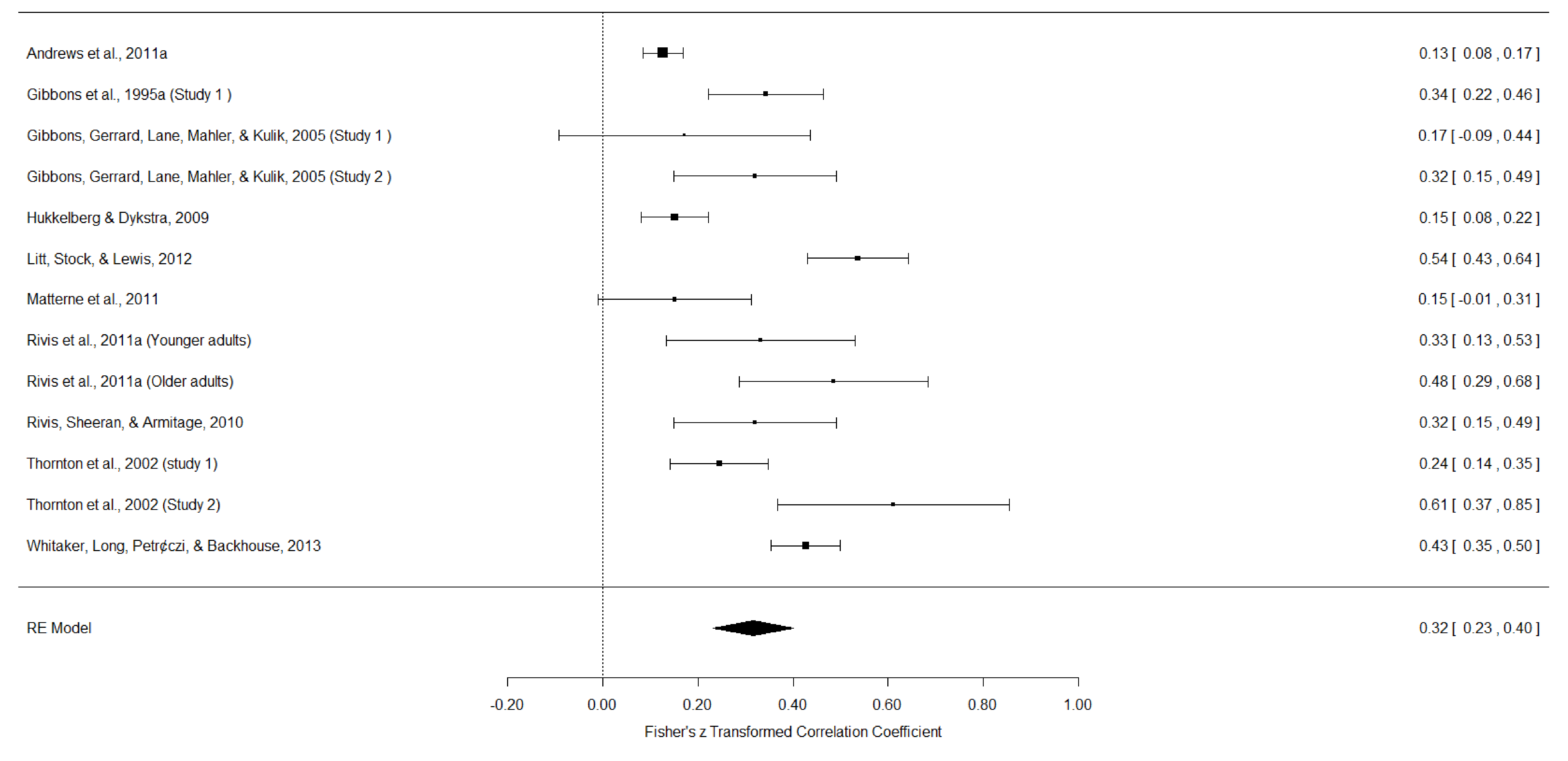


Andrews et al., 2011a

Dodge, Stock, \& Litt, 2013

Eggleston, 1997

Gibbons et al., 1995a (Study 1)

Hukkelberg \& Dykstra, 2009

Lane, Gibbons, O'Hara, \& Gerrard, 2011

Matterne et al., 2011

Myklestad \& Rise, 2007 (Female)

Myklestad \& Rise, 2007 (Male)

Myklestad \& Rise, 2008 (Combined genders)

Myklestad \& Rise, 2008 (Females only)

Norman, Armitage, \& Quigley, 2007

Pomery, 2008

Rivis \& Sheeran, 2003

Rivis, Sheeran, \& Armitage, 2010

Scott-Parker, Hyde, Watson, \& King, 2013

Thornton et al., 2002 (study 1)

Thornton et al., 2002 (Study 2)

Gerrard, Gibbons, Zhao, Russell, \& Reis-Bergan, 1999

Cristea, Paran, \& Delhomme, 2013

Delhomme, Cristea, \& Paran, In press

Gibbons et al., 2004b

Gibbons et al., 1995a (Study 2)

Gibbons et al. 1998a (Study 2)

Gibbons et al, 1998a (Study 3)

Gibbons, Helweg-Larsen, \& Gerrard, 1995b (American)

Gibbons, Helweg-Larsen, \& Gerrard, 1995b (Danish)

Andrews \& Peterson, 2006 (Cigarettes)
Andrews \& Peterson, 2006 (Alcohol)

Andrews \& Peterson, 2006 (Substance use)

Andrews, Hampson, \& Barckley, 2008a

Andrews, Hampson, \& Peterson, 2011

Hampson, Andrews, \& Barckley, 2008 (cigarettes)

Hampson, Andrews, \& Barckley, 2008 (substance use)

Gerrard et al., 2006

Zimmermann \& Sieverding, 2010 (Male)

Zimmermann \& Sieverding, 2010 (Female)

Zimmermann \& Sieverding, 2011b

RE Model

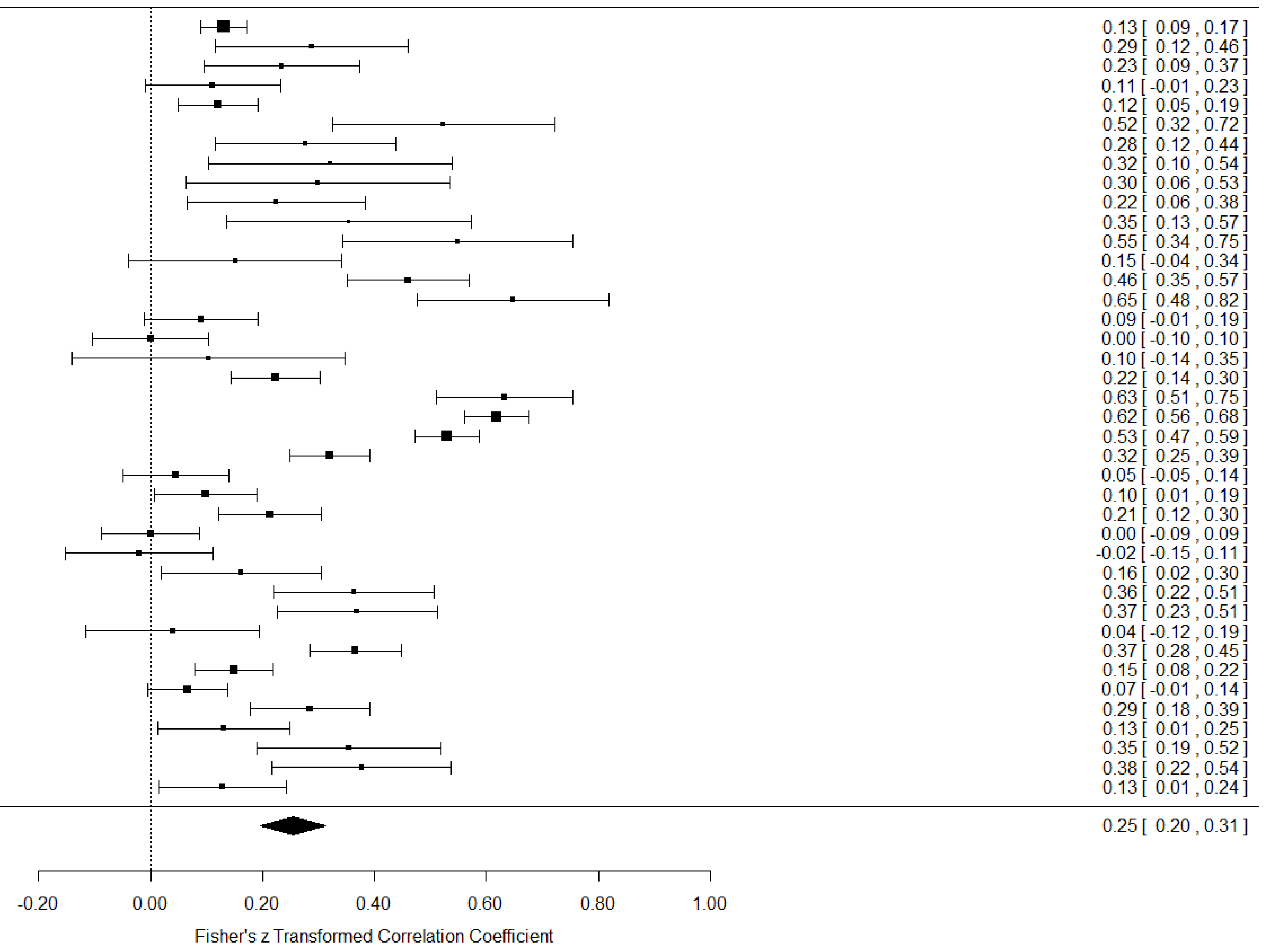




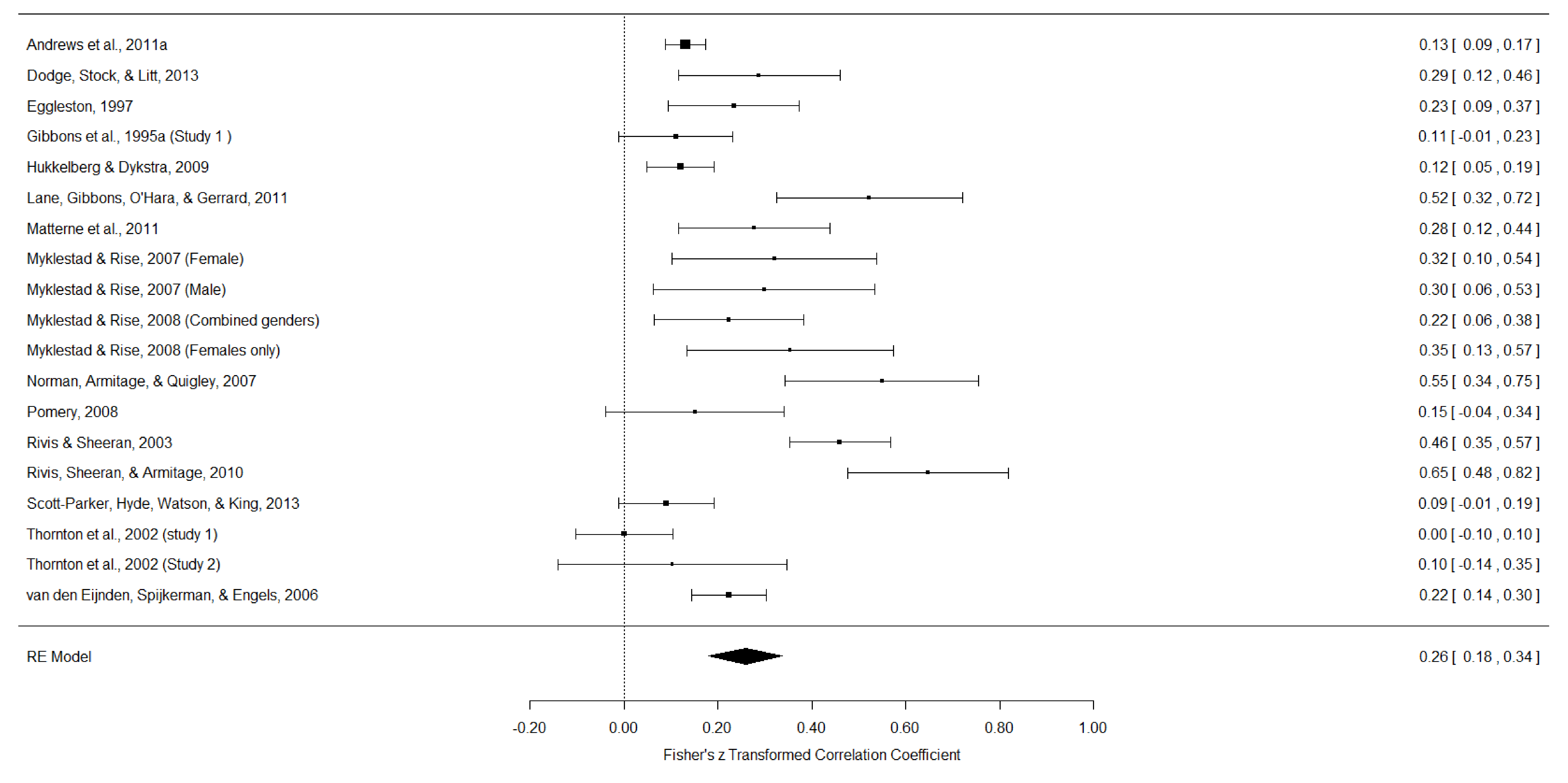




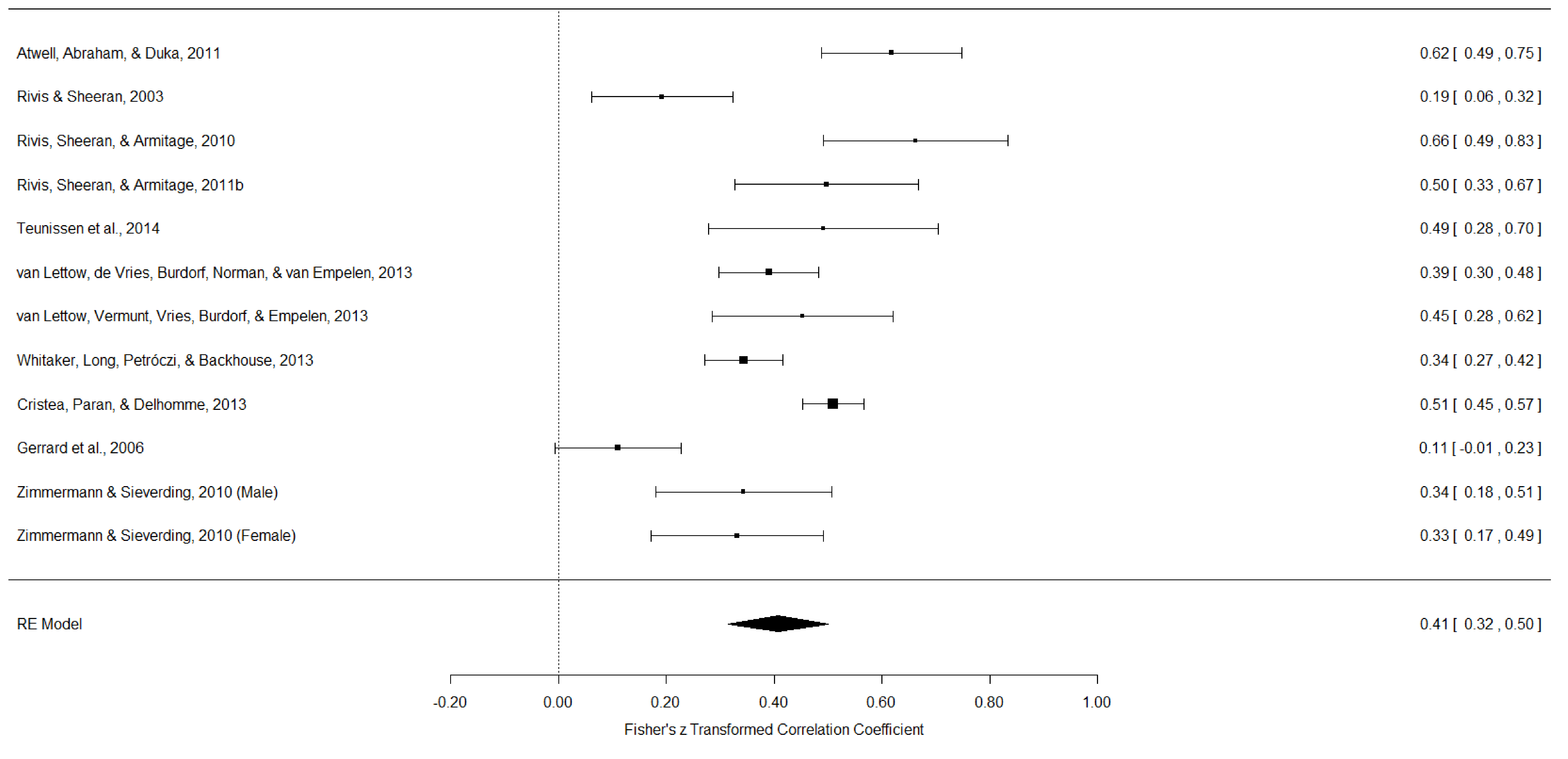




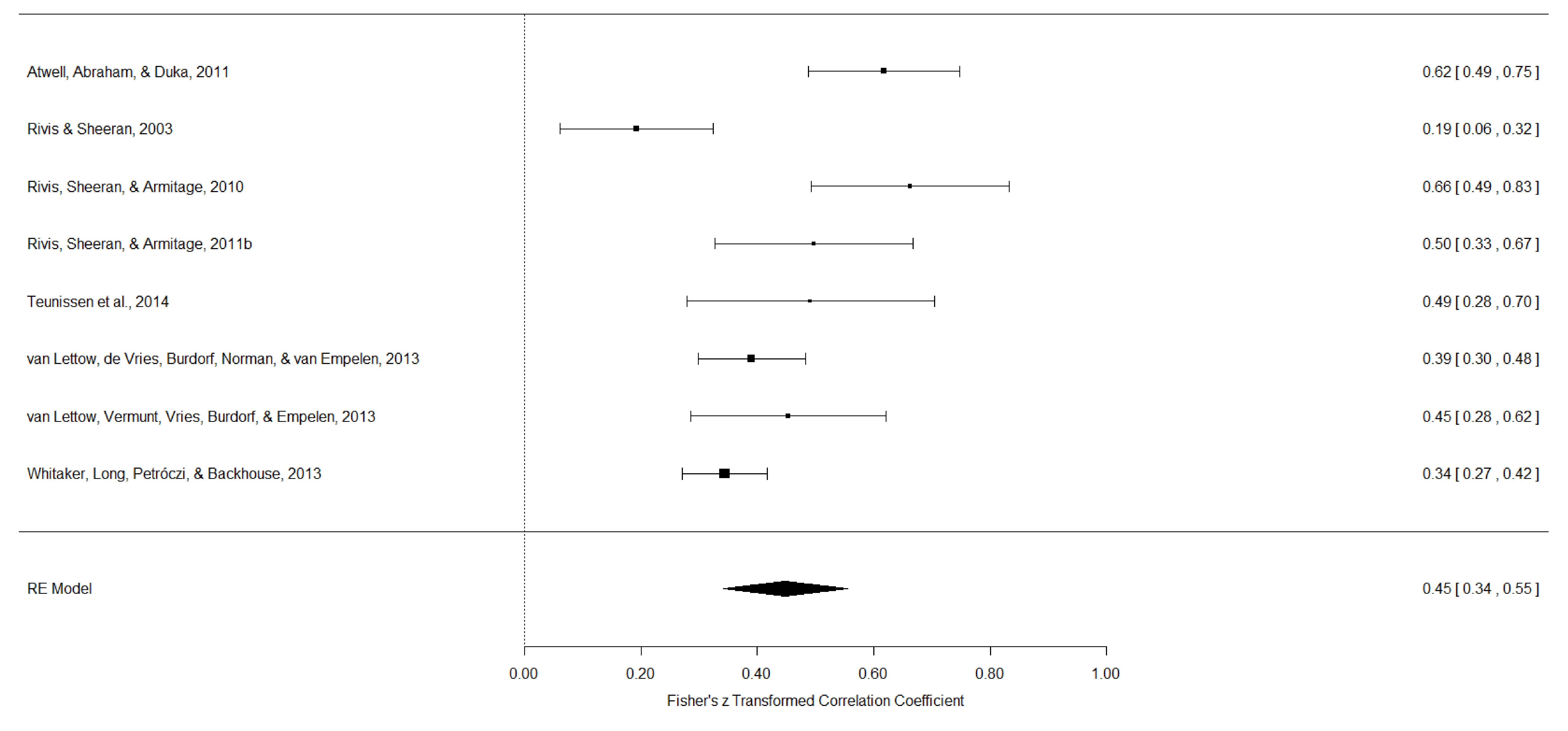


Gibbons et al., 1995a (Study 1 )

Lane, Gibbons, O'Hara, \& Gerrard, 2011

\section{Matterne et al., 2011}

Norman, Armitage, \& Quigley, 2007

Rivis \& Sheeran, 2003

Rivis, Sheeran, \& Armitage, 2010

Cristea, Paran, \& Delhomme, 2013

Delhomme, Cristea, \& Paran, In press

Gerrard et al., 2006

Gibbons et al., 1995a (Study 2)

Zimmermann \& Sieverding, 2010 (Male)

Zimmermann \& Sieverding, 2010 (Female)
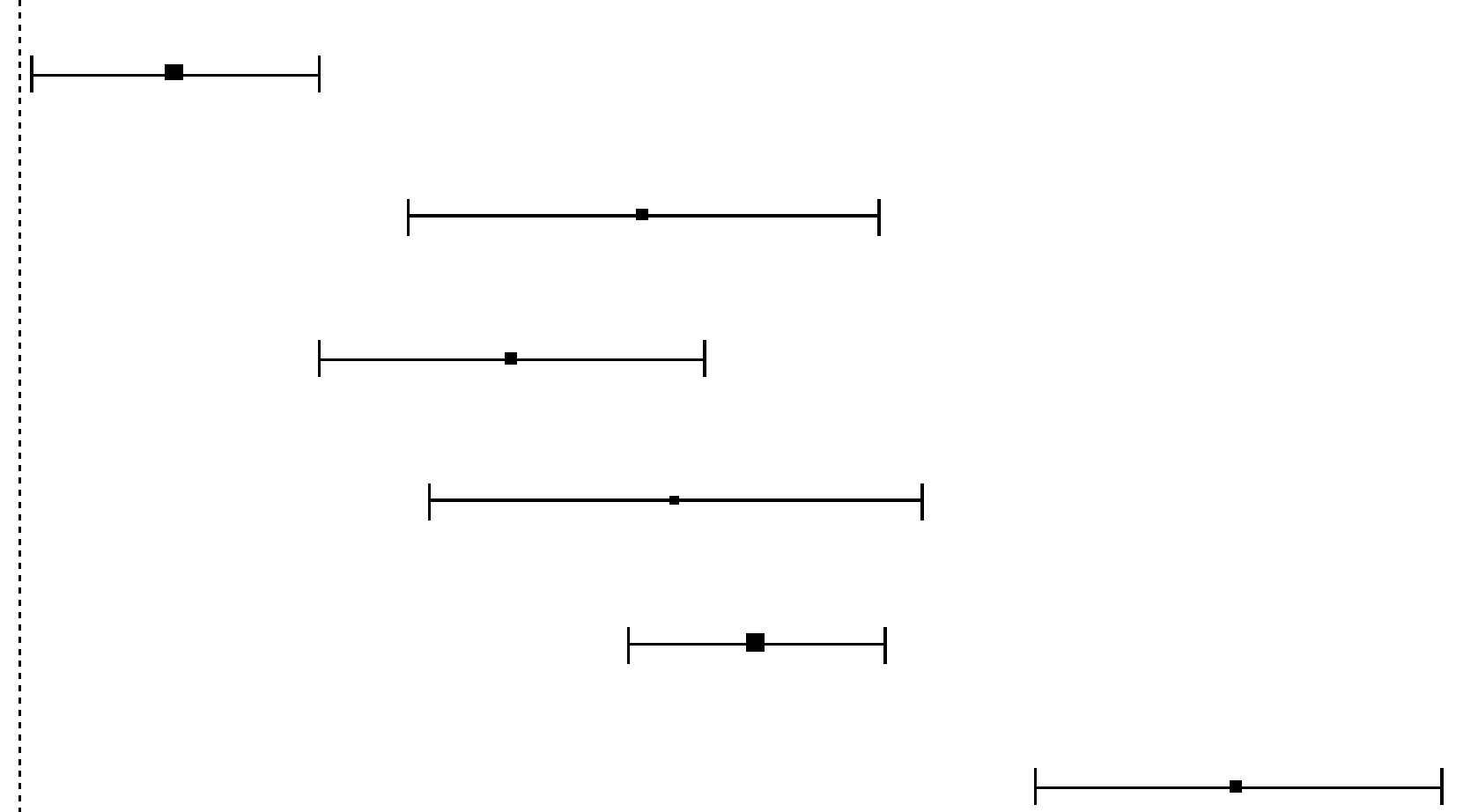

$\mapsto-1$
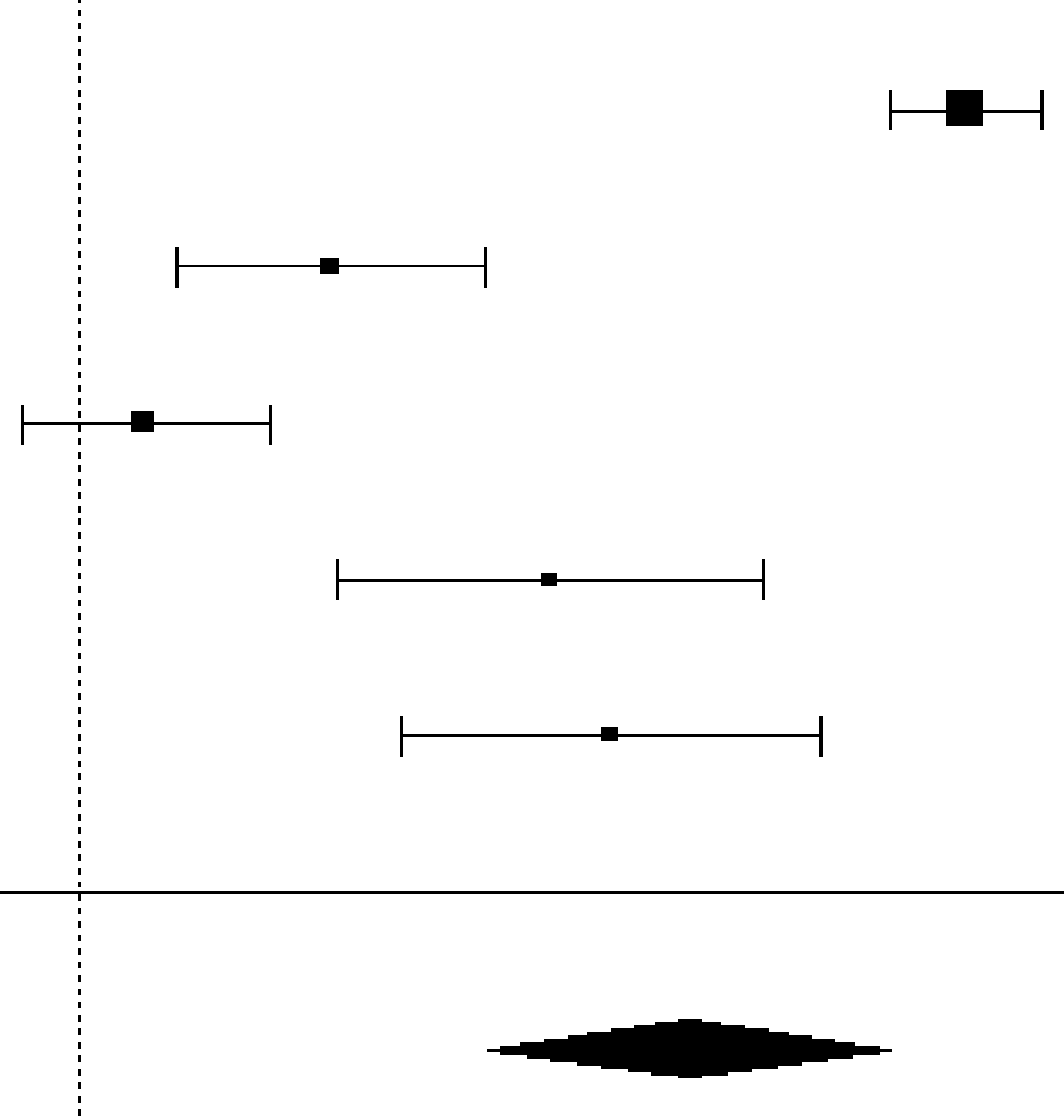

0.00
$0.13[0.01,0.25]$

$0.52[0.32,0.72]$

$0.41[0.25,0.57]$

$0.55[0.34,0.75]$

$0.62[0.51,0.73]$

$1.02[0.85,1.19]$

$0.68[0.62,0.73]$

$0.68[0.62,0.73]$

$0.19[0.07,0.31]$

$0.05[-0.04,0.14]$

$0.36[0.20,0.52]$

$0.41[0.25,0.57]$ 


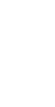

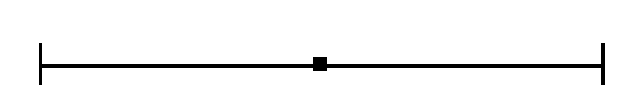

$0.52[0.32,0.72]$

$\longmapsto$

$0.41[0.25,0.57]$

Norman, Armitage, \& Quigley, 2007

Rivis \& Sheeran, 2003

Rivis, Sheeran, \& Armitage, 2010

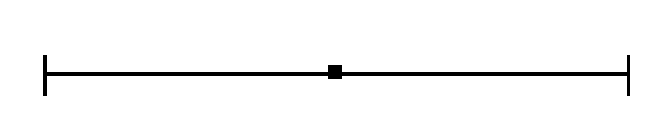

$0.55[0.34,0.75]$

$0.62[0.51,0.73]$

$1.02[0.85,1.19]$

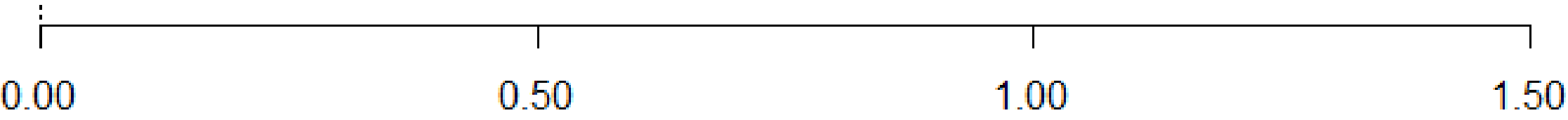

Fisher's z Transformed Correlation Coefficient 
Gibbons et al., 1995a (Study 1 )

Gibbons, Gerrard, Lane, Mahler, \& Kulik, 2005 (Study 1 )

Gibbons, Gerrard, Lane, Mahler, \& Kulik, 2005 (Study 2 )

Lane, Gibbons, O'Hara, \& Gerrard, 2011

Lane, Gibbons, O'Hara, \& Gerrard, 2011

Matterne et al., 2011

Rivis et al., 2011a (Younger adults)

Rivis et al., 2011a (Older adults)

Rivis, Sheeran, \& Armitage, 2010

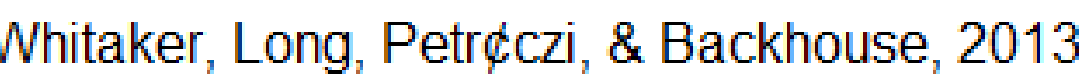

Gerrard et al., 2006

Gibbons et al., 1995a (Study 2)

Zimmermann \& Sieverding, 2010 (Male)

Zimmermann \& Sieverding, 2010 (Female)

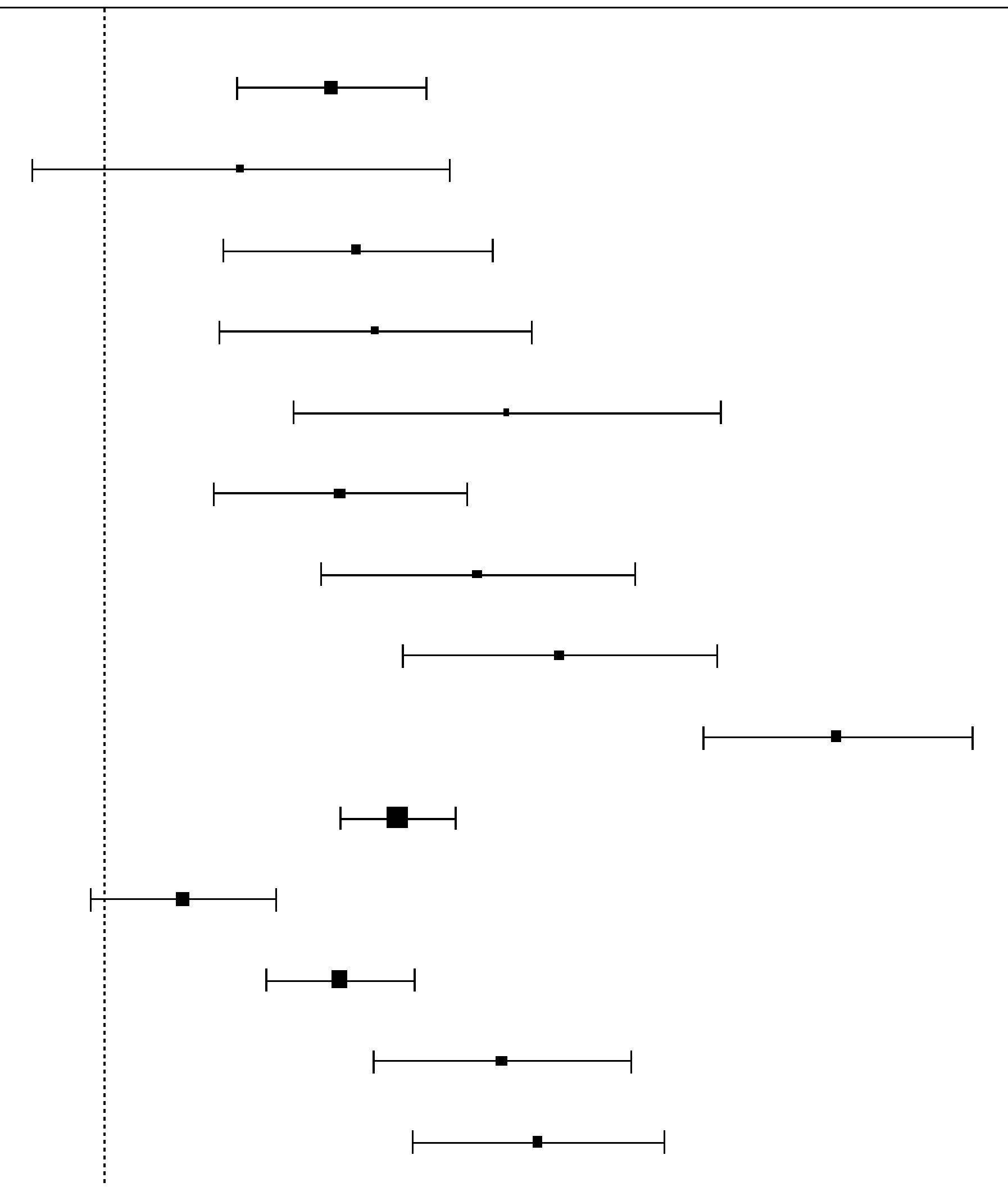

$0.29[0.17,0.41]$

$0.17[-0.09,0.44]$

$0.32[0.15,0.49]$

$0.34[0.14,0.54$

$0.51[0.24,0.78]$

$0.30[0.14,0.46]$

$0.47[0.27,0.67]$

$0.58[0.38,0.78]$

$0.93[0.76,1.10]$

$0.37[0.30,0.44]$

$0.10[-0.02,0.22]$

$0.30[0.20,0.39$ ]

$0.50[0.34,0.67]$

$0.55[0.39,0.71]$

\begin{tabular}{|c|c|c|c|c|}
\hline$\Gamma$ & 1 & $T$ & $T$ & ᄀ \\
\hline-0.50 & 0.00 & 0.50 & 1.00 & 1.50 \\
\hline
\end{tabular}


Gibbons et al., 1995a (Study 1 )

Gibbons, Gerrard, Lane, Mahler, \& Kulik, 2005 (Study 1 )

Gibbons, Gerrard, Lane, Mahler, \& Kulik, 2005 (Study 2)

Lane, Gibbons, O'Hara, \& Gerrard, 2011

Lane, Gibbons, O'Hara, \& Gerrard, 2011

Matterne et al., 2011

Rivis et al., 2011a (Younger adults)

Rivis et al., 2011a (Older adults)

Rivis, Sheeran, \& Armitage, 2010

Whitaker, Long, Petrфczi, \& Backhouse, 2013
$0.29[0.17,0.41]$

$0.17[-0.09,0.44]$

$0.32[0.15,0.49]$

$0.34[0.14,0.54]$

$0.51[0.24,0.78]$

$0.30[0.14,0.46]$

$0.47[0.27,0.67]$

$0.58[0.38,0.78]$

$0.93[0.76,1.10]$

$0.37[0.30,0.44]$

$0.43[0.30,0.56]$

\section{RE Mode}

\begin{tabular}{|c|c|c|c|c|}
\hline$\Gamma$ & Tं & $T$ & 1 & $\neg$ \\
\hline-0.50 & 0.00 & 0.50 & 1.00 & 1.50 \\
\hline
\end{tabular}


Andrews et al., 2011a
Dodge, Stock, \& Litt, 2013
Eggleston, 1997

ibbons et al., 1995a (Study

Gulik, 2005 (Study 1

Hukkelberg \& Dykstra, 2009

ane, Gibbons, O'Hara, \& Gerrard, 2011

Litt \& Stock, 2011

Litt, Stock, \& Lewis, 2012

Myklestad \& Rise, 2007 (Female)

Myklestad \& Rise, 2007 (Male)

Peterson, 2013

Rivis et al., 2011a (Younger adults)

Rivis et al. 2011a (Older adults)

Rivis, Sheeran, \& Armitage, 2010

Scott-Parker, Hyde, Watson, \& King, 2013

Spjkerman, van den Eijnden, \& Engels, 2005

Stock, Litt, Arlt, Peterson, \& Sommerville, 2013c

Thornton et al., 2002 (study 1)

Thornton et al., 2002 (Study 2)

(1)

Gerrard, Gibbons, Zhao, Russell, \& Reis-Bergan, 1999

hornton et al., 2002 (Study 3 )

Gibbons et al., 2010b (African American participants)

Gibbons et al, 2010b (European American participants)

Gerrard, Gibbons Stock, Lune, \& Cleveland, 2005

Gibbons et al., 2004b

Gibbons et al., 2012 (Substa

Gibbons et al., 2012 (Sex)

Houlihan et al.,2008

Gerrard et al., 2002a

Gibbons et al., 1995a (Study 2 )

Gibbons et al., 1998a (Study 2

Gibbons, Helweg-Larsen, \& Gerrard, 1995b (American)

Gibbons, Helweg-Larsen, \& Gerrard, 1995b (American)

Andrews et al., 2008b

Andrews, Hampson, \&

Gerrard et al., 2006

Zimmermann \& Sieverding. 2010 (Male) IImmermann \& Sieverding, 2010 (Female) Zimmermann \& Sieverding, 2011b

RE Model

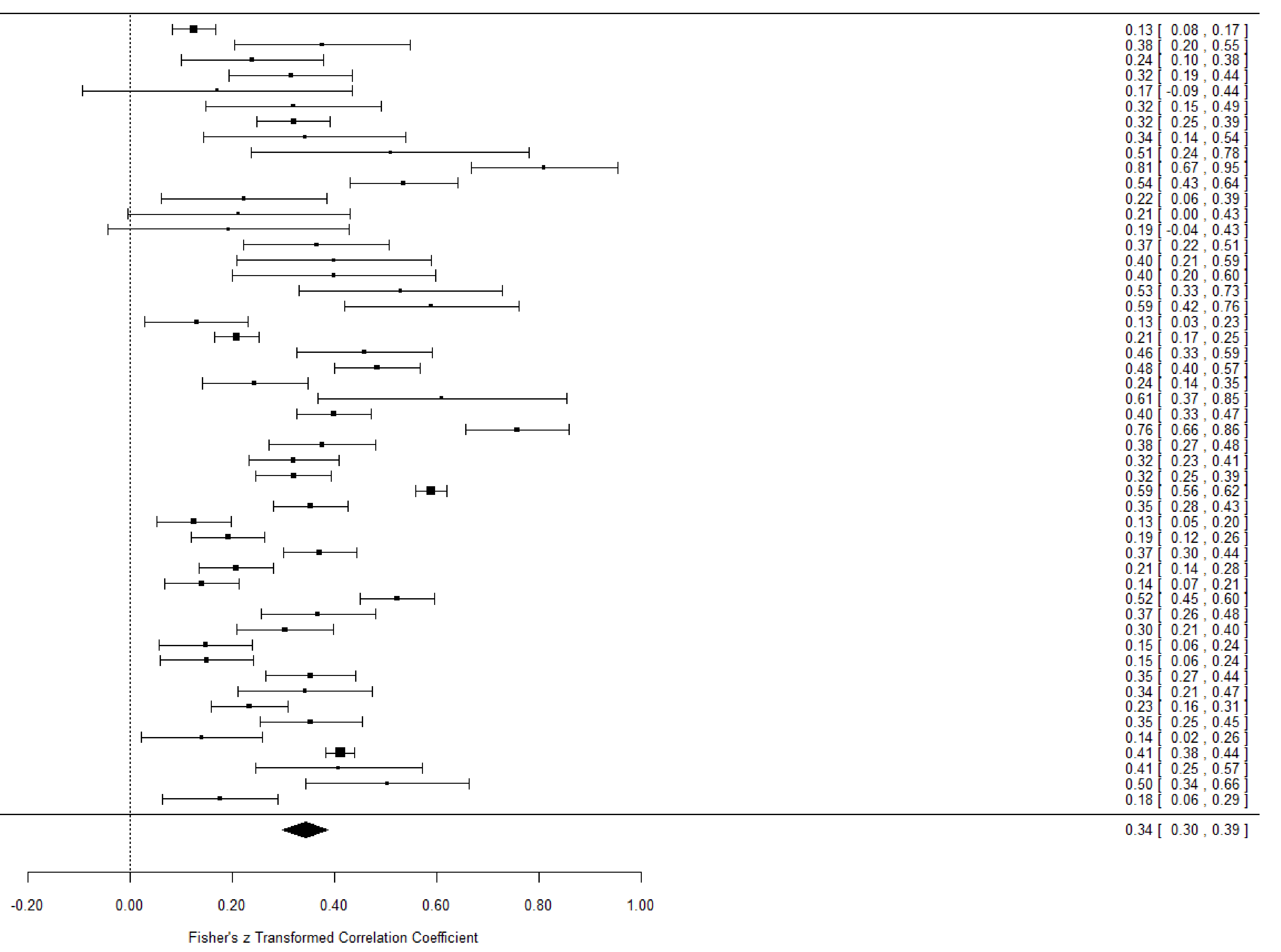




\section{Andrews et al., 2011a}

Dodge, Stock, \& Litt, 2013

Eggleston, 1997

Gibbons et al., 1995a (Study 1 )

Gibbons, Gerrard, Lane, Mahler, \& Kulik, 2005 (Study 1 )

Gibbons, Gerrard, Lane, Mahler, \& Kulik, 2005 (Study 2 )

Hukkelberg \& Dykstra, 2009

Lane, Gibbons, O'Hara, \& Gerrard, 2011

Lane, Gibbons, O'Hara, \& Gerrard, 2011

Litt \& Stock, 2011

Litt, Stock, \& Lewis, 2012

Matterne et al., 2011

Myklestad \& Rise, 2007 (Female)

Myklestad \& Rise, 2007 (Male)

Peterson, 2013

Pomery, 2008

Rivis et al., 2011a (Younger adults)

Rivis et al., 2011a (Older adults)

Rivis, Sheeran, \& Armitage, 2010

Scott-Parker, Hyde, Watson, \& King, 2013

Spijkerman, van den Eijnden, \& Engels, 2005

Stock, 2007

Stock, Litt, Arlt, Peterson, \& Sommerville, 2013c

Thornton et al., 2002 (study 1)

Thornton et al., 2002 (Study 2)

Whitaker, Long, Petrфczi, \& Backhouse, 2013

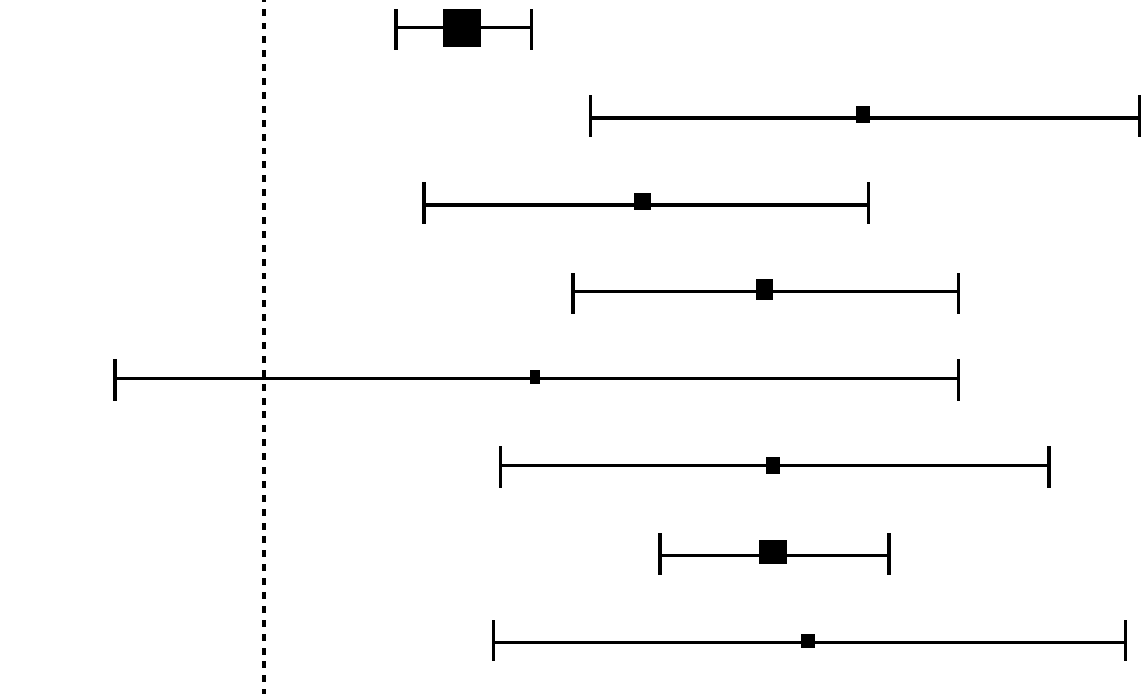

$0.13[0.08,0.17]$

$0.38[0.20,0.55]$

$0.24[0.10,0.38]$

$0.32[0.19,0.44]$

$0.17[-0.09,0.44]$

$0.32[0.15,0.49]$

$0.32[0.25,0.39]$

$0.34[0.14,0.54]$

$0.51[0.24,0.78]$

$0.81[0.67,0.95]$

$0.54[0.43,0.64]$

$0.22[0.06,0.39]$

$0.21[0.00,0.43]$

$0.19[-0.04,0.43]$

$0.37[0.22,0.51]$

$0.40[0.21,0.59]$

$0.40[0.20,0.60]$

$0.53[0.33,0.73]$

$0.59[0.42,0.76]$

$0.13[0.03,0.23]$

$0.21[0.17,0.25]$

$0.46[0.33,0.59]$

$0.48[0.40,0.57]$

$0.24[0.14,0.35]$

$0.61[0.37,0.85$

$0.40[0.33,0.47]$

$0.36[0.30,0.43]$

RE Model 
Dodge, Stock, \& Litt, 2013

Gebhardt, Van Empelen, \& Van Beurden, 2009

Hukkelberg \& Dykstra, 2009

Litt et al, 2013

2012

'Hara, 2012 (vaccination)

Ohtomo, Hirose, \& Midden, 2011 (Dut

Dhomo, Hirose, \& Midden, 2011 (Dutch)

Peterson, 2013 13

coott-Parker, Hyde, Watson, \& King, 2013

tock, Gibbons, Peterson, \& Gerrard, $2013 \mathrm{~b}$ (Substance use)

tock, Litt, Arlt, Peterson, \& Sommerville, 2013c

Todd \& Mullan, 2011
van Empelen \& Kok, 2006

Whitaker, Long, Petróczi, \& Backhouse, 2013

(1999

uellette, Gerrard, Gibbons,
Thornton et al., 2002 (Study 3 )

Gibbons et al., 2010b (African American participants)

Cleveland, Gibbons, Gerrard, Pomery, \& B Brody, 2005

Gibbons et al., 2004b

Gibobons et al.l, 2012 (Substance use)
Gibbons et al., 2012 (Sex)

Houlihan et al., 2008
Pomery et al., 2005

Stock et al., 2013a

Gerrard, Gibbons, Vande Lune, Pexa, \& Gano, 2002b (Cigarettes)

Gerrard, Gibbons, Vande Lune, Pexa, \& Gano, 2002 b (Substance use)

Gerrard et al., 2002a

1998a (Study 1)

Gibbons et al., 1998a (Study 3 )

Gibbons et al., 1998 b (Study 1 )

Andrews et al., 2008b \& Peterson, 201

Gerrard et al., 2006

Zimmermann \& Sieverding, 2010 (Male)

Kalebi Maglica, 2011 (Cigarettes)

Kalebi Maglica, 2011 (Alcohol)

RE Model

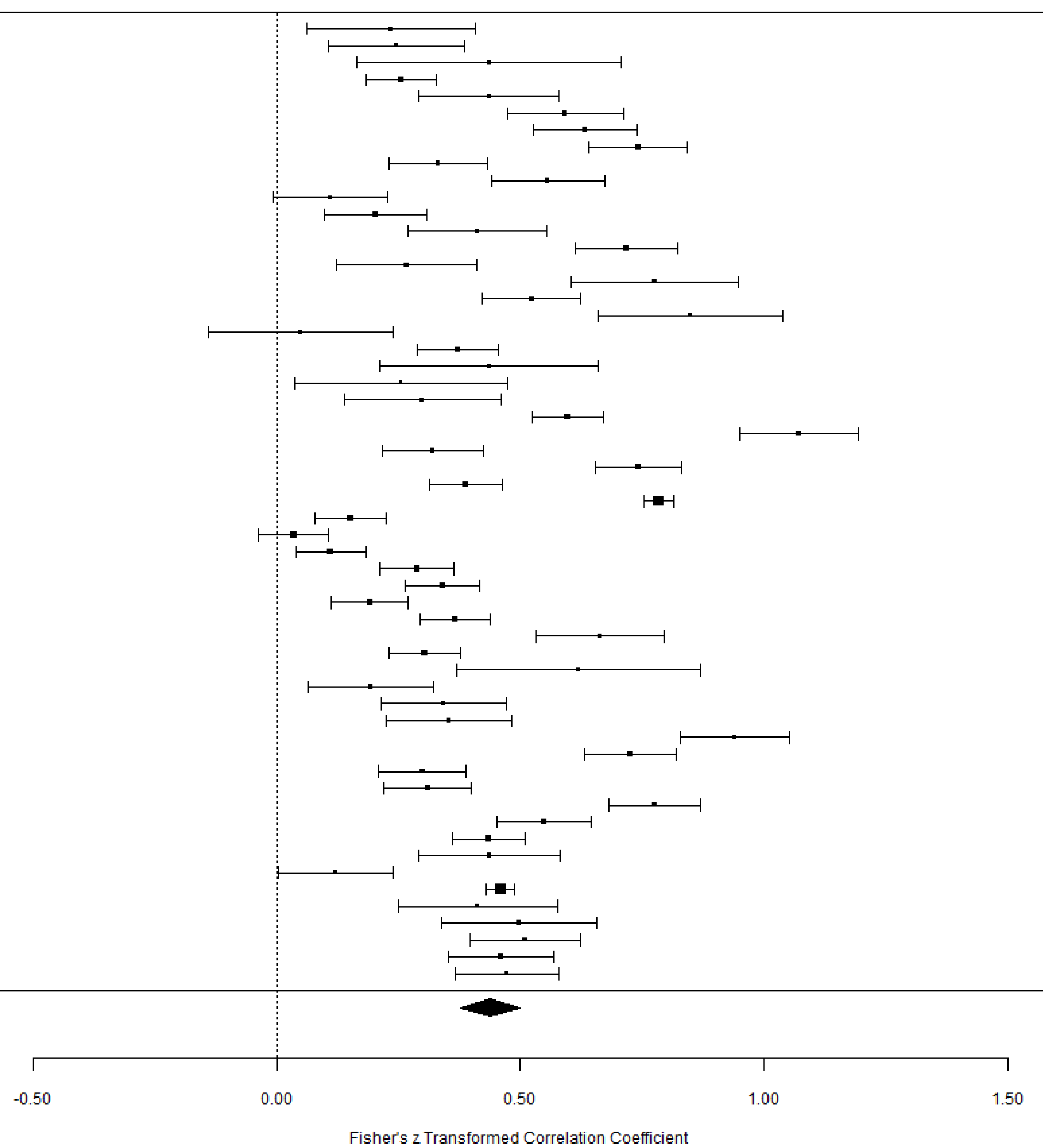

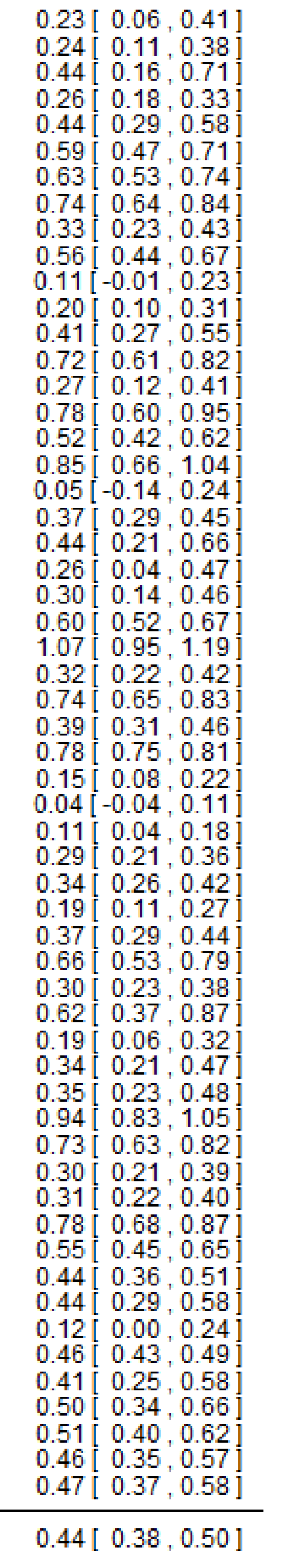




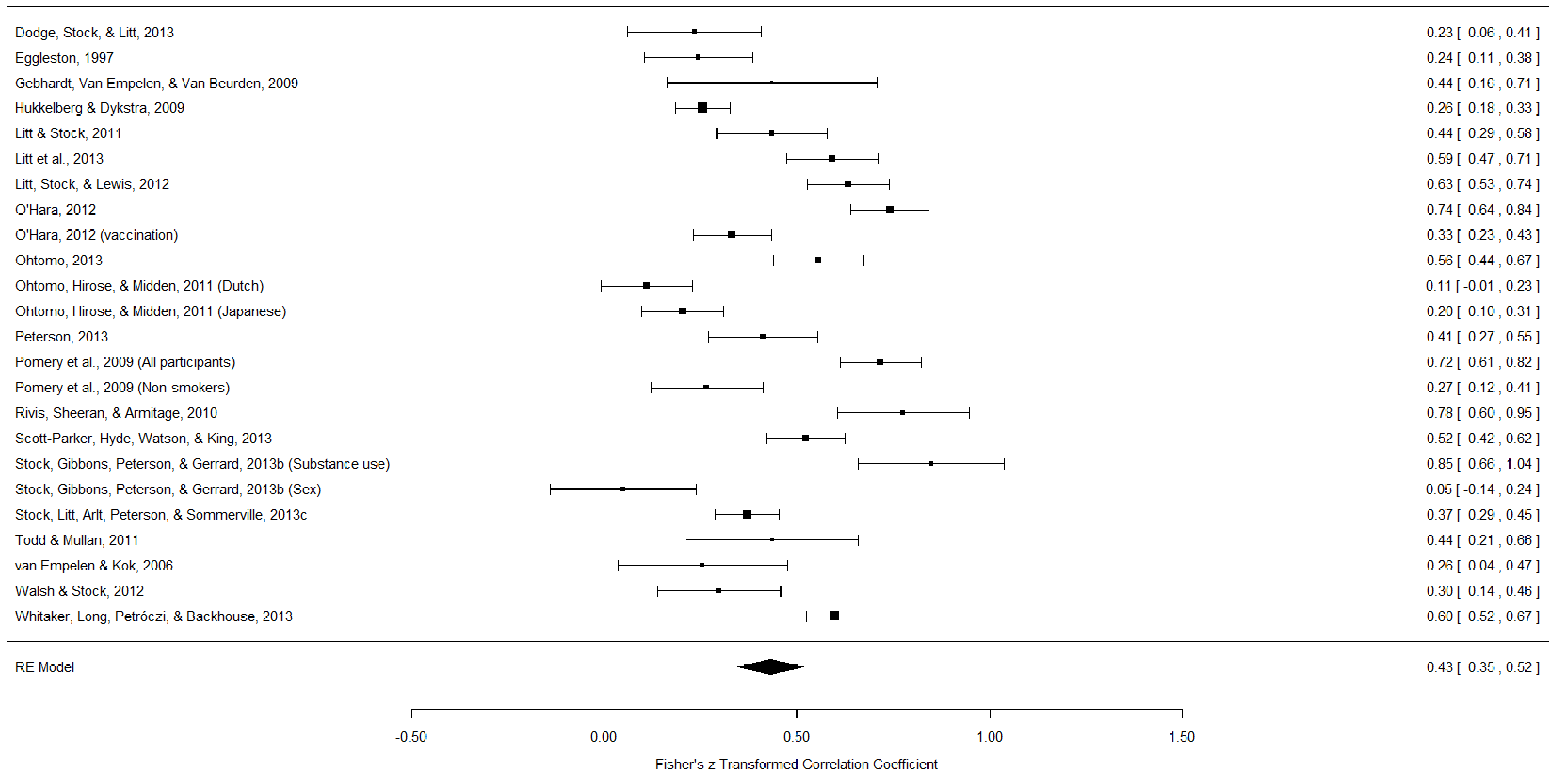


Andrews et al., 2011a

Dodge, Stock, \& Litt, 2013

Ggleston, 1997

en \& Van Beurden, 2009

Hukkelberg \&

ane, Gibbons, O'Hara, \& Gerrard, 2011

Litt et al., 2013

Myklestad \& Rise, 2007 (Female)

Myklestad \& Rise, 2007 (Male)

O'Hara, 2012

O'Hara, 2012 (vaccination)

Ohtomo, 2013

Ohtomo, Hirose, \& Midden, 2011 (Dutch)

Ohtomo, Hirose, \& Midden, 2011 (Japanese)

Pomery et al., 2009 (Non-smokers)

Pomery, 2008

Reimer, 2009 (Study 1 )

Rivis, Sheeran, \& Armitage, 2010

Scott-Parker, Hyde, Watson, \& King, 2013

Stock, 2007

Thornton et al., 2002 (study 1 )

Thornton et al., 2002 (Study 2)

Todd \& Mullan, 201

van Empelen \& Kok, 2006

Gerrard, Gibbons, Zhao, Russell, \& Reis-Bergan, 1999

Thornton et al., 2002 (Study 3 )

Gibbons et al., 2004b

Gibbons et al., 1995a (Study 2)

Gibbons et al., 1998a (Study 1 )

Gibbons et al., 1998a (Study 2

Gibbons et al., 1998a (Study 3 )

Gibbons et al., 1998b (Study 1)

Gibbons et al., 1998b (Study 2)

Gibbons, Helweg-Larsen, \& Gerrard, 1995b (American)

Gibbons, Helweg-Larsen, \& Gerrard, 1995b (Danish)

Andrews et al., 2008b

Zimmermann \& Sieverding, 2010 (Male)

immermann \& Sieverding, 2010 (Female)

Zimmermann \& Sieverding, 2011a

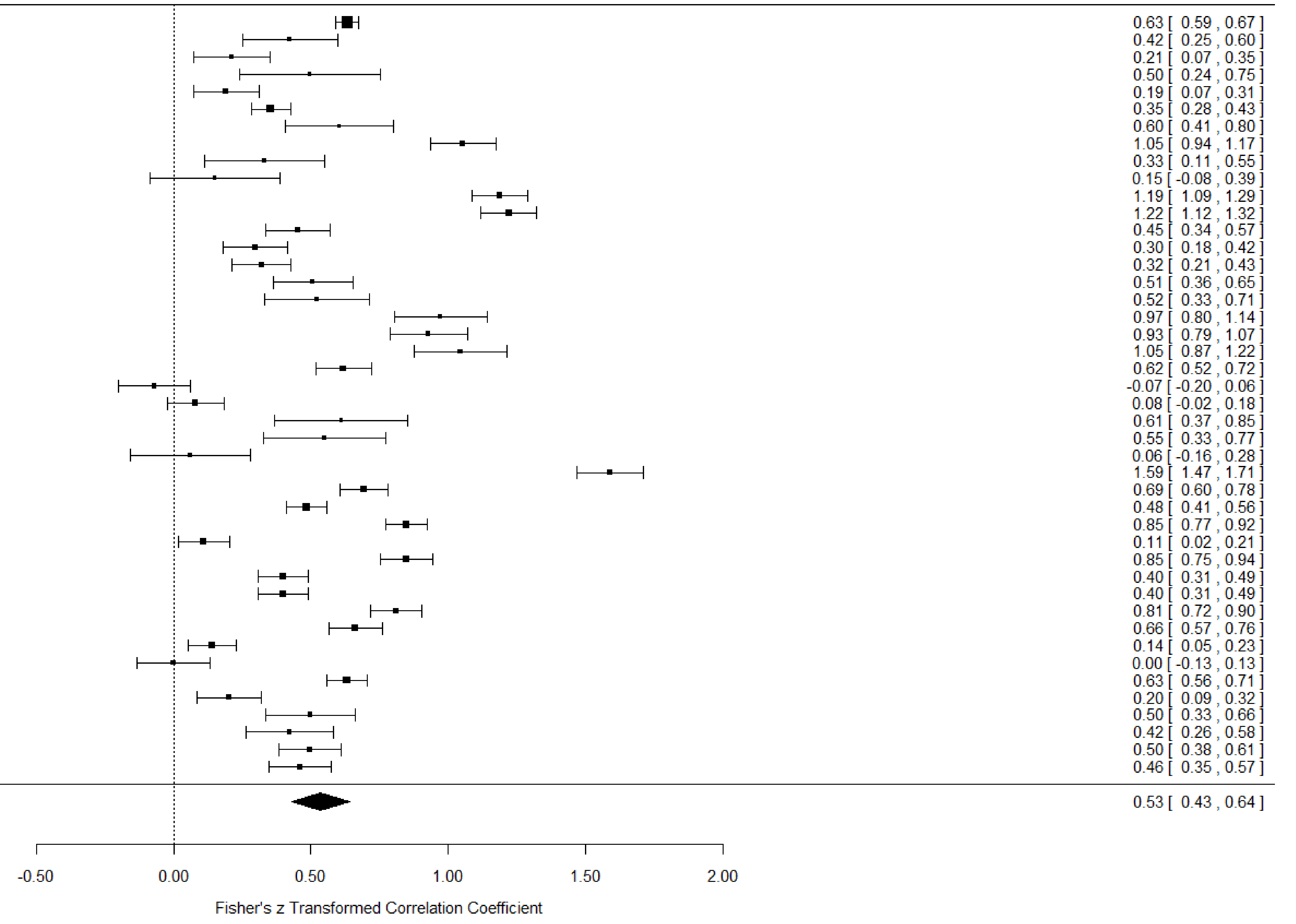




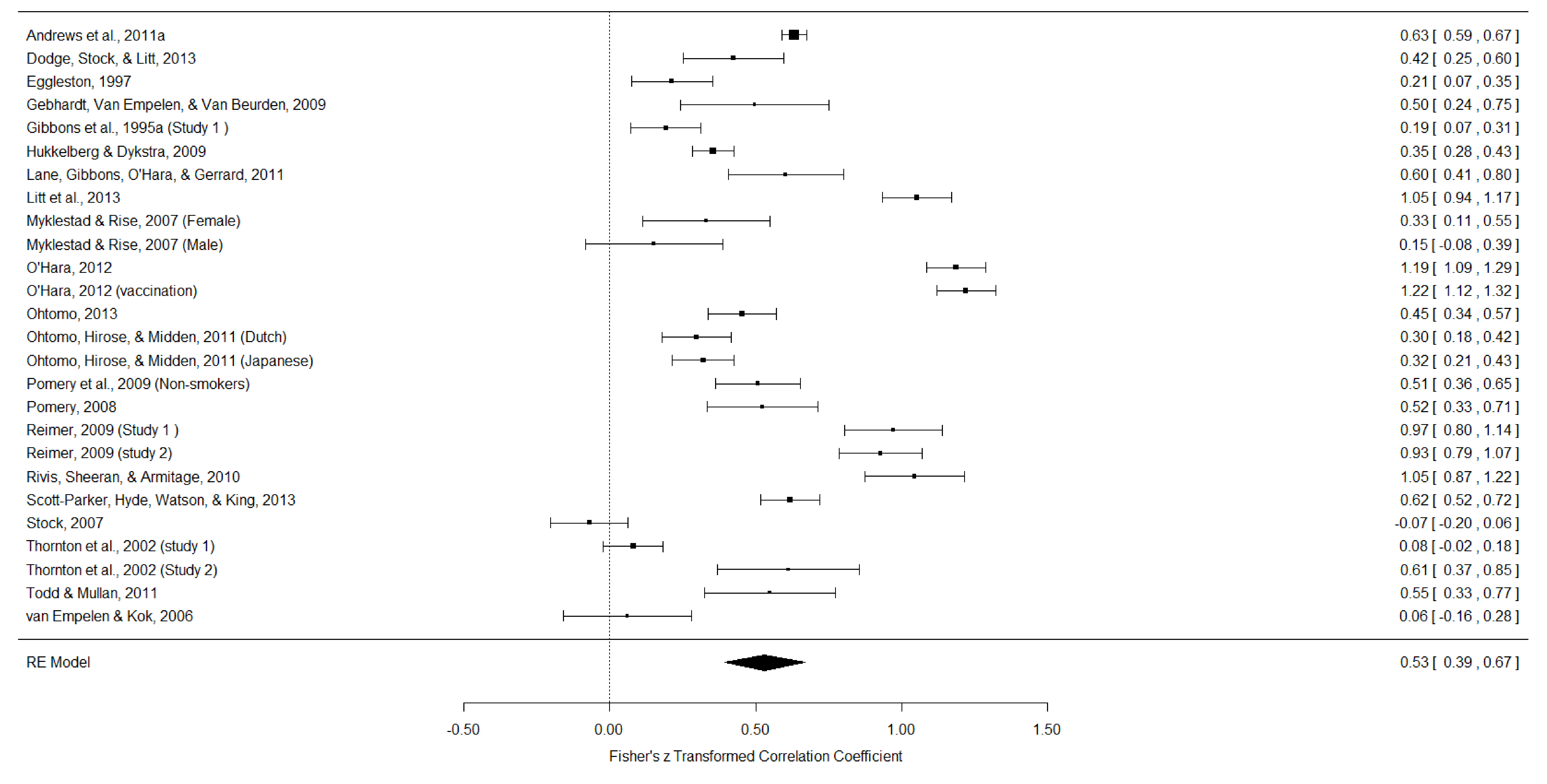




\section{SUPPLEMENTARY FILE 7}

\section{Path Analysis Fit Statistics}

Fit statistics for path analyses of the prototype willingness model with reasoned and heuristic pathways (path analysis Model 2) for overall dataset and each level of the behaviour and age category moderators $(d f=2)$

\begin{tabular}{|c|c|c|c|c|c|c|}
\hline & AIC & RMR & RMSEA & $\chi^{2}$ & $\mathrm{p}$ & $\mathrm{N}$ \\
\hline Overall & 409.77 & 0.012 & 0.10 & 393.76 & $<.001$ & 18697 \\
\hline Alcohol & 149.42 & 0.013 & 0.13 & 133.42 & $<.001$ & 4031 \\
\hline Cigarette & 27.98 & 0.004 & 0.04 & 11.98 & .003 & 3769 \\
\hline Substance Use & 263.26 & 0.026 & 0.19 & 247.26 & $<.001$ & 3136 \\
\hline Sex & 39.7 & 0.007 & 0.06 & 23.7 & $<.001$ & 3467 \\
\hline Pre-adolescent & 81.18 & 0.011 & 0.10 & 65.18 & $<.001$ & 9866 \\
\hline Adolescent & 97.21 & 0.008 & 0.08 & 81.20 & $<.001$ & 3482 \\
\hline Adult & 295.19 & 0.014 & 0.12 & 279.20 & $<.001$ & 6700 \\
\hline
\end{tabular}

